\author{
Aus der Klinik für Neurochirurgie \\ (Prof. Dr. med. V. Rohde) \\ im Zentrum Neurologische Medizin \\ der Medizinischen Fakultät der Universität Göttingen
}

\title{
Einfluss der Blockade des Kaliumkanals Eag1 durch trizyklische und nicht-trizyklische Antidepressiva auf die Überlebenszeit von Patienten mit Glioblastoma multiforme bzw. Hirnmetastasen und Depression:
}

Eine klinische und immunhistochemische Analyse

\author{
INAUGURAL - DISSERTATION \\ zur Erlangung des Doktorgrades \\ für Zahnheilkunde \\ der Medizinischen Fakultät der \\ Georg-August-Universität zu Göttingen \\ vorgelegt von \\ Julian Michael Schell \\ aus \\ Filderstadt
}

Göttingen 2014 
Dekan:

Prof. Dr. rer. nat. H. K. Kroemer

I. Berichterstatter:

II. Berichterstatter:

III. Berichterstatter/in:

Tag der mündlichen Prüfung:
PD Dr. med. R. Martínez-Olivera

Prof. Dr. rer. nat. W. Stühmer 
Inhaltsverzeichnis

Seite
I)
Einleitung

$1.1 \quad$ Der spannungsgesteuerte Kaliumkanal Eag1

1.1.1 Die Rolle von $\mathrm{K}^{+}$-Kanälen in der Onkologie ...................................... 1

1.1.2 Die Rolle von Eag1 in der Onkologie ........................................... 1

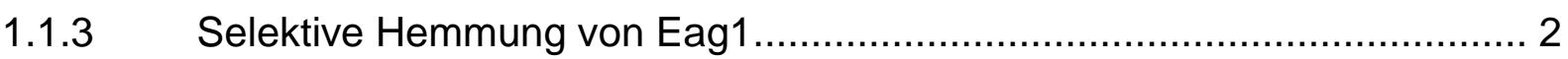

$1.2 \quad$ Hirnmetastasen 3

1.2.1 Epidemiologie der Hirnmetastasen ............................................ 3

1.2.2 Ätiopathogenese der Hirnmetastasen................................................. 4

1.2.3 Klinik der Hirnmetastasen ............................................................. 9

1.2.4 Therapie und Prognose der Hirnmetastasen ................................... 10

1.2.5 Molekulare Marker in Hirnmetastasen ............................................ 13

$\begin{array}{lll}1.3 & \text { Glioblastoma multiforme } & 14\end{array}$

1.3.1 Epidemiologie des Glioblastoma multiforme .................................... 14

1.3.2 Ätiopathogenese des Glioblastoma multiforme ................................. 14

1.3.3 Klinik des Glioblastoma multiforme ............................................ 15

1.3.4 Therapie und Prognose des Glioblastoma multiforme ......................... 16

1.3.5 Molekulare Marker in Glioblastoma multiforme .................................. 17

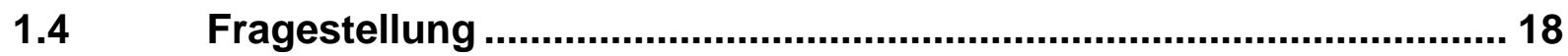

II) Material und Methoden

$\begin{array}{lll}2.1 & \text { Patienten } & 19\end{array}$

2.1.1 Patienten mit Diagnose Hirnmetastase ......................................... 19

2.1.2 Patienten mit Diagnose Glioblastoma multiforme ............................... 19

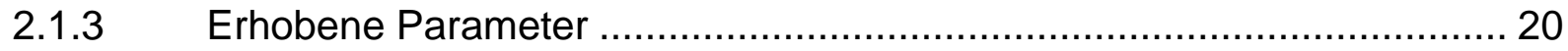


$2.2 \quad$ Material 20

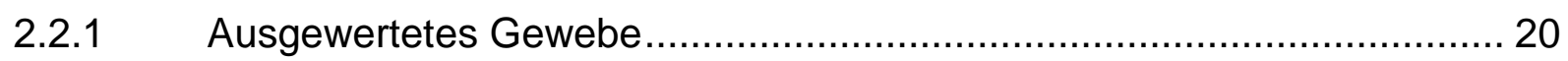

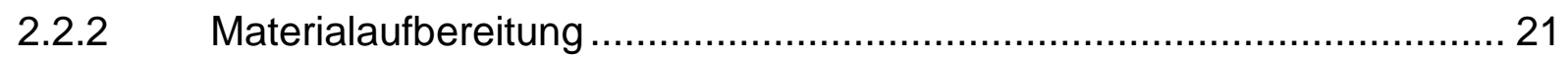

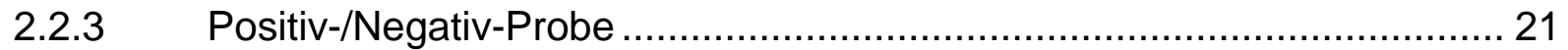

$2.3 \quad$ Methoden 21

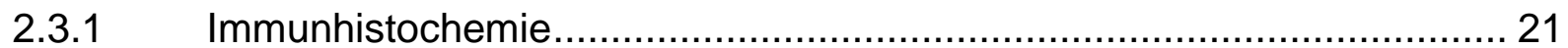

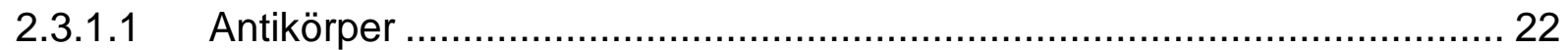

2.3.1.2 Alkalische Phosphatase (AP)-Methode ........................................ 22

2.3.1.3 Durchführung der AP-Methode ..................................................... 24

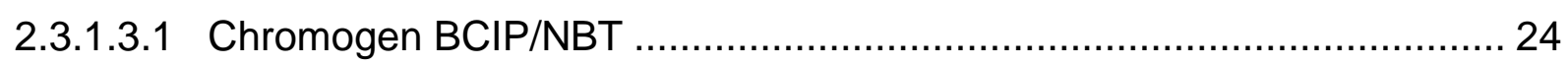

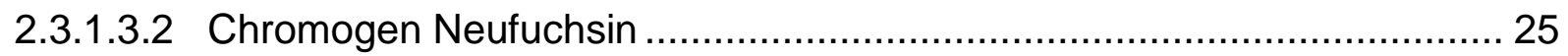

2.3.1.4 Lösungen und Puffer .................................................................. 26

2.3.2 Immunhistochemische Auswertung .............................................. 27

2.3.3 Statistische Auswertung …........................................................ 27

III) Ergebnisse

3.1 Klinische Daten 29

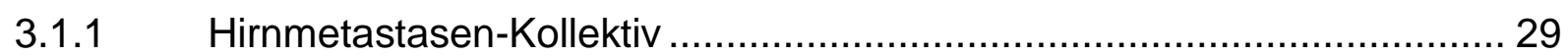

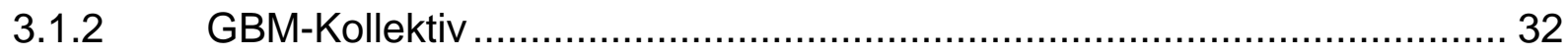

$3.2 \quad$ Eag1-Expression 35

3.2.1 Eag1-Expression in Hirnmetastasen-Biopsien.................................... 35

3.2.2 Eag1-Expression in GBM-Biopsien................................................. 39

3.3 Einfluss der Eag1-Expression auf die Überlebenszeit 41

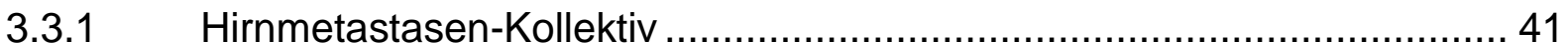

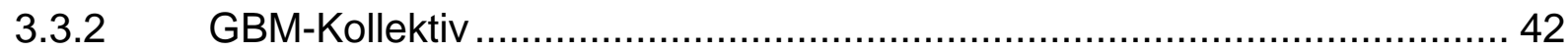

3.4 Einfluss der Antidepressiva-Therapie auf die Überlebenszeit in 43 Abhängigkeit von der Eag1-Expression

3.4.1 Hirnmetastasen-Kollektiv ......................................................... 43

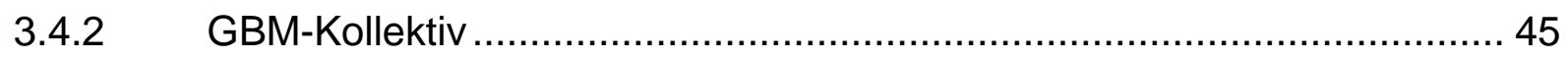


3.5 Betrachtung der Eag1-Expression in unterschiedlichen Hirnarealen in Bezug auf die Überlebenszeit

3.5.1 Hirnmetastasen-Kollektiv ................................................................. 47

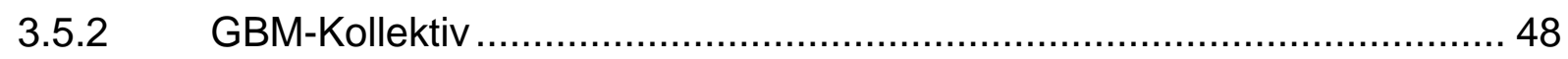

3.6 Geschlechtsspezifische Analyse der Überlebenszeit 50 in Abhängigkeit von der Eag1-Expression

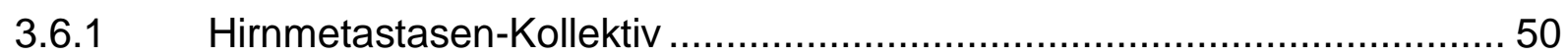

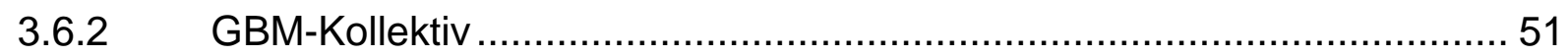

IV) Diskussion

4.1 Das Kollektiv 52

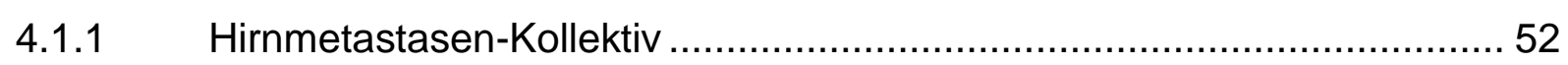

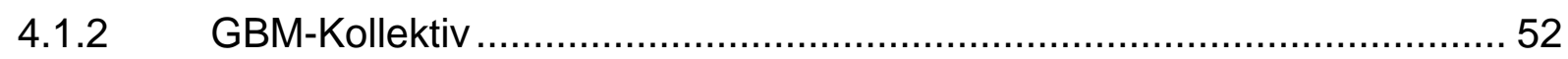

4.2 Eag1 als Tumor-Marker 53

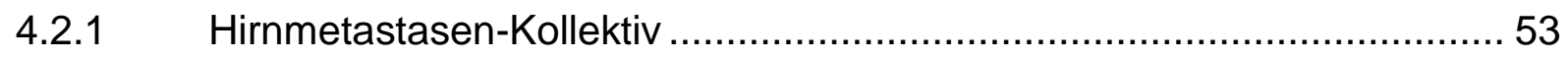

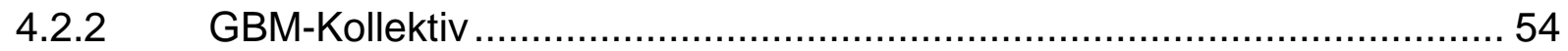

4.3 Eag1 als Prognose-Marker $\quad 55$

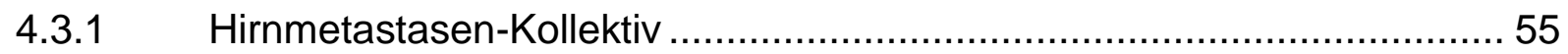

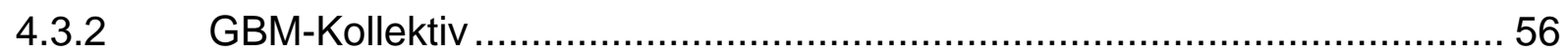

4.4 Eag1 als mögliches medikamentöses Oncotarget 56

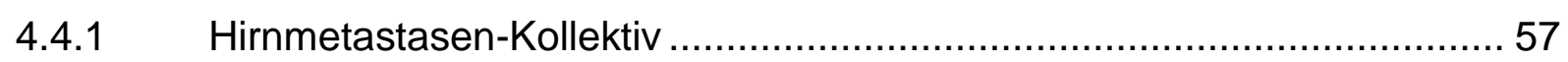

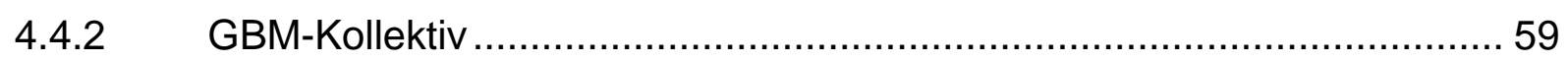

4.5 Einfluss klinischer Parameter auf die Eag1-Expression 60

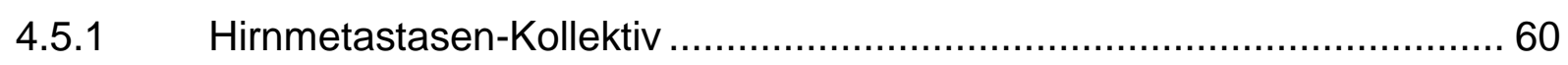

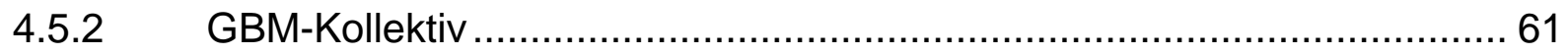




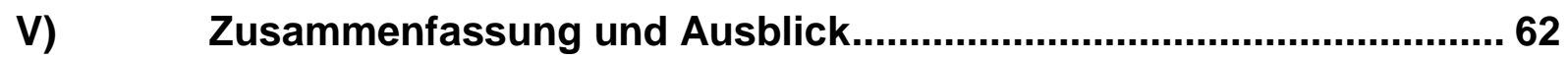

VI) Verzeichnis der verwendeten Abkürzungen...................................... 64

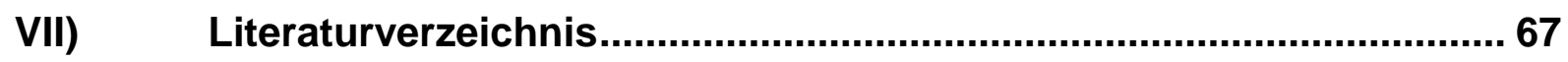




\section{I) Einleitung}

\subsection{Der spannungsgesteuerte Kaliumkanal Eag1}

\subsubsection{Die Rolle von $\mathrm{K}^{+}$-Kanälen in der Onkologie}

lonenkanäle gehören zur Klasse der Membranproteine, die neben Transportern und Pumpen für den Stofftransport in und aus der Zelle zuständig sind. Der lonentransport über lonenkanäle spielt bei vielen Prozessen eine wichtige Rolle wie bei der Erregung von Nerven- und Muskelzellen, der Hormonsekretion, Zellproliferation, sensorischen Signaltransduktion, Regulation des Blutdrucks und des Wasserhaushaltes sowie der Apoptose (Ashcroft 2000). Eine Veränderung in der Expression und Aktivität dieser lonenkanäle steht in Zusammenhang mit vielen pathologischen Veränderungen und Prozessen im menschlichen Körper, zum Beispiel Muskelschwäche (Myasthenie), Epilepsie, zystische Fibrose und kardiale Arrhythmie (Ashcroft 2006). Ionenkanäle werden schon sehr lange in der onkologischen Forschung betrachtet, da sie das innere Milieu der Zelle aufrechterhalten und Einflüsse auf die Zellproliferation haben, die bei der Tumorentstehung entscheidend ist (Kunzelmann 2005). Schon Mitte der 90er Jahre wurde die Hypothese aufgestellt, dass spannungsgesteuerte Kaliumkanäle Einfluss auf die mitotische Teilung der Zelle haben und eine erhöhte Proliferationsrate verursachen können (Wonderlin und Strobl 1996). Die direkten Einflüsse sind noch nicht vollständig geklärt, man geht jedoch davon aus, dass das Zellvolumen und das Membranpotential, das auch durch spannungsgesteuerte Kaliumkanäle reguliert wird, wichtige Faktoren für die Zellteilung sind (Pardo 2004; Pardo et al. 2005).

\subsubsection{Die Rolle von Eag1 in der Onkologie}

Ein sehr wichtiger lonenkanal in der Onkologie ist der spannungsgesteuerte Kaliumkanal Eag1 (Ether-à-go-go-1; $\mathrm{K}_{\mathrm{v}} 10.1 ; \mathrm{KCNH} 1$ ), da er eine entscheidende Rolle in der Zellteilung und bei der Tumorzellproliferation spielt (Pardo et al. 1998). Dies konnte bei menschlichen Karzinomen wie zum Beispiel dem Kolonkarzinom (Ousingsawat et al. 2007) und Zervixkarzinom (Farías et al. 2004) sowie auch bei humanen Zelllinien eines Mamma-, Zervix- und Nierenzell-Karzinoms (Pardo et al. 1999) beobachtet werden. Von besonderer Bedeutung ist das limitierte natürliche Vorkommen von Eag1 im menschlichen Körper, das auf das Gehirn begrenzt ist (Pardo et al. 1999). Hierbei ist eine Eag1-Expression vorwiegend in Neuronen des zerebralen Kortex, Hippocampus, Hypothalamus, Bulbus olfactorius und des Zerebellums zu finden (Martin et al. 2008). 
Experimente haben gezeigt, dass eine Injektion von $\mathrm{CHO}$-Zellen mit überexprimiertem Eag1Protein (CHOhEAG) in Labormäuse, die durch einen schweren kombinierten Immundefekt (SCID) beeinflusst wurden, zu Tumorbildung führt (Pardo et al. 1999). Darüber hinaus haben einige Studien der letzten Jahre dies auch anhand von Tumorbiopsien für mehrere Krebserkrankungen untersucht: So lässt sich eine deutlich erhöhte Expression von Eag1 in Mammakarzinomen, Lungenkarzinomen und Prostatakarzinomen (Hemmerlein et al. 2006), in Kopf-Hals-Tumoren allgemein (Menéndez et al. 2012) und in Oesophaguskarzinomen speziell (Ding et al. 2008), in Magenkarzinomen (Ding et al. 2007 a), Kolonkarzinomen (Ousingsawat et al. 2007) bzw. kolorektalen Karzinomen (Ding et al. 2007 b), Ovarialkarzinomen (Asher et al. 2010), Zervixkarzinomen (Farías et al. 2004; Ortiz et al. 2011) sowie in Sarkomen der Weichgewebe (Mello de Queiroz et al. 2006), der Knochen (Wu et al. 2012) und bei der akut myeloischen Leukämie (Agarwal et al. 2010) zeigen. Des Weiteren wurde beobachtet, dass die Eag1-Expression mit erhöhter VEGF-Sekretion in Verbindung steht, was eine verstärkte Angiogenese und einen Überlebensvorteil für die Tumorzellen zur Folge hat (Downie et al. 2008). Dadurch ist Eag1 nicht nur als TumorMarker zu werten, sondern auch als Prognose-Marker, da Patienten mit einer erhöhten Eag1-Expression zumeist eine schlechtere Prognose haben. Dies konnte bei Patienten mit einem Ovarialkarzinom (Asher et al. 2010), einem Oesophaguskarzinom (Ding et al. 2008) und auch bei Patienten mit myeloischer Leukämie (Agarwal et al. 2010) beobachtet werden.

\subsubsection{Selektive Hemmung von Eag1}

Eag1 stellt einen möglichen Ansatzpunkt in der onkologischen Therapie dar, dadurch dass Eag1 mit der Tumorzellproliferation assoziiert ist und das nahezu ausschließliche Vorkommen in Tumorzellen die Möglichkeit bietet, Nebenwirkungen und Kreuzreaktionen zu verhindern. Darüber hinaus bietet Eag1 den Vorteil, als Membranprotein durch eine extrazelluläre Domäne gut erreichbar zu sein. Demzufolge wurden mehrere Ansätze untersucht, die Aktivität von Eag1 zu hemmen und dadurch die Tumorzellproliferation einzuschränken. Ein Ansatz ist, spezifische Antikörper gegen Eag1 zu entwickeln und regulativ einzusetzen. Hierbei haben sich gute Ergebnisse gezeigt, so dass eine Blockade mit Antikörpern zu einer verringerten Proliferation von Tumorzellen führte: Zum einen in vitro in Zelllinien eines Mammakarzinoms (Verringerung um 60\%), Ovarialkarzinoms (um 40\%), Zervixkarzinoms (um 40\%), Pankreaskarzinoms (um 20-25\%) und Kolonkarzinoms (um 30\%) sowie eines Melanoms (um 35\%) und Fibrosarkoms (um 30-40\%), zum anderen in vivo mit gleichen Ergebnissen in einem Mammakarzinom-Mausmodell (MDA-MB-435S) sowie Pankreaskarzinom-Mausmodell (PAXF 1657) (Gómez-Varela et al. 2007). Des Weiteren konnte durch einen spezifischen Antikörper gegen Eag1, der mit TRAIL verbunden wurde, eine vermehrte 
Apoptose-Rate von Eag1-positiven Tumorzellen beobachtet werden (Hartung et al. 2011). Auf molekularer Basis wurde in einer In-Vitro-Studie die Auswirkung einer Verringerung der Eag1-Expression durch siRNA untersucht: Es zeigte sich eine reduzierte Zellproliferation an Tumorzellinien eines Mammakarzinoms (Reduktion um 44,9\%), Fibrosarkoms (um 54,1\%), Rhabdomyosarkoms (um 83,8\%) sowie Medulloblastoms (um 31,9\%) (Weber et al. 2006). Mittels shRNA konnte an Zellen eines Osteosarkoms in vitro wie auch in vivo ein reduziertes Tumorwachstum durch Hemmung von Eag1 gezeigt werden (Wu et al. 2012). In gleicher Studie wurde zusätzlich beobachtet, dass durch die verringerte Eag1-Expression auch die VEGF-Expression reduziert wird und damit die Angiogenese des Tumors eingeschränkt ist. Ein weiterer Ansatz ist die medikamentöse Blockade von Eag1. In einer In-Vitro-Studie mit Tumorzelllinien eines Mammakarzinoms konnte gezeigt werden, dass das Antihistaminikum Astemizol Eag1 hemmen kann und dadurch die Proliferationsrate von Tumorzellen reduziert wird (Ouadid-Ahidouch et al. 2001). Dieser medikamentöse Effekt wurde in einer weiteren Studie untersucht, in der eine Blockade von Eag1 durch das trizyklische Antidepressivum Imipramin festgestellt werden konnte, was eine Reduktion der Tumorzellproliferation von Zelllinien eines Melanoms (IGR1) zur Folge hatte (Gavrilova-Ruch et al. 2002). Der genaue Wirkmechanismus von Imipramin und Astemizol bei der Blockade von Eag1 wurde in vitro durch die Arbeitsgruppe um García-Ferreiro et al. (2004) untersucht: Imipramin und Astemizol durchdringen in ihrer ungeladenen Form die Membran der Zelle, binden in ihrer geladenen Form an der intrazellulären Domäne des Kanals und wirken im Sinne einer open pore-Blockade. Diese Erkenntnisse legen die vielversprechende therapeutische Möglichkeit nah trizyklische Antidepressiva bei soliden Hirntumoren wie zum Beispiel Hirnmetastasen und Glioblastomen zu benutzen, da die Blut-Hirn-Schranke bekanntermaßen einen limitierenden Faktor für viele Chemotherapeutika darstellt.

\subsection{Hirnmetastasen}

\subsubsection{Epidemiologie der Hirnmetastasen}

Hirnmetastasen spielen eine große Rolle in der Neuroonkologie, da sie den häufigsten Hirntumor im Erwachsenenalter darstellen (Davis et al. 2012). Die Inzidenz von Hirnmetastasen im Verlauf einer Krebserkrankung hat in den letzten Jahren deutlich zugenommen, da die Tumorkontrolle des Primarius immer besser geworden ist, einhergehend mit einer Verlängerung der Überlebenszeit von betroffenen Patienten (Diener und Weimar 2012). Von allen Patienten mit einer systemischen Krebserkrankung entwickeln mehr als $25 \%$ zusätzlich Hirnmetastasen (Gavrilovic und Posner 2005). 
Die häufigsten Karzinome, die zerebral metastasieren, sind nach Lassman und DeAngelis (2003):

- $40-50 \% \quad$ Bronchialkarzinom

- $15-20 \%$ Mammakarzinom

- $5-10 \% \quad$ malignes Melanom

- $4-6 \%$ gastrointestinale Karzinome

\subsection{2 Ätiopathogenese der Hirnmetastasen}

Damit sich Tumorzellen von primären Tumoren separieren und Tochtergeschwulste in Form von Metastasen bilden können, müssen im Körper einige Schritte durchlaufen werden, die in ihren Grundzügen auf der anerkannten seed and soil-Theorie von Stephen Paget (1889) basieren. Paget beschrieb als erster, dass Zellen eines bestimmten Tumors (seed) nicht willkürlich im Körper eine Metastase zu bilden scheinen, sondern, dass es präferierte Regionen und Organe (soil) zu geben scheint, die für die jeweiligen Tumorzellen Voraussetzungen zur Bildung einer Metastase mitbringen. Der gesamte Vorgang ist in mehrere Schritte unterteilt, die sich in Anlehnung an Fidler (2003) sowie Gavrilovic und Posner (2005) wie folgt aufzählen lassen:

Organ des primären Tumors (z.B. Mammakarzinom, Bronchialkarzinom)

Transformation

- genetische und epigenetische Veränderung

- Wachstum

- Angiogenese

- Invasion

Transport der Tumorzelle (seed)

- Blutkreislauf

- Extravasation in ein primäres Kapillarbett

Gehirn (soil)

Transport der Tumorzelle (seed)

- hämatogener Weg

- Extravasation

- Ruhezustand

- Angiogenese und Tumorwachstum 
Transformation im Organ des primären Tumors

- genetische und epigenetische Veränderung

Gesunde Zellen in Organen des menschlichen Körpers, in denen sich metastasierende Tumoren bilden können, müssen in einem komplexen Prozess genetische und epigenetische Veränderungen durchlaufen, bevor sie sich vermehren können und somit die Eigenschaft erlangen, einen Tumor auszubilden (Macaluso et al. 2003; Herman und Baylin 2003).

Im ersten Schritt werden Regulatorgene aktiviert, die für die Steuerung der Zellproliferation zuständig sind (Macaluso et al. 2003). Darauf folgt die Inaktivierung von Tumorsuppressorgenen über Mutationen und Verlust der Heterozygosität bzw. über Genpromotor-Hypermethylierung, wodurch die genetische Stabilität der Zelle entfällt (Herman und Baylin 2003). In den Tumorzellen von unterschiedlichen Karzinomen ist das Tumorsuppressorgen-TP53 mutiert, was dazu führt, dass das mutierte Tumorsuppressorprotein-p53 einen Verlust der Wildtyp-TP53-Proteinfunktion bewirkt. Es entsteht eine direkte Beeinflussung der Transkription durch Bindung an die DNA oder durch Aktivierung von Transkriptionsfaktoren, welche die Transkription verstärken (Muller und Vousden 2013). Eine wichtige epigenetische Rolle spielt die Hypermethylierung von microRNAs (miR-148a, miR-34b/c und miR-9), kurzen nicht kodierenden RNA-Sequenzen, die als Tumorsuppressorgene die Genexpression regulieren und bei Inaktivierung mit Tumorbildung assoziiert sind (Lujambio et al. 2008). Neueste Ergebnisse zeigen auch, dass eine verringerte Aktivität des DICER1Enzyms, einer Endoribonuklease, die bei der Synthese von microRNAs von entscheidender Bedeutung ist, zusätzlich die Bildung von Tumorzellen begünstigt (Iliou et al. 2013). Tumorzellen von Metastasen scheinen im Vergleich zu Tumorzellen des primären Tumors, von dem sie abstammen, eine epigenetische Besonderheit durch die PromoterHypermethylierung der 5'CpG-Insel des Cadherin-11-Gens aufzuweisen. Dieses Gen codiert für ein Adhäsionsprotein, das bei Zell-Zell-Kontakten mitwirkt, bei Inaktivierung in Tumorzellen jedoch Tumorwachstum, Motilität und Ausbreitung der Tumorzellen begünstigt (Carmona et al. 2012).

- Wachstum

Neben den oben angesprochenen genetischen und epigenetischen Veränderungen, die ein Tumorwachstum ermöglichen, sind verschiedene Wachstumsfaktoren für das Wachstum eines Tumors von Bedeutung. Eine erhöhte Aktivität in Tumorzellen weisen die epidermalen Wachstumsfaktorrezeptoren (vor allem HER2/neu bei Mammakarzinomen), der hepatozytische Wachstumsfaktorrezeptor (HGFR/c-MET), der transformierende Wachstumsfaktor TGF- $\beta$ mit zugehörigem Rezeptor (TGFBR) sowie der vaskuläre endotheliale Wachstumsfaktor (VEGF) auf (Lowery und Yu 2012). Das Wachstum des primären Tumors spielt zwar 
eine Rolle in der Entstehung von Metastasen, die Größe des Tumors als Faktor für ein Metastasierungsrisiko wird in der Literatur allerdings kontrovers diskutiert: Am Beispiel des Mammakarzinoms gibt es Evidenz dafür, dass pro Millimeter Tumorausdehnung das Risiko einer Metastasierung um $1 \%$ steigt, einhergehend mit einem Letalitätsrisiko um $1 \%$ (Michaelson et al. 2003). Dagegen konnten auch schon bei sehr kleinen Mammakarzinomen, zur Zeit der initialen Diagnose, Metastasen gefunden werden (Engel et al. 2003).

\section{- Angiogenese}

Die Ausbildung einer eigenen Blutversorgung des Tumors ist für dessen Wachstum äußerst wichtig und wird u.a. gewährleistet durch den vaskulären endothelialen Wachstumsfaktor VEGF (Holash et al. 1999). Man geht davon aus, dass Tumorzellen in der Lage sind in die neugebildeten, versorgenden Gefäße des Tumors einzutreten und dadurch in den systemischen Blutkreislauf des Körpers zu gelangen (Laferriere et al. 2002).

- Invasion

Beim Metastasierungsprozess kommt es dazu, dass sich Tumorzellen aus der Tumormasse des primären Tumors abspalten. Die zugrundeliegenden Mechanismen werden nach derzeitigem Forschungsstand mit der Theorie der epithelial-mesenchymalen Transition (EMT) beschrieben: Eine epitheliale Zelle erlangt temporär mesenchymale Eigenschaften und kann sich im Verlauf wieder zurückdifferenzieren (Ramakrishna und Rostomily 2013). Man geht davon aus, dass unter anderem spezielle Transkriptionsfaktoren (EMT-TF), aber auch Wachstumsfaktoren (EGF, HGF, IGF etc.) die Transition induzieren können. Im Folgenden durchläuft die ursprünglich epitheliale Zelle wichtige Veränderungen, die zur Invasion und Abspaltung befähigen (Verlust der Zell-Zell-Kontakte, Änderung der Zellpolarität sowie Umstrukturierung des Zytoskelettes) (Thiery et al. 2009; Hanahan und Weinberg 2011). Die differenzierten Tumorzellen infiltrieren das Stroma des Ursprungorgans, indem sie sich an der extrazellulären Matrix anhaften und diese mittels Enzymen mit proteolytischer Qualität (Metalloproteinasen) abbauen. Somit gelangen sie durch die extrazelluläre Matrix und erreichen Blut- oder Lymphgefäße (Ridley et al. 2003).

Transport der Tumorzelle (seed) vom Organ des primären Tumors

- Blutkreislauf

Schon frühe Beobachtungen haben gezeigt, dass Tumorzellen, die in den Blutkreislauf gelangt sind, zum größten Teil sehr schnell absterben, nur sehr ineffizient sind und eher selten zu Metastasen führen (Fidler 1970; Weiss 1990). Genauere Erkenntnisse über den Verbleib und die Aktivität von Tumorzellen im Blutkreislauf konnten erstmals von der Arbeits- 
gruppe um Luzzi et al. (1998) aufgezeigt werden: Tumorzellen eines Melanoms (B16F1) wurden in einem In-Vivo-Modell in die Pfortader von Mäusen injiziert und der zeitliche Verbleib der Zellen in der Leber mittels Videomikroskopie verfolgt. Es zeigte sich, dass 90 min nach der Injektion 87\% der Tumorzellen in der Leber überlebt hatten, 83\% dieser Tumorzellen nach 3 Tagen erfolgreich aus den Gefäßen in das Leberparenchym übergetreten waren, jedoch nach 13 Tagen nur $2 \%$ dieser Tumorzellen ein weiteres Überleben durch die Bildung von Mikrometastasen gesichert hatten. Von dieser geringen Anzahl bildeten nur 0,02\% der Tumorzellen eine wachsende Metastase mit progressivem Verlauf. Dies verdeutlicht, dass der Prozess der Extravasation von Tumorzellen noch effizient verläuft, die Bildung von Metastasen im Parenchym jedoch äußerst selten ist und die Tumorzellen absterben. Zudem kann das Immunsystem des menschlichen Körpers einige Tumorzellen durch natürliche Killerzellen zerstören, wenn sie in die Blutzirkulation gelangt sind. Jedoch können Tumorzellen dagegen auch Komplexe mit Thrombozyten bilden, wodurch sie vor Lyse geschützt sind (Nieswandt et al. 1999).

- Extravasation in ein primäres Kapillarbett

Tumorzellen verweilen, nachdem sie vom Ort des primären Tumors in die Blutzirkulation gelangt sind, zumeist im ersten nachgeschalteten Kapillarbett, da Tumorzellen einen relativ größeren Durchmesser haben als Kapillargefäße (Chambers et al. 2002).

Transport der Tumorzelle (seed) zum Gehirn (soil)

- hämatogener Weg

Hirnmetastasen entstehen sehr häufig von Bronchialkarzinomen, da die Tumorzellen auf relativ kurzem Wege über die linke Herzseite in die versorgenden Arterien des Gehirns gelangen. Wichtige Erkenntnisse hierzu konnten durch die Etablierung eines hämatogenen In-Vivo-Modells erlangt werden, in dem durch die Injektion von Tumorzellen eines Melanoms in die Halsschlagader von Mäusen zuverlässig die Bildung von Hirnmetastasen simuliert werden konnte, ohne, dass eine Tumorlast in anderen Organen entstand (Schackert und Fidler 1988; Schackert und Fidler 2000). Tumoren aus anatomisch weiter entfernt gelegenen Organen metastasieren allerdings ebenfalls ins Gehirn, nachdem die Tumorzellen durch die Blutzirkulation der Lunge gelangt sind und dort teilweise auch schon eine weitere Metastase gebildet haben (Gavrilovic und Posner 2005).

\section{- Extravasation}

Über die großen Arterien des Halses gelangen Tumorzellen in kleinere Arteriolen und Kapillaren des Gehirns und kommen darauf zu 80\% in den zerebralen Hemisphären, zu 15\% 
im Kleinhirn und zu 3 \% am Hirnstamm zu liegen, wo sie Metastasen bilden können (Delattre et al. 1988). Der genaue Vorgang, wie sich Tumorzellen an Endothelzellen anhaften können und im nächsten Schritt aus den Kapillaren in das Parenchym des Gehirns übertreten ist noch nicht vollständig bekannt. Die Blut-Hirn-Schranke stellt jedoch kein unüberwindbares Hindernis für die Tumorzellen dar (Gavrilovic und Posner 2005; Langley und Fidler 2013). Ein möglicher Ansatz, der sich in einem In-Vivo-Mausmodell mit Tumorzellen eines Melanoms (B16-BL16) zeigte, ist eine Interaktion des Transmembranproteins $\alpha_{4} \beta_{1}$-Integrin von Melanomzellen mit dem vaskulären Zell-Adhäsionsmolekül-1 (VCAM-1) an der Oberfläche von Endothelzellen (Langley et al. 2001). Genexpressionsanalysen an Zellreihen eines metastasierenden Mammakarzinoms legten dagegen offen, dass die Extravasation mediatorgekoppelt zu verlaufen scheint: So erhöht die Cyclooxygenase-2 (COX2) die Permeabilität der Blut-Hirn-Schranke. Die Expression des ST6GALNAC5-Enzyms, das als Sialyltransferase an der extrazellulären Matrix Zell-Zell-Interaktionen vermittelt, scheint die Adhäsion von Mammakarzinom-Tumorzellen an Endothelzellen zu verstärken. Des Weiteren vermittelt die Aktivierung des endothelialen Wachstumsfaktorrezeptor (EGFR) durch den HBEGF-Liganden die Invasion der Tumorzellen in das Hirnparenchym (Bos et al. 2009).

\section{- Ruhezustand}

Tumorzellen, die ins Parenchym des Gehirns gelangt sind, bilden nicht in jedem Falle eine wachsende Metastase, sondern können noch über sehr lange Zeit in einem Ruhezustand verweilen (Chambers et al. 2002). Dies kommt häufig bei Patienten mit einem Mammakarzinom oder einem malignen Melanom vor, die schon mehrere Jahre erfolgreich therapiert wurden und im Verlauf einen Progress durch Hirnmetastasen erleiden (Gavrilovic und Posner 2005). Es kann jedoch nach der soil-Theorie auch dazu kommen, dass sich keine Metastase bildet, wenn die Tumorzelle im Parenchym keine vorteilhaften Verhältnisse vorfindet. In-Vivo-Experimente an Mäusen konnten diese Theorie belegen, dadurch dass die Injektion von Tumorzellen eines Melanoms (B16) in verschiedene Organe nicht in jedem Falle zur Bildung einer Metastase führte, sondern nur selektiv (Hart und Fidler 1980).

\section{- Angiogenese und Tumorwachstum}

Nachdem Tumorzellen im Hirngewebe günstige Verhältnisse für sich vorgefunden haben, durchlaufen sie nach aktuellen Forschungsergebnissen eine mesenchymal-epitheliale Transition (MET). Diese erneute Differenzierung wird vor allem durch Wachstumsfaktoren (unter anderem EGF) induziert (Yao et al. 2011). Bis es zu einem Tumorwachstum im Hirngewebe kommt, unternehmen Tumorzellen komplexe molekulare Interaktionen mit dem umgebenden Parenchym, die nur unvollständig verstanden sind. Beobachtungen haben gezeigt, dass der Oberflächenrezeptor-p75NTR auf Tumorzellen eines malignen Melanoms 
eine entscheidende Rolle zu spielen scheint, da der Nervenwachstumsfaktor (NGF) als Ligand an diesen Rezeptor binden kann, was einen Überlebensvorteil für die Tumorzellen darstellt (Marchetti et al. 2000). Neueste Erkenntnisse lassen darauf schließen, dass die Immunantwort des Gewebes auf das Eindringen der Tumorzellen in Form einer Aktivierung von Mikrogliazellen nicht zu einer Apoptose der Tumorzellen führen muss. Die Gewebereaktion kann sogar die Invasion der Tumorzellen begünstigen (Chuang et al. 2013). Auch für das Wachstum der Metastase ist - vergleichbar zum Wachstum des Primarius - die Angiogenese von zentraler Bedeutung. Real-time-Beobachtungen durch MultiphotonLaserscan-Mikroskopie in einem In-Vivo-Mausmodell ermöglichten aufzuzeigen, dass für das Wachstum einer Metastase, ausgehend von Tumorzellen eines Melanoms, besonders die Nähe zum Gefäßsystem im Gehirn mit Ausbildung von Kollateralen von Bedeutung ist. Für das Wachstum einer Metastase, ausgehend von Tumorzellen eines Bronchialkarzinoms, schien die frühzeitige Neoangiogenese (vermittelt durch VEGF) das entscheidende Kriterium zu sein (Kienast et al. 2010). Die Arbeitsgruppe um Yano et al. (2000) untersuchte an Zelllinien eines Kolonkarzinoms (KM12SM), eines bronchialen Adenokarzinoms (PC14PE6, $\mathrm{PC} 14 \mathrm{Br}$ ) und bronchialen Plattenepithelkarzinoms (H226) sowie Nierenzellkarzinoms (SN12PM6) und Melanoms (TXM13) den genauen Einfluss der VEGF-Expression auf das Wachstum von Hirnmetastasen: Es zeigte sich, dass grundsätzlich eine erhöhte VEGFExpression die Neoangiogenese verstärkt, jedoch bei Tumorzellen eines bronchialen Plattenepithelkarzinoms das Wachstum der Hirnmetastase auch ohne signifikanten Einfluss von VEGF zu beobachten ist.

\subsubsection{Klinik der Hirnmetastasen}

Hirnmetastasen können bei gleichzeitig diagnostizierten extrazerebralen Metastasen oder solitär, als einzige Metastase des primären Tumors auftreten. Für die Sicherung der Diagnose Hirnmetastase empfiehlt sich (laut den Leitlinien der DGN) eine klinischneurologische Untersuchung der Patienten mit Hinblick auf Folgen von erhöhtem intrakraniellen Druck, eine allgemeinkörperliche Untersuchung zum Zustand vorhandener Tumorerkrankungen und eine Bildgebung in Form einer MRT des Gehirns mit oder ohne Gadolinium (Diener und Weimar 2012). 
Nach Diener und Weimar (2012) manifestieren sich Hirnmetastasen durch:

- unspezifische Symptome

- fokale neurologische Defizite je nach Lokalisation:

- Großhirn

- Hirndruckzeichen
Kopfschmerz, Schwindel

epileptische Anfälle, Paresen, Sensibilitätsstörungen, Gesichtsfeldausfälle, Sprachstörungen, Persönlichkeitsänderungen (Frontalhirnsyndrom), organisches

Psychosyndrom

- Kleinhirn Ataxie

- Hirnstamm Hirnstammsyndrom

Übelkeit, Erbrechen, Aphatie

Die neurologischen Defizite sind zumeist Resultat der raumfordernden Wirkung des Tumors und des perifokalen Ödems. Ein infiltratives Wachstum des Tumors tritt selten auf (Schmid et al. 2002). In der neuropathologischen Diagnostik von Hirnmetastasen werden herkömmliche Untersuchungsmethoden wie die lichtmikroskopische Betrachtung und Gradierung des Tumorgewebes sowie immunhistochemische Färbungen vorgenommen. Mittels mono- oder polyklonalen Antikörpern können tumorspezifische Marker (wie z.B. Zytokeratine) identifiziert werden. Dadurch können die Hirnmetastasen den jeweiligen primären Tumoren molekularbiologisch zugeordnet werden (Felsberg und Reifenberger 2000; Becher et al. 2006). Gerade bei Metastasen mit unbekanntem Primärtumor (CUP-Syndrom) sind diese molekularen Methoden ein hilfreiches Mittel zur Identifizierung des primären Karzinoms (Fernandez et al. 2012).

\subsubsection{Therapie und Prognose der Hirnmetastasen}

Das mediane Überleben nach Diagnosestellung von Patienten mit Hirnmetastasen wird ohne Therapiemaßnahmen auf einen Monat und bei einer symptomatischen Behandlung mit Steroiden auf zwei Monate beziffert (Diener und Weimar 2012). Wichtige Faktoren wie Karnofsky-Index, Alter, Art und Kontrolle des primären Karzinoms sowie Ausmaß neurologischer Defizite können die Prognose der Patienten günstig beeinflussen (Gaspar et al. 1997). Die Prognose ist jedoch im Allgemeinen als schlecht einzustufen, weshalb umfangreiche Therapiemaßnahmen eine große Bedeutung haben. Als Möglichkeiten in der Therapie sind zu nennen, die mikrochirurgische Tumorentfernung (Therapie der ersten Wahl bei einer resektablen Metastase, oder multiplen Metastasen bis 3 oder 4), die fraktionierte 
konventionelle Radiotherapie, die Radiochirurgie (Gamma-Knife oder Linearbeschleuniger) und die Chemotherapie. Bezogen auf die gesundheitliche Gesamtsituation des Patienten kann nun ein individuelles Behandlungskonzept aus Kombinationen der Therapiemöglichkeiten erstellt werden (Schmid et al. 2002). In den letzten Jahren sind viele Studien durchgeführt worden, um die verschiedenen Therapiekombinationen zu vergleichen und eine bestmögliche Überlebenszeit für die Patienten zu ermöglichen.

Nach den Leitlinien der DGN ist die Ganzhirnbestrahlung die Standardtherapie bei multiplen (mehr als 4) oder inoperablen, tief gelegenen Metastasen (Hirnstamm, Stammganglien) (Diener und Weimar 2012). Bei sehr strahlensensiblen Primärtumoren wie dem kleinzelligen Bronchialkarzinom (SCLC) kann die Ganzhirnbestrahlung auch prophylaktisch, vor einer Manifestation von Hirnmetastasen, eingesetzt werden. Dadurch kann die Inzidenz späterer Hirnmetastasen verringert und die Prognose für die Patienten verbessert werden, wobei dies immer noch kontrovers diskutiert wird (Aupérin et al. 1999; Slotman et al. 2007).

Die chirurgische Tumorentfernung ist ein sehr wichtiger Bestandteil der Gesamttherapie und Therapie der ersten Wahl (mit den oben genannten Ausnahmen). Eine Tumorresektion verbessert die Prognose der Patienten erheblich und lindert die Symptome (Al-Shamy und Sawaya 2009; Kalkanis et al. 2010). Eine adjuvante Ganzhirnbestrahlung (WBRT) nach chirurgischer Tumorentfernung oder Radiochirurgie verbessert die Prognose der Patienten gegenüber einer alleinigen Ganzhirnbestrahlung und verringert das Rezidivrisiko (Patchell et al. 1998; Kocher et al. 2011).

Die medikamentöse Tumortherapie durch Chemotherapie ist kein essentieller Bestandteil in der Therapie von Hirnmetastasen, da Chemotherapeutika in der Regel größere Moleküle darstellen, welche die Blut-Hirn-Schranke nicht passieren und somit die Hirnmetastasen nicht erreichen können. Die Tumorkontrolle des Primarius in Form von Chemotherapie hat jedoch für die Prognose von Patienten mit Hirnmetastasen eine entscheidende Bedeutung und zeichnet sich speziell im Falle des nicht-kleinzelligen Bronchialkarzinoms durch verbesserte Therapieerfolge ab (Mehta et al. 2010). 
Um Prognosewerte in der Therapie von Patienten mit Hirnmetastasen zu erhalten, hat die amerikanische Gesellschaft Radiation Therapy Oncology Group (RTOG) anhand einer Patientenstudie eine Klassifizierung (Recursive Partitioning Analysis, RPA) vorgenommen und klassenspezifische Überlebenszeiten festgelegt (Gaspar et al. 1997):

\begin{tabular}{|c|l|c|}
\hline RPA-Klasse & \multicolumn{1}{|c|}{ Definition } & $\begin{array}{l}\text { Mediane Überlebenszeit nach } \\
\text { Ganzhirnbestrahlung in Monaten }\end{array}$ \\
\hline I & $\begin{array}{l}\text { Karnofsky-Index } \geq 70 \\
\text { Alter < 65 Jahre } \\
\text { system. Erkrankung kontrolliert }\end{array}$ & 7,7 \\
\hline II & Alle Patienten außerhalb KI. I und II & 4,5 \\
\hline III & Karnofsky-Index <70 & 2,3 \\
\hline
\end{tabular}

Tabelle 1: Prognoseklassen (RTOG-RPA) nach Gaspar et. al (1997).

Nach Analyse von weiteren Daten wurde diese Klassifizierung überarbeitet und ein Score (Graded Prognostic Assessment, GPA) hinzugefügt (Sperduto et al. 2008):

\begin{tabular}{|l|c|c|c|}
\hline Score & $\mathbf{0}$ & $\mathbf{0 , 5}$ & $\mathbf{1}$ \\
\hline Alter & $>60$ & $50-59$ & $<50$ \\
\hline Karnofsky-Index & $<70$ & $70-80$ & $90-100$ \\
\hline Zahl der Metastasen & $>3$ & $2-3$ & 1 \\
\hline $\begin{array}{l}\text { extrazerebrale } \\
\text { Metastasen }\end{array}$ & vorhanden & & nicht vorhanden \\
\hline
\end{tabular}

Tabelle 2: Prognoseklassen (GPA) nach Sperduto et al. (2008).

Für jeden der vier Parameter (Tabelle 2) kann dem Patienten ein Score von 0-1 zugewiesen werden. Diese werden summiert und es ergibt sich ein Gesamtscore. Als Beispiel: Bei einem 48-jährigen Patienten (Score 1 für Alter) mit einem Karnofsky-Index von 92 (Score 1 für Karnofsky-Index) wurden 2 zerebrale Metastasen diagnostiziert (Score 0,5 für Zahl der Metastasen) bei fehlenden extrazerebralen Metastasen (Score 1 für Nichtvorhandensein extrazerebraler Metastasen). Anhand der Parameter errechnet sich eine Prognoseklasse von 1+1+0,5+1= GPA 3,5 entsprechend einer prognostischen Überlebenszeit von 11 Monaten.
GPA $0-1$
2,6 Monate
GPA $\quad 1,5-2,5$
3,8 Monate
GPA 3
6,9 Monate
GPA $3,5-4$
11 Monate 


\subsubsection{Molekulare Marker in Hirnmetastasen}

Molekulare Marker in Tumorzellen von Hirnmetastasen sind Gegenstand aktueller Forschung, da es bisher kaum Tumormarker gibt, die außerhalb von experimentellen Studien in der klinischen Routine eingesetzt werden. Ziel ist es in Zukunft durch die Erforschung von Tumormarkern gezielte Chemotherapieansätze zu erhalten. Begleitend dazu ist die pharmakologische Weiterentwicklung von Chemotherapeutika von Bedeutung, da niedermolekulare Chemotherapeutika, welche die Blut-Hirn-Schranke passieren können, derzeit noch fehlen. Es wird diskutiert, inwieweit Chemotherapeutika, die zur Behandlung des primären Tumors verabreicht werden und durch ihre Molekülgröße die Blut-Hirn-Schranke nur schwierig passieren können, auf dessen Hirnmetastasen wirken. Die Datenlage ist jedoch noch kontrovers (Chen und Davies 2012). Folgende molekulare Marker sind Gegenstand aktueller Forschung, um die Therapierbarkeit von Hirnmetastasen zu verbessern:

VEGF, der bei der Vaskularisierung (Neoangiogenese) und beim Wachstum des Tumors eine große Rolle spielt, wird bei mehreren extrazerebralen Tumoren, aber auch bei intrazerebralen Tumoren wie dem Glioblastoma multiforme mit dem monoklonalen Antikörper Bevacizumab therapiert, um das Tumorwachstum einzuschränken. Der Effekt auf Hirnmetastasen konnte anhand experimenteller Ergebnisse schon gezeigt werden, klinisch muss dies durch aktuelle Studien jedoch noch erfolgen (Preusser et al. 2012). Ein weiter Marker ist der epidermale Wachstumsfaktor-Rezeptor (EGFR), der bei nicht-kleinzelligen Bronchialkarzinomen therapeutisch blockiert wird durch die Tyrosinkinase-Inhibitoren Erlotinib und Gefitinib (Preusser et al. 2012). Auch hier konnten die Ergebnisse, die bei nicht-kleinzelligen Bronchialkarzinomen erzielt wurden, noch nicht hinreichend in der Therapie von Hirnmetastasen gezeigt werden. Vielversprechende Studien wurden jedoch schon durchgeführt (Preusser et al. 2012). Bei mehreren Tumoren, vornehmlich beim malignen Melanom, führen Mutationen der Proteinkinase-BRAF im MAP-Kinase-Signalweg zu einem unkontrollierten Zellwachstum und einer Tumorentstehung (Preusser et al. 2012). Durch den spezifischen Inhibitor Vemurafenib kann die Prognose von Patienten mit einem metastasierenden Melanom deutlich verbessert werden. Dieser Einfluss wird in aktuellen Studien auch für Hirnmetastasen untersucht (Preusser et al. 2012). Des Weiteren verspricht man sich viel davon die Polo-like-Kinase 1 (PLK1) als gezielten Ansatzpunkt einer medikamentösen Blockade für die klinische Therapie zu erschließen. Das Enzym lässt sich nur in teilenden Zellen finden, ist in einigen Tumoren überexprimiert und kann gehemmt werden durch den selektiven Inhibitor-GSK461364A (Preusser et al. 2012). 


\subsection{Glioblastoma multiforme}

\subsubsection{Epidemiologie des Glioblastoma multiforme}

Das Glioblastoma multiforme (GBM) zählt nach der Klassifikation der World Health Organization (WHO) zum Grad IV der primären Hirntumoren und hat somit den höchsten Malignitätsgrad inne (Louis et al. 2007). Nach dem aktuellen statistischen Report der Central Brain Tumor Registry of the United States (CBTRUS) machen Gliome 28\% aller primären Hirntumoren und $80 \%$ aller malignen primären Hirntumoren aus (Ostrom et al. 2013). Das Glioblastoma multiforme hat bezogen auf alle primären Hirntumoren einen Anteil von 15,6\% und bezogen auf alle malignen primären Hirntumoren einen Anteil von 45,2\% mit einer Inzidenz von 3,19 pro 100.000/Jahr (Ostrom et al. 2013). Glioblastome stellen somit die häufigsten primären Hirntumoren im Erwachsenenalter dar, die gleichzeitig den höchsten Malignitätsgrad (WHO-Grad IV) haben.

\subsection{2 Ätiopathogenese des Glioblastoma multiforme}

GBM haben astrozytären bzw. oligoastrozytären Ursprung. Sie können schnell innerhalb von wenigen Wochen bis wenigen Monaten entstehen, breiten sich infiltrativ aus und zeigen dabei als besonderes histologisches Charakteristikum Tumorgewebsnekrosen und Gefäßproliferation (Louis et al. 2007).

In den letzten Jahren wurde in der Forschung verstärkt Augenmerk darauf gelegt, welche genetischen Veränderungen in den glialen Zellen zum Tumorwachstum führen. Erkenntnisse zeigen, dass mehrere genetische Veränderungen mit einer sukzessiven Tumorprogression in Verbindung stehen (Ohgaki und Kleihues 2007). So lassen sich zwei Entstehungswege für das GBM differenzieren: In ca. 85\% der Fälle entsteht ein primäres Glioblastom de novo, auf direkte und schnelle Weise aus dem Gliagewebe. Dies ist assoziiert mit einer Amplifikation des EGFR-Onkogens, einer Inaktivierung des Zellzyklus-Regulatorgens-p16 ${ }^{\text {INK4a }}$ durch homozygote Deletion, Promotor-Hypermethylierung oder einer Punkt-Mutation des PTENTumorsuppressorgens zusammen mit Heterozygotieverlust und Verlust der Chromosomenregion-10p24 (Ohgaki und Kleihues 2007). Als wichtiges Differenzierungsmerkmal besitzen primäre Glioblastome Wildtyp-TP53 (Ohgaki und Kleihues 2007). Auf diesem Wege entstandene Glioblastome finden sich vornehmlich in der Altersgruppe über 60 Jahren.

Sekundäre Glioblastome, die vornehmlich bei jüngeren Patienten ab ca. 40 Jahren auftreten, entstehen aus niedriggradigen Astrozytomen (WHO-Grad II) assoziiert mit verstärkten PunktMutationen des Tumorsuppressorgens-TP53 zusammen mit Heterozygotieverlust auf der Chromosomenregion-17p13.1 (wo TP53 lokalisiert ist) (Ohgaki und Kleihues 2007). 
Die durch Punkt-Mutationen verursachte Inaktivierung von TP53 ist fast immer mit fehlender Amplifikation von EGFR und umgekehrt verbunden, so dass sich primäre Glioblastome von sekundären auf genetischer Ebene differenzieren lassen (von Deimling et al. 1995; Kleihues und Ohgaki 1999). Eine weitere genetische Besonderheit, die nur bei sekundären Glioblastomen und Astrozytomen WHO-Grad II zu beobachten ist, ist die von Parsons et al. (2008) entdeckte Mutation des Isocitratdehydrogenase-1-Gens (IDH1) sowie die Mutation des Gens des zugehörigen Isoenzyms-IDH2 (Yan et al. 2009). Die Isocitrat-Dehydrogenase ist Teil des Citratzyklus der Zelle, in dem sie die oxidative Decarboxylierung von Isocitrat zu a-Ketoglutarat mit Gewinnung von NADPH katalysiert. Das IDH1-Gen befindet sich auf Chromosom-2q33. In Tumorzellen von sekundären Glioblastomen lässt sich eine PunktMutation an Position-395 (G395A) des IDH1-Gens finden (Parsons et al. 2008). Studien deuten darauf hin, dass IDH1 und IDH2 verheißungsvolle Prognosemarker in der Therapie von Glioblastomen darstellen, da die Mutationen in Zusammenhang mit einer Verlängerung der Überlebenszeit stehen (Yan et al. 2009). Näher beschrieben in Abschnitt 1.3.5.

\subsubsection{Klinik des Glioblastoma multiforme}

Bei Patienten mit Verdacht auf ein Glioblastom empfiehlt es sich, eine klinisch-neurologische Untersuchung mit differenzialdiagnostischem Ausschluss von primären, extrazerebralen und metastasierenden Tumoren, eine Bestimmung des Karnofsky-Index und eine Bildgebung in Form einer MRT des Gehirns mit oder ohne Gadolinium durchzuführen (Diener und Weimar 2012).

Nach Diener und Weimar (2012) manifestieren sich GBM durch:

- unspezifische Symptome

- fokale neurologische Defizite je nach Lokalisation:

- Großhirn

- Hirndruckzeichen
Kopfschmerz, Schwindel

epileptische Anfälle, Paresen, Sensibilitätsstörungen, Gesichtsfeldausfälle, Sprachstörungen, Persönlichkeitsänderungen (Frontalhirnsyndrom), organisches

Psychosyndrom Übelkeit, Erbrechen, Aphatie 
Ähnlich zur neuropathologischen Diagnostik von Hirnmetastasen wird für die histologische Diagnosesicherung von GBM eine lichtmikroskopische Betrachtung des Tumorgewebes mit immunhistochemischen Färbungen vorgenommen sowie eine WHO-Gradierung zur genauen Zuordnung (Louis et al. 2007). Zunehmend hält auch die Bestimmung des MGMTPromotormethylierung-Status sowie des IDH1-Status Einzug in die klinische Routine.

\subsubsection{Therapie und Prognose des Glioblastoma multiforme}

Durch den höchsten Malignitätsgrad des GBM wird eine umfangreiche Therapie zusammengesetzt aus kompletter Tumorresektion (>98\% Tumorresektion, zu belegen durch ein frühes postoperatives MRT innerhalb von 48 Stunden), Strahlentherapie und Chemotherapie empfohlen (Hegi et al. 2005; Stupp et al. 2005; Gorlia et al. 2008; Stupp et al. 2009). Voraussetzungen hierfür sind allerdings ein günstiger Karnofsky-Index (>70), um zu gewährleisten, dass der Allgemeinzustand des Patienten die belastenden Therapien zulässt.

Die komplette Tumorresektion ist ein extrem wichtiges Therapiemittel, da hierdurch die Prognose der Patienten deutlich verbessert wird (Stummer et al. 2008). Die Möglichkeit mittels fluoreszenzgestützter Resektion mit ALA (5-Aminolävulinsäure) eine Komplettresektion des Tumors besser durchführen zu können, verbessert das progressionsfreie Überleben der Patienten 6 Monate nach dem Eingriff (Stummer et al. 2006). Somit ist die komplette Tumorresektion als Standardtherapie anzusehen und wird bei resektablen Tumoren sowie gutem Allgemeinzustand des Patienten immer angestrebt. Durch eine angeschlossene Strahlentherapie wird die mediane Überlebenszeit von Patienten um 6 Monate statistisch signifikant verlängert und zählt auch zur Standardtherapie (Laperriere et al. 2002). Noch bessere Ergebnisse lassen sich mit Strahlentherapie und konkomitanter Chemotherapie mit dem alkylierenden Zytostatikum Temozolomid erreichen. Eine Verlängerung der medianen Überlebenszeit von 12,1 Monaten auf 14,6 Monate bei einer erhöhten 2-Jahres-Überlebensrate von 10\% auf 26\% ist möglich (Stupp et al. 2005; Hegi et al. 2005; Gorlia et al. 2008). Obgleich die 5-Jahres-Überlebensrate der Patienten durch die allgemein schlechte Prognose sehr gering ist, konnte sie mit einer konkomitanten Therapie auf $11 \%$ verbessert werden im Vergleich zu einer nur 3\% 5-Jahres-Überlebensrate von Patienten, die postoperativ alleinig Strahlentherapie erhalten hatten (Stupp et al. 2009). Insbesondere Patienten, die eine Methylierung des DNA-Reparaturgens $\mathrm{O}^{6}$-MethylguaninDNA-Methyltransferase (MGMT) aufweisen, haben eine bessere Prognose. MGMT wirkt Strangbrüchen der DNA, die durch Alkylierung hervorgerufen werden, entgegen. Temozolomid bewirkt als gewünschter Effekt eine Alkylierung der DNA in Tumorzellen, was eine Apoptose der Tumorzellen zur Folge hat. Durch die Methylierung der MGMT ist die Reparatur der DNA in Tumorzellen eingeschränkt, weshalb die Temozolomid-Therapie 
besser wirken kann. Dies spiegelt sich in einer signifikant erhöhten 2-Jahres-Überlebensrate der Patienten von 46\% wider (Hegi et al. 2005). Neben der MGMT-Methylierung beeinflussen das Alter der Patienten, der Karnofsky-Index und das Ausmaß der Tumorresektion die Prognose der Patienten signifikant (Gorlia et al. 2008).

\subsubsection{Molekulare Marker in Glioblastoma multiforme}

Molekulare Marker in Tumorzellen von Gliomen sind ein wichtiger Bestandteil der Forschung der letzten Jahre. Durch sie gewinnt man Erkenntnisse darüber, welche Veränderungen in der Zelle sich negativ auf die Prognose der Patienten auswirken und wo man in der Therapie gezielt ansetzen kann. Somit ergibt sich eine Personalisierung der Therapie, die durch die Beeinflussung individueller Faktoren mehr Erfolg versprechen könnte. Im Vergleich zu niedriggradigen Gliomen wie zum Beispiel den Oligodendrogliomen sind die Ergebnisse bei GBM noch heterogen und finden klinisch wenig translationale Anwendung. Folglich sind weitere Studien Gegenstand aktueller Forschung.

Der wichtigste Marker in Glioblastomen, der auch in der Therapie eine aktive Rolle spielt, ist die schon angesprochene MGMT. Das MGMT-Gen ist bei ca. 45\% der GBM methyliert, wodurch selbige Patienten ein besseres Ansprechen auf die Temozolomid-Therapie mit einer verlängerten Überlebenszeit haben (Esteller et al. 2000; Hegi et al. 2005).

Weitere wichtige Marker sind die Mutationen des Isocitratdehydrogenase-1-Gens (IDH1) sowie dessen Isoenzyms-IDH2, die auch schon in Abschnitt 1.3.2 angesprochen wurden. Beide Mutationen stehen nachweislich mit einer besseren Prognose der Patienten und verlängerten Überlebenszeit in Verbindung. Dies zeigte sich in der Studie von Yan et al. (2009), in der Patienten mit Glioblastoma und IDH1/2-Mutation eine signifikant verlängerte

mediane Überlebenszeit (31 Monate) gegenüber Patienten ohne IDH1/2-Mutation (15 Monate) aufwiesen. Auch die Hypermethylierung des proapoptotischen TMS1/ASC-Gens, das als Mediator von Apoptose-Vorgängen und Entzündungsreaktionen in der Zelle fungiert, zeigte sich als möglicher prognostischer Biomarker, da eine Hypermethylierung signifikant häufiger bei GBM-Patienten mit verlängerter Überlebenszeit auftritt (Martinez et al. 2007). Weitere vielversprechende Marker sind VEGF sowie besonders EGFR, der, wie schon in der Ätiopathogenese beschrieben, in primären Glioblastomen amplifiziert ist. In aktuellen Therapieansätzen versucht man das Tumorwachstum durch die Hemmung von VEGF mit dem monoklonalen Antikörper Bevacizumab respektive durch die Hemmung von EGFR mit dem Tyrosinkinase-Inhibitor Erlotinib einzuschränken. Anwendung finden beide Inhibitoren schon bei mehreren extrazerebralen Karzinomen. Diese Therapieansätze mit dem Versuch den onkogenen PI3K/AKT/mTOR-Pfad gezielt zu hemmen haben vielversprechende Ergebnisse in In-Vivo-Mausmodellen sowie In-Vitro-Studien gezeigt, in Phase-II-Patienten- 
studien sind die Ergebnisse bezüglich einer Verbesserung der Überlebenszeit dagegen enttäuschend (Omuro et al. 2007; Sathornsumetee 2011; Wick et al. 2011). Erfolge zeigten sich nur in Patientenstudien mit dem Angiogenesehemmer Cilengitide, der Integrine hemmen kann. Des Weiteren mit Bevacizumab (Avastin) in der Therapie von rezidivierenden GBM im Anschluss an Tumorresektion, Strahlentherapie und konkomitanter Chemotherapie mit Temozolomid (Onishi et al. 2013).

\subsection{Fragestellung}

Eag1 wird seit wenigen Jahren intensiv erforscht, da man aussichtsreiche Ergebnisse gewonnen hat, die gezeigt haben, dass Eag1 eine große Rolle in der Pathogenese von malignen Tumoren spielt. Unter anderem durch die Beeinflussung der Zellteilung, Erhöhung der Proliferationsrate von Tumorzellen und durch die Eag1 abhängige Steigerung der VEGFSekretion einhergehend mit verbesserter Neoangiogenese des Tumors. Die Expression und Aktivität von Eag1 ist bei mehreren extrazerebralen Karzinomen bereits untersucht worden, eine Funktion als Tumor- und Prognose-Marker konnte aufgezeigt werden. Darüber hinaus ist Eag1 als Oncotarget beschrieben, da In-Vitro-, als auch In-Vivo-Studien gezeigt haben, dass Eag1 zum Beispiel durch Medikamente wie Antihistaminika (Astemizol), trizyklische Antidepressiva (Imipramin) sowie durch Antikörper blockiert werden kann.

In der vorliegenden Studie wird die Expression von Eag1 im Tumorgewebe von Hirnmetastasen und GBM immunhistochemisch untersucht, da Ergebnisse zu Hirnmetastasen bisher noch nicht vorliegen und die Datenlage bezüglich GBM kontrovers ist.

Die Überlebenszeit von den Patienten wird in beiden Kollektiven in Abhängigkeit von der Eag1-Expression analysiert.

Ziel der beiden Untersuchungen ist es aufzuzeigen, ob Eag1 auch bei Hirnmetastasen und Glioblastomen einen Einfluss als Tumor- und Prognose-Marker hat.

Eine komparative Analyse der Überlebenszeit von Patienten mit Antidepressiva-Therapie im Vergleich zu Patienten ohne Antidepressiva-Therapie wird in Abhängigkeit von der Eag1Expression durchgeführt. Dies soll Aufschluss darüber geben, welchen Einfluss die Blockade von Eag1 durch Antidepressiva auf die Überlebenszeit von Patienten mit Hirnmetastasen und GBM hat. 


\section{II) Material und Methoden}

\subsection{Patienten}

\subsubsection{Patienten mit Diagnose Hirnmetastase}

Im Zuge der retrospektiven Patientenakquirierung wurde auf die PatientendatenVerarbeitungssoftware von $\mathrm{SAP}^{\circledR}$ (Walldorf, Deutschland), die an der Universitätsmedizin Göttingen verwendet wird, zurückgegriffen. Mittels des ICD-10-Diagnoseschlüssels konnten zum einen Patienten mit der Diagnosekombination C79.3 (sekundäre bösartige Neubildung des Gehirns) plus F32.* (depressive Episode) und zum anderen Patienten mit der alleinigen Diagnose C79.3 ermittelt werden. Somit ergab sich im Studiendesign:

- Eine experimentelle Gruppe, in die Patienten mit Hirnmetastasen und einer endogenen Depression, die mittels Antidepressiva therapiert wurde, eingeschlossen wurden.

- Eine Kontrollgruppe, in die Patienten mit Hirnmetastasen ohne Depression, bei denen kein pharmakologischer Einfluss durch ein Antidepressivum bestand, eingeschlossen wurden.

Bei beiden Gruppen wurden die Patienten nach Zufall ausgewählt, um einen Bias zu vermeiden. Insgesamt wurden 75 Patienten eingeschlossen, die im Zeitraum von 2004 bis 2011 in die Klinik für Neurochirurgie der Universitätsmedizin Göttingen stationär aufgenommen wurden und eine operative Tumorentfernung hatten. Alle Patienten wurden postoperativ mit einer Dosis von 30 - 45 Gray (Mittelwert 35,8 Gray) adjuvant bestrahlt. Von diesen 75 Patienten wurden 23 Patienten mit trizyklischen und nicht-trizyklischen Antidepressiva therapiert und der experimentellen Gruppe zugewiesen.

\subsubsection{Patienten mit Diagnose Glioblastoma multiforme}

Wie schon bei der Patientengruppe mit Hirnmetastasen wurden auch für diese Gruppe Patienten auf die gleiche Art und Weise ermittelt. Zum einen mit der Diagnosekombination C71. * (bösartige Neubildung des Gehirns) plus F32. ${ }^{*}$, zum anderen alleinig mit der Diagnose C71. *.Somit ergab sich im Studiendesign:

- Eine experimentelle Gruppe, in die Patienten mit GBM und einer endogenen Depression, die mittels Antidepressiva therapiert wurde, eingeschlossen wurden.

- Eine Kontrollgruppe, in die Patienten mit GBM ohne Depression, bei denen kein pharmakologischer Einfluss durch ein Antidepressivum bestand, eingeschlossen wurden. 
Bei beiden Gruppen wurden die Patienten nach Zufall ausgewählt, um einen Bias zu vermeiden. Im Gesamtkollektiv wurden 71 Patienten mit einem GBM WHO-Grad IV eingeschlossen, die im Zeitraum von 2004 bis 2011 in die Klinik für Neurochirurgie der Universitätsmedizin Göttingen stationär aufgenommen wurden und eine operative Tumorentfernung hatten. Alle Patienten wurden postoperativ adjuvant mit einer Dosis von 60 Gray bestrahlt sowie mit dem Chemotherapeutikum Temozolomid in 6 Zyklen therapiert. Von diesen 71 Patienten wurden 26 Patienten mit trizyklischen und nicht-trizyklischen Antidepressiva therapiert und somit der experimentellen Gruppe zugewiesen.

\subsubsection{Erhobene Parameter}

Für die vorliegende Studie wurden die Patientenakten gesichtet und folgende Parameter ausgewertet:

- Geschlecht

- Alter

- Antidepressivum

- Primärtumor (für Patientengruppe mit Hirnmetastasen)

- Lokalisation der Hirnmetastase bzw. des Glioblastoms

- Überlebenszeit

Da für die Erfassung der Überlebenszeit der postoperative Verlauf der Patienten nicht immer vollständig aktenkundig gewesen ist, wurden zum Erhalt des Sterbedatums der Patienten die Einwohnermeldeämter kontaktiert. Dieses Vorgehen wurde im Vorfeld von der EthikKommission der Medizinischen Fakultät der Georg-August-Universität Göttingen überprüft und befürwortet (Votum vom 02.01.2013, Antragsnummer: 5/7/12).

\subsection{Material}

\subsubsection{Ausgewertetes Gewebe}

Bei dem Gewebe, das in der vorliegenden Studie untersucht wurde, handelt es sich um in Paraffin eingebettete Tumorbiopsien von Hirnmetastasen und GBM, die routinemäßig zur neuropathologischen Diagnostik bei den jeweiligen Tumoroperationen entnommen wurden. Es wurden Biopsien verwendet, die im Zeitraum von 2004 bis 2011 entnommen und in den Archiven der Neuropathologie der Universitätsmedizin Göttingen eingelagert wurden. 
Auch die Untersuchung des humanen Tumorgewebes wurde durch die Ethik-Kommission geprüft und befürwortet (Votum vom 02.01.2013, Antragsnummer: 5/7/12).

\subsubsection{Materialaufbereitung}

Zur Herstellung von Leerschnitten wurden mit einem Rotationsmikrotom (RM2255, Leica ${ }^{\circledR}$, Wetzlar, Deutschland) $5 \mu \mathrm{m}$ dünne Gewebeschnitte aus den Paraffin-Blöcken angefertigt, die im DEPC-Bad auf Silane-beschichtete Objektträger (SuperFrost ${ }^{\circledR}$ Plus, Menzel-Gläser ${ }^{\circledR}$, Braunschweig, Deutschland) aufgetragen wurden. Darauf wurden die Gewebeschnitte für 1 Stunde auf einer $37^{\circ} \mathrm{C}$ warmen Wärmeplatte und 2 Stunden im Wärmeschrank bei $60^{\circ} \mathrm{C}$ getrocknet.

\subsubsection{Positiv-/Negativ-Probe}

Bei jedem Färbedurchlauf wurde als Positiv-Probe ein zerebraler Sagittalschnitt von WildtypMäusen bzw. Ratten verwendet, da Eag1 in bestimmten Bereichen des Gehirns endogen exprimiert ist (Martin et al. 2008). Zur Herstellung einer Negativ-Probe wurde das Gewebe mit einer Pufferlösung ohne Antikörper inkubiert.

\subsection{Methoden}

\subsubsection{Immunhistochemie}

Die Immunhistochemie dient dazu, Antigene in Form von Proteinen und anderen Strukturen mit Hilfe von spezifischen Antikörpern zu markieren und über einen Farbstoff (Chromogen) unter dem Mikroskop sichtbar zu machen. Somit besteht die Möglichkeit zur Analyse, wo in der Zelle und in welchem Gewebe ein gewisses Antigen vorhanden ist. Klassischerweise wird die Immunhistochemie in der klinischen Routine eingesetzt, um anhand charakteristischer Antigene Tumorzellen zu identifizieren und zu klassifizieren. Bei der Durchführung unterscheidet man zwischen einer direkten und einer indirekten Methode. Die direkte Methode zeichnet sich dadurch aus, dass der spezifische Antikörper mit einem Enzym konjugiert ist, das - nach Bindung des Antikörper-Enzym-Komplexes an das Antigen - ein zugeführtes Substrat direkt in ein Farbprodukt umsetzt.

Antigen + Antikörper konjugiert mit Enzym + Substrat $=$ Farbe 
Bei der indirekten Methode wird ein sekundärer Antikörper, der spezifisch zur Art des primären Antikörper-Wirtes ist (z.B. anti-Maus, anti-Ratte) und mit einem Enzym konjugiert ist, in den Reaktionsweg eingefügt, um die Sensitivität der Reaktion zu erhöhen.

Antigen + prim. Antikörper + sek. Antikörper konjugiert mit Enzym + Substrat $=$ Farbe

Abhängig von dem zu verwendenden Antikörper und vom darzustellenden Antigen ist die Methode zu wählen, mit der ein sicheres und reproduzierbares Ergebnis erreicht werden kann. In der vorliegenden Studie wurde die direkte Methode gewählt, beschrieben im Abschnitt 2.3.1.2.

\subsubsection{Antikörper}

Der verwendete Antikörper ist ein im Max-Planck-Institut für Experimentelle Medizin Göttingen, Abteilung für Molekulare Biologie Neuronaler Signale entwickelter monoklonaler Antikörper (Hemmerlein et al. 2006). Es handelt sich um einen rekombinanten single-chainAntikörper, der an das Protein alkalische Phosphatase gebunden und spezifisch für das Epitop im Bereich der möglichen Porenregion von Eag1 ist (scFv62-PhoA). Die Sensitivität für Eag1 ist sehr gut, Kreuzreaktionen zu strukturähnlichen Kanalproteinen von Eag1 wie Eag2 oder aber auch dem HERG-Kanal sind nahezu auszuschließen.

\subsubsection{Alkalische Phosphatase (AP)-Methode}

Bei der AP-Methode wird die alkalische Phosphatase als Enzym verwendet. Sie eignet sich besonders gut für die Konjugation mit einem rekombinanten single-chain-Antikörper.

Die alkalische Phosphatase kommt naturgemäß im menschlichen Organismus vor, hydrolysiert Phosphorsäureester und spaltet Phosphat-Gruppen ab. Immunhistologisch werden organische Phosphatverbindungen als Substrat verwendet, die durch die enzymatische Dephosphorylierung zu einem farbigen Endprodukt reagieren. Sehr häufig ist dies das Chromogen 5-Brom-4-chlor-3-indoxylphosphat (BCIP) in Verbindung mit NitroblauTetrazoliumchlorid (NBT). Hierbei entsteht ein bläuliches Reaktionsprodukt. Die Methodik mit diesem Chromogen ist für die Eag1-Expression in extrazerebralen Tumoren schon beschrieben (Hemmerlein et al. 2006). Zusätzlich wurde zur Verbesserung der AntigenDarstellung noch das Chromogen Neufuchsin verwendet mit geringfügigen Veränderungen in der Durchführung der Methodik. 
Eine vereinfachte Darstellung der AP-Methode mit dem Chromogen BCIP/NBT und Neufuchsin ist in Abbildung 1 zu sehen.
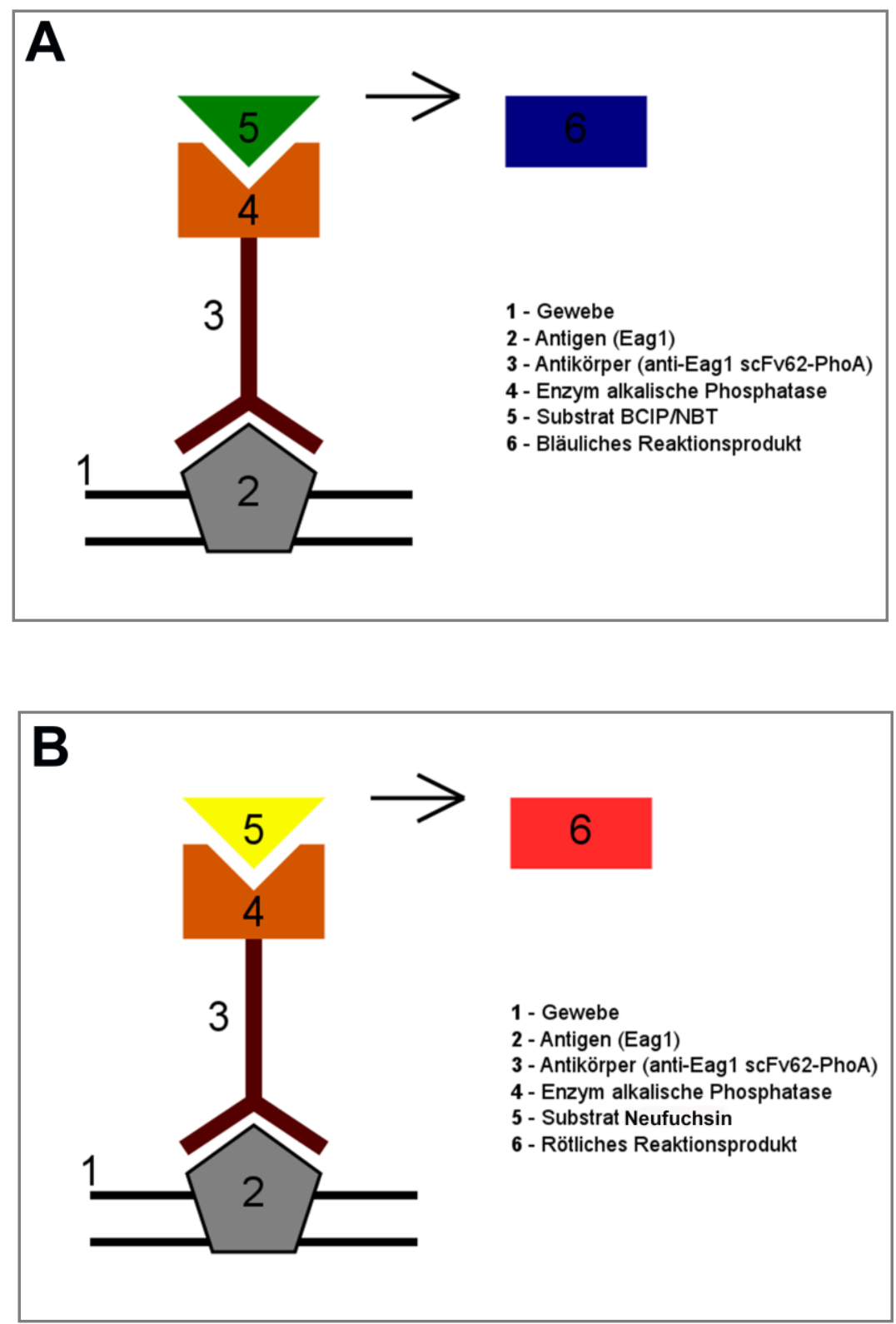

Abb. 1: Vereinfachte Darstellung der AP-Methode mit A dem Chromogen BCIP/NBT und B Neufuchsin. 


\subsubsection{Durchführung der AP-Methode}

\subsection{Chromogen BCIP/NBT}

Das folgende Protokoll wurde zur Erreichung bestmöglich identischer Bedingungen für jeden Gewebeschnitt automatisiert mit Ventana Discovery XT (Roche Diagnostics ${ }^{\circledR}$, Rotkreuz, Schweiz) durchgeführt. Alle Chemikalien sind, wenn nicht anders angegeben, Bestandteil des BlueMap Detection Kit (Roche Diagnostics ${ }^{\circledR}$ ).

\section{$\underline{\text { Vorbehandlung des Gewebes }}$}

Die Gewebeschnitte wurden im Xylol-Bad entparaffiniert (2x für je 10 Minuten) und anschließend rehydriert in einer Ethanol-Verdünnungsreihe mit absteigender Konzentration (10 Minuten in 100\%, 5 Minuten in 90\% und je 2 Minuten in 70\%, 50\% und 30\%) und abschließender Spülung in Aqua dest.

Um die Antigene zu demaskieren, wurde das Gewebe für 30 Minuten im Wasserbad bei $90^{\circ} \mathrm{C}$ in $10 \mathrm{mM}$ Citrat-Puffer $\mathrm{pH} \mathrm{6,0} \mathrm{erhitzt.} \mathrm{Anschließend} \mathrm{wurde} \mathrm{das} \mathrm{Gewebe} \mathrm{über} \mathrm{eine}$ Stunde wieder abgekühlt und darauf 5 Minuten in TBS pH 8,0 gewaschen.

Im nächsten Schritt wurden die nicht spezifischen Bindungsstellen mit 10\% BSA in TBS für eine 1 Stunde bei Raumtemperatur blockiert. Dieser Vorgang wurde abgeschlossen, indem das Gewebe 2x für 5 Minuten in TBS pH 8,0 gewaschen wurde.

\section{Antikörper-Inkubation}

Der Antikörper scFv62-PhoA wurde in TBS verdünnt und mit einer Konzentration von 1:100 angewendet. Bei einer Temperatur von $24^{\circ} \mathrm{C}$ hatte der Antikörper eine Inkubationszeit von 18 Stunden auf das Gewebe. Anschließend wurde das Gewebe 3x für 3 Minuten im Detektionspuffer pH 8,8 (siehe 2.3.1.4) gewaschen.

\section{Entwicklung und Gegenfärbung}

Die Antigen-Färbung erfolgte durch die Inkubation in BCIP/NBT $(100 \mu$ Substrat auf $5 \mathrm{ml}$ Detektionspuffer) für 20 Minuten. Die Reaktion wurde beendet durch einmaliges Waschen für 5 Minuten in TBS $\mathrm{pH} 8,0$.

Nachfolgend wurde mit Nuclear Fast Red $\left(D{ }^{\circledR} o^{\circledR}\right.$, Glostrup, Dänemark) für 10 Minuten gegengefärbt. 


\section{Lagerung der gefärbten Gewebeschnitte}

Vor der Eindeckung wurde das gefärbte Gewebe in einer Ethanol-Verdünnungsreihe mit aufsteigender Konzentration (je 2 Minuten in 30\%, 50\%, 70\%, 5 Minuten in $90 \%$ und 10 Minuten in 100\%) dehydriert und anschließend 2x für 10 Minuten in Xylol gelegt. Als Eindeckmedium wurde Permount (Thermo Fisher Scientific ${ }^{\circledR}$, Waltham, USA) verwendet.

\subsection{Chromogen Neufuchsin}

\section{$\underline{\text { Vorbehandlung des Gewebes }}$}

Die Gewebeschnitte wurden im Xylol-Bad entparaffiniert (2x für je 10 Minuten) und anschließend rehydriert in einer Ethanol-Verdünnungsreihe mit absteigender Konzentration (10 Minuten in 100\%, 5 Minuten in 90\% und je 2 Minuten in 70\%, 50\% und 30\%) und abschließender Spülung in Aqua dest.

Um die Antigene zu demaskieren wurde das Gewebe für 30 Minuten im Steamer (60 bis $70^{\circ} \mathrm{C}$ ) in Tris-EDTA Puffer pH 9,0 erhitzt. Anschließend wurde das Gewebe über eine Stunde wieder abgekühlt und darauf 5 Minuten in TBS pH 8,0 gewaschen.

Im nächsten Schritt wurden die nicht spezifischen Bindungsstellen mit 0,2\% Casein für 20 Minuten bei Raumtemperatur blockiert. Dieser Vorgang wurde abgeschlossen, indem das Gewebe 2x für 5 Minuten in TBS pH 8,0 gewaschen wurde.

\section{Antikörper-Inkubation}

Der Antikörper scFv62-PhoA wurde in TBS verdünnt und mit einer Konzentration von 1:100 angewendet. Bei einer Temperatur von $24^{\circ} \mathrm{C}$ hatte der Antikörper eine Inkubationszeit von 18 Stunden auf das Gewebe. Anschließend wurde das Gewebe 3x für 3 Minuten im Detektionspuffer pH 8,8 (siehe 2.3.1.4) gewaschen.

\section{Entwicklung und Gegenfärbung}

Die Antigen-Färbung erfolgte durch die Inkubation in Neufuchsin (Sigma ${ }^{\circledR}$, Kawasaki, Japan) für 20 Minuten. Die Reaktion wurde beendet durch einmaliges Waschen für 5 Minuten in Aqua dest.

Nachfolgend wurden die Schnitte zum Gegenfärben in Hämalaun-Blau (verdünnt 1:1 mit Aqua bidest) eingetaucht und 10 Minuten unter laufendem Wasser gebläut. 


\section{Lagerung der gefärbten Gewebeschnitte}

Das gefärbte Gewebe wurde mit dem Medium Glycergel (Dako ${ }^{\circledR}$, Glostrup, Dänemark) eingedeckt.

\subsubsection{Lösungen und Puffer}

\begin{tabular}{|c|c|}
\hline Lösung/Puffer & Zusammensetzung \\
\hline NBT/BCIP & $\begin{array}{l}18,75 \mathrm{mg} / \mathrm{ml} \mathrm{NBT} \\
9,4 \mathrm{mg} / \mathrm{mg} \mathrm{BCIP}\end{array}$ \\
\hline $\begin{array}{l}\text { Neufuchsin } \\
\text { - Lösung I: }\end{array}$ & $\begin{array}{l}50 \text { ml TBS-Puffer pH 8,8 } \\
+20-25 \text { mg Levamisol }\end{array}$ \\
\hline - Lösung II: & $\begin{array}{l}14 \text { mg Naphtol-AS-Biphosphat in } \\
300 \mu \mathrm{l} \mathrm{N}, \mathrm{N} \text {-Dimethylformamid }\end{array}$ \\
\hline - Lösung III: & $\begin{array}{l}10 \text { mg Natriumnitrit in } 250 \mu \mathrm{l} \mathrm{H}_{2} \mathrm{O} \text { dest. } \\
+100 \text { ml Neufuchsin-Stammlösung } \\
\text { (5g Neufuchsin }+30 \mathrm{ml} \mathrm{HCL} 25 \% \text { ad } 100 \mathrm{ml} \\
\mathrm{H}_{2} \mathrm{O} \text { bidest.) }\end{array}$ \\
\hline $\begin{array}{l}\text { Tris-EDTA-Puffer } \\
\mathrm{pH} \mathrm{9,0}\end{array}$ & $\begin{array}{l}10 \mathrm{mM} \text { Tris Base } \\
1 \mathrm{mM} \text { EDTA }\end{array}$ \\
\hline $\begin{array}{l}\text { TBS } \\
\mathrm{pH} 8,0\end{array}$ & $\begin{array}{l}50 \mathrm{mM} \text { Tris } \\
137 \mathrm{mM} \mathrm{NaCl} \\
2,7 \mathrm{mM} \mathrm{KCl}\end{array}$ \\
\hline Blockierungspuffer & $\begin{array}{l}\text { TBS pH } 8,0 \\
10 \% \text { BSA }\end{array}$ \\
\hline $\begin{array}{l}\text { Citrat-Puffer } \\
\mathrm{pH} 6,0\end{array}$ & 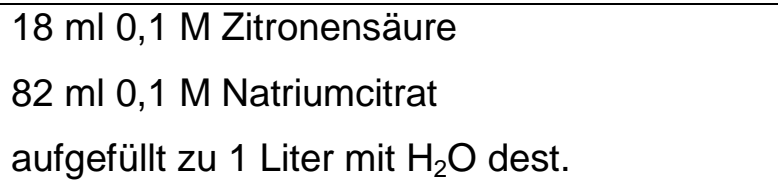 \\
\hline $\begin{array}{l}\text { Detektionspuffer } \\
\mathrm{pH} 8,8\end{array}$ & $\begin{array}{l}100 \mathrm{mM} \text { Tris-Base } \\
100 \mathrm{mM} \mathrm{NaCl} \\
5 \mathrm{mM} \mathrm{MgCl}_{2}\end{array}$ \\
\hline
\end{tabular}

Tabelle 3: Immunhistochemisch verwendete Lösungen und Puffer. 


\subsubsection{Immunhistochemische Auswertung}

Das immunhistochemisch gefärbte Tumorgewebe wurde mit einem Lichtmikroskop (Axioskop 50, Carl Zeiss ${ }^{\circledR}$, Jena, Deutschland) unter gleichbleibenden Einstellungen betreffend Vergrößerung und Lichtintensität ausgewertet. Zur Durchführung einer semiquantitativen Auswertung der Eag1-Expression wurde ein Score mit vier Graden angewendet (Ding et al. $2007 \mathrm{a}, \mathrm{b}$ ):

- Grad $0<10 \%$ der Zellen zeigen eine Antigen-Färbung

- Grad 1+ > > $\quad>10 \%$ der Zellen zeigen eine schwache Antigen-Färbung

- Grad 2+ $\quad>10 \%$ der Zellen zeigen eine moderate Antigen-Färbung

- Grad 3+ $\quad>10 \%$ der Zellen zeigen eine starke Antigen-Färbung

Tumorschnitte mit Grad 0 wurden durch die limitierte Anzahl an gefärbten Zellen als negativ bewertet. Um Rückschlüsse auf die Prognose der Patienten treffen zu können wurde Grad 0 und 1+ zusammengefasst als niedrige Eag1-Expression bewertet, in den Ergebnissen nachfolgend weiter bezeichnet als Eag1 low. Grad 2+ und 3+ wurde zusammengefasst als erhöhte Eag1-Expression bewertet, bezeichnet als Eag1 high. Die mikroskopische Auswertung wurde standardisiert ohne Einsicht der klinischen Verlaufsdaten der Patienten durchgeführt und von einer zweiten Person verifiziert. Digitale Aufnahmen der Gewebe wurden mit einem inversen Mikroskop (Axiovert 200M, AxioCam HR, AxioVision Software, Carl Zeiss ${ }^{\circledR}$, Jena, Deutschland) mit festgelegten Einstellungen für jedes Bild angefertigt.

\subsubsection{Statistische Auswertung}

Für die statistische Auswertung wurden die Daten der Eag1-Expression sowie der klinischen Parameter mit dem Kolmogorow-Smirnow-Test auf Normalverteilung überprüft, um die weiteren statistischen Testverfahren zu eruieren. Da eine Normalverteilung gegeben war, wurden parametrische Tests angewendet. Um Einflüsse auf die abhängige Variable - die Überlebenszeit von Patienten - zu überprüfen, wurde bei einem Einflussfaktor ein t-Test für unabhängige Gruppen durchgeführt. Bei zwei Einflussfaktoren wurde eine zweifaktorielle Varianzanalyse (two-way-ANOVA) angewendet. Zur weiteren Untersuchung wurde eine Überlebenszeitanalyse nach Kaplan-Meier durchgeführt mit Überprüfung der Einflussfaktoren durch einen Log-Rank-Test. 
Eine statistische Signifikanz war bei einem $p$-Wert kleiner $0,05(p<0,05)$ gegeben. Die berechneten Überlebenszeiten wurden mit Medianwert sowie dem jeweilig dazugehörigen 95\%-Konfidenzintervall (KI) angegeben. Die grafische Darstellung erfolgte durch Box- und Whiskerdiagramme (Boxplot) sowie durch Kaplan-Meier-Kurven. Die Datenanalyse wurde mit der Statistik-Software STATISTICA 10 (StatSoft, Tulsa, USA) durchgeführt, die KaplanMeier Überlebenszeitanalyse mit SPSS Vers. 21 (SPSS Inc. der IBM Company, Chicago, USA). 


\section{III) Ergebnisse}

\subsection{Klinische Daten}

\subsubsection{Hirnmetastasen-Kollektiv}

\section{Geschlechts- und Altersverteilung}

Das Hirnmetastasen-Kollektiv bestand aus 36 (48\%) weiblichen Patienten und 39 (52\%) männlichen Patienten. Bei Erstdiagnose der Hirnmetastasen respektive Zeitpunkt der Tumoroperation lag der Altersmittelwert der weiblichen Patienten bei 59,7 \pm 11,5 Jahren (Medianwert 59 Jahre) mit einer Altersspanne von 39 bis 85 Jahren und der männlichen Patienten bei 61,6 \pm 9,9 Jahren (Medianwert 61 Jahre) mit einer Altersspanne von 38 bis 80 Jahren (Abb. 2).

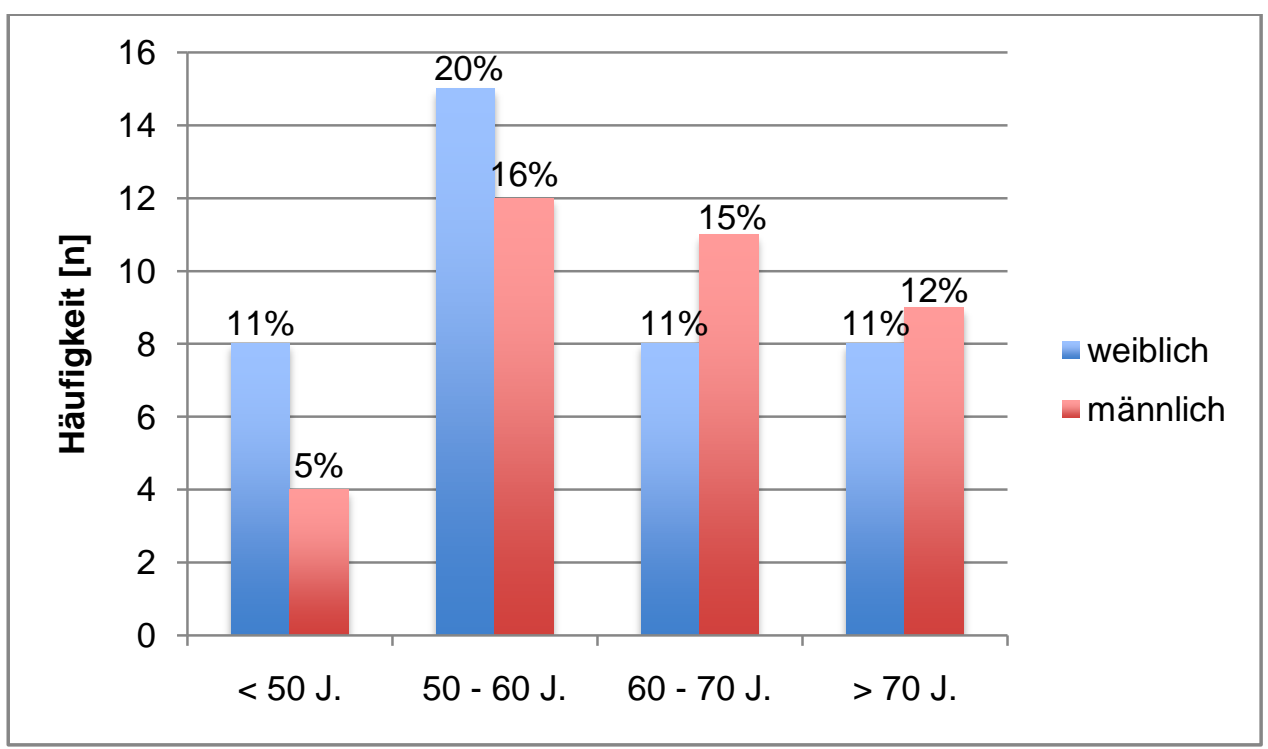

Abb. 2: Geschlechtsabhängige Altersverteilung im Hirnmetastasen-Kollektiv.

\section{Antidepressiva-Therapie}

In der experimentellen Gruppe des Hirnmetastasen-Kollektivs wurden 23 Patienten (31\%) zusätzliche mit einem Antidepressivum therapiert, die restlichen 52 Patienten (69\%) bildeten die Kontrollgruppe. Von diesen 23 Patienten nahmen 10 Patienten $(43,5 \%)$ das trizyklische Antidepressivum Amitriptylin, 8 Patienten (35\%) den selektiven Serotonin-Wiederaufnahmehemmer (SSRI) Citalopram und 5 Patienten (21,5\%) das tetrazyklische Antidepressivum Mirtazapin ein (Abb. 3). 


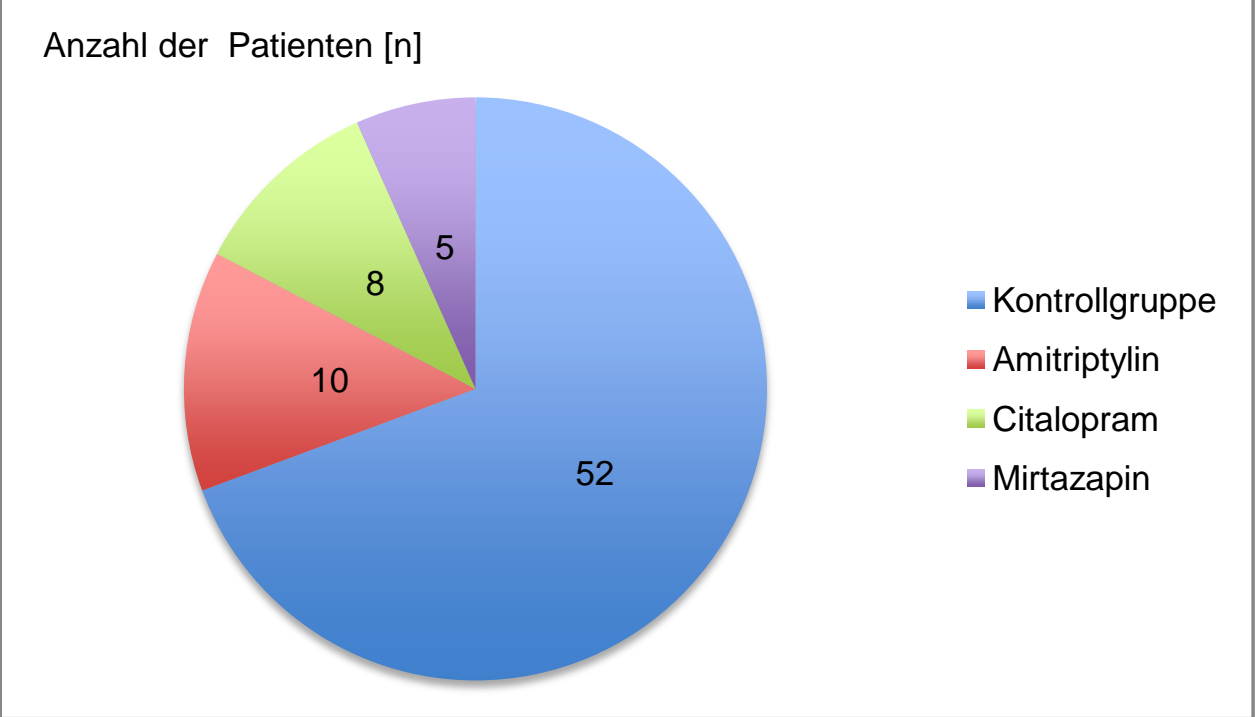

Abb. 3: Verteilung der Antidepressiva im Hirnmetastasen-Kollektiv.

\section{Primärtumor}

Im Hirnmetastasen-Kollektiv wurden anhand der Aktenauswertung unterschiedliche Primärtumoren ausgemacht. Am häufigsten waren zerebral metastasierende Bronchialkarzinome sowie Mammakarzinome. Eine vollständige Auflistung ist in Abbildung 4 aufgeführt.

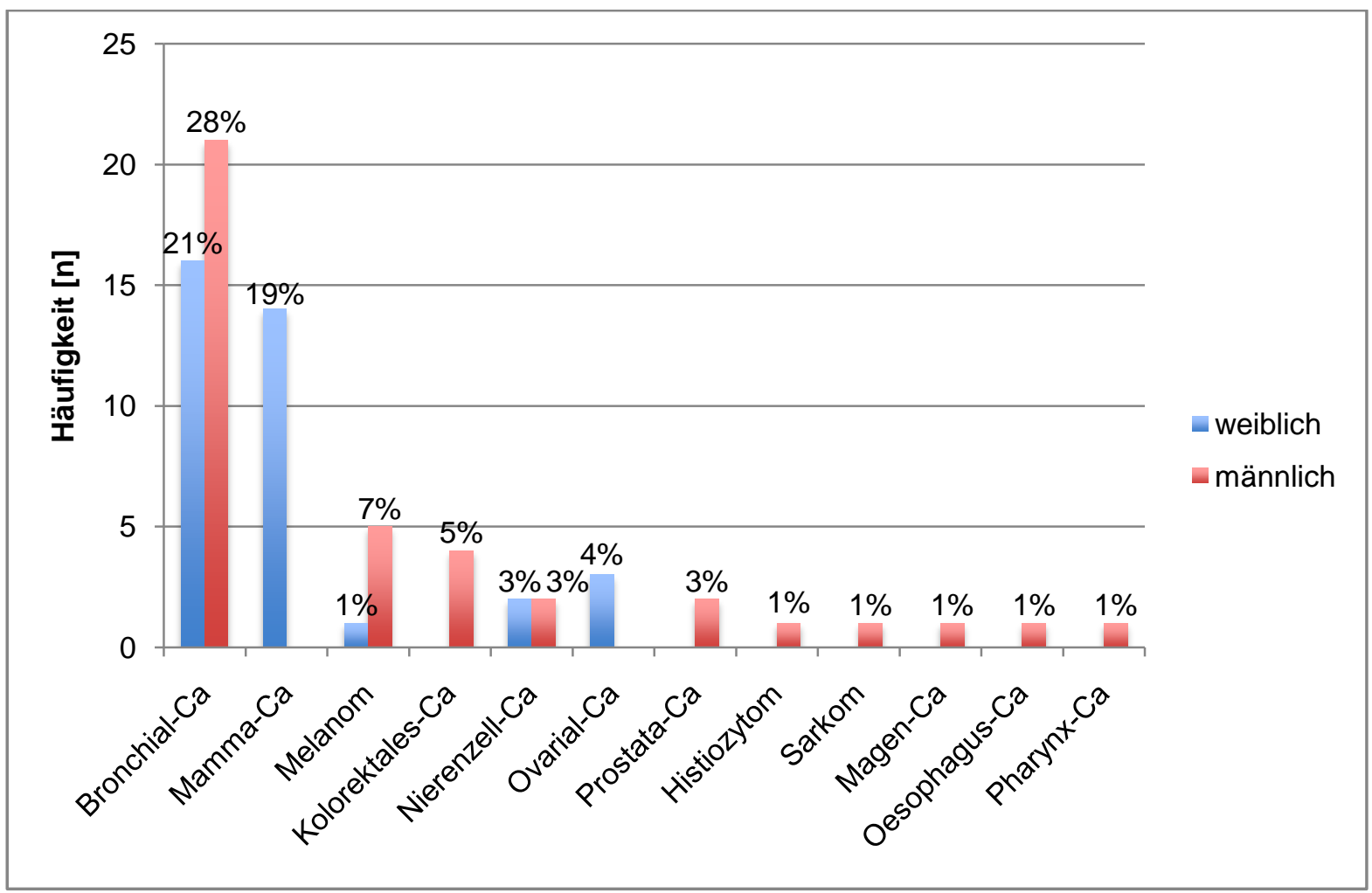

Abb. 4: Verteilung der Primärtumoren im Hirnmetastasen-Kollektiv. 


\section{$\underline{\text { Lokalisation der Hirnmetastasen }}$}

Die untersuchten Tumorbiopsien ließen sich durch MRT Aufnahmen des Neurokraniums (insbesondere T1 gewichtete Sequenzen nach Gadolinium-Gabe) den unterschiedlichen Hirnarealen zuordnen (Abb. 5).

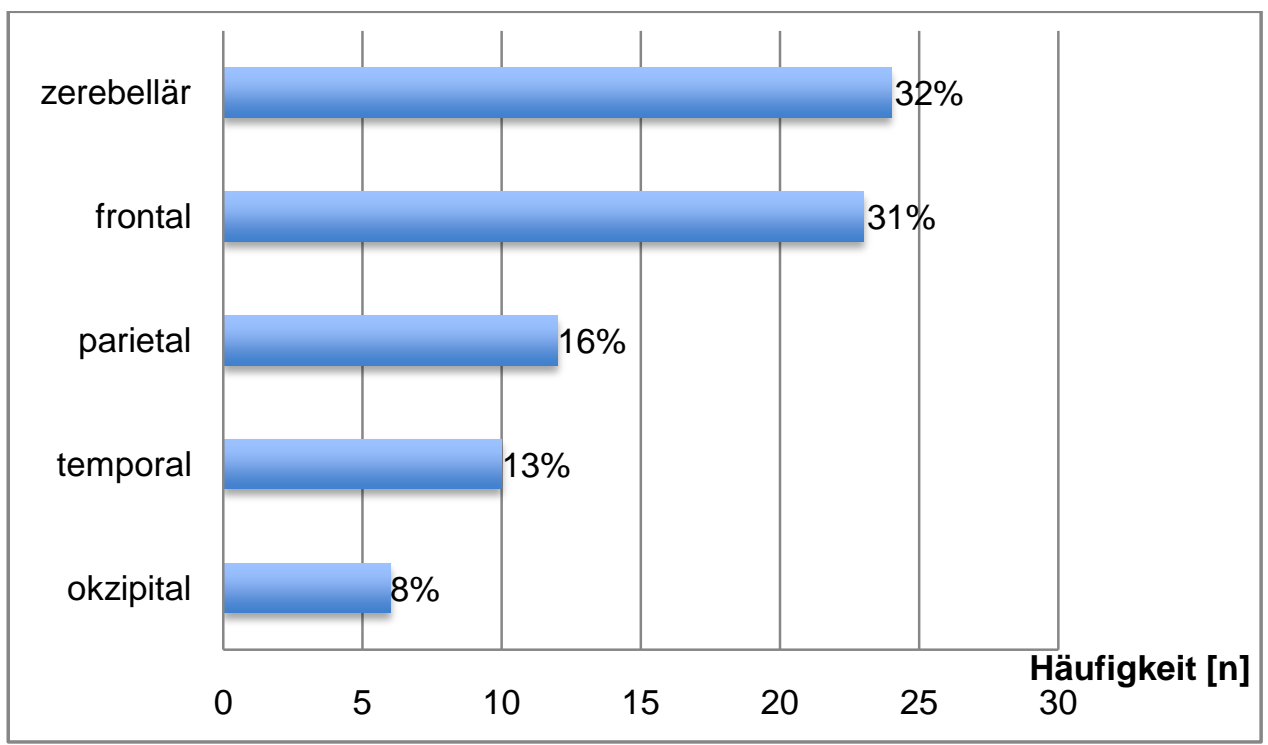

Abb. 5: Verteilung der Tumorlokalisationen im Hirnmetastasen-Kollektiv.

\section{$\underline{\text { Überlebenszeit }}$}

Für die Patienten im Hirnmetastasen-Kollektiv $(n=75)$ ergab sich eine mediane Überlebenszeit von 7 Monaten (95\%-KI 6 - 10) (Abb. 6).

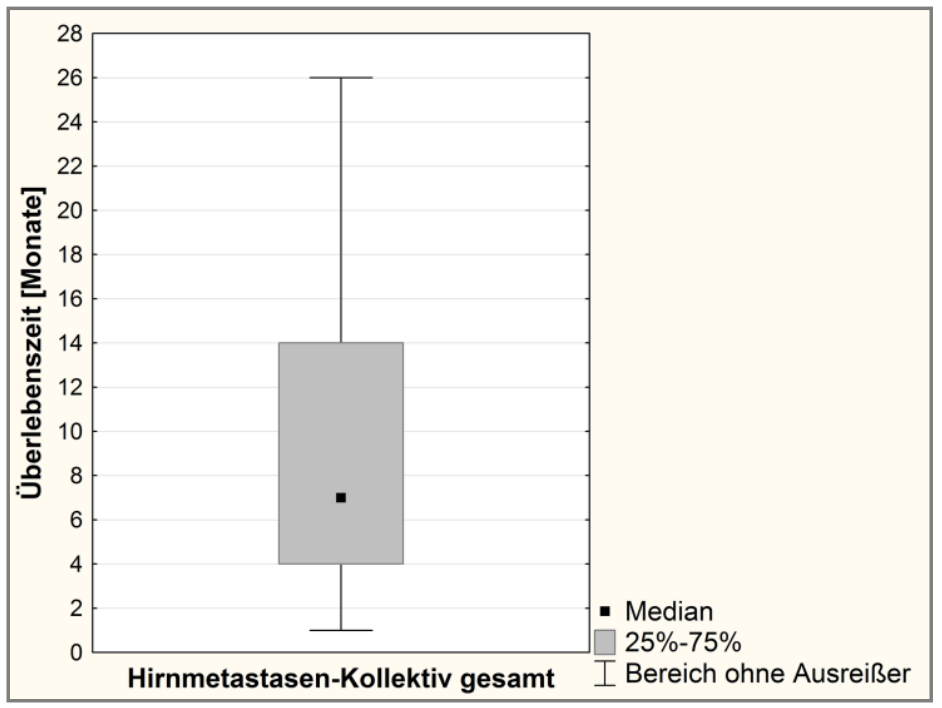

Abb. 6: Boxplot der medianen Gesamtüberlebenszeit im Hirnmetastasen-Kollektiv. 


\subsubsection{GBM-Kollektiv}

\section{Geschlechts- und Altersverteilung}

Das GBM-Kollektiv bestand aus 33 (46,5\%) weiblichen Patienten und 38 (53,5\%) männlichen Patienten. Bei Erstdiagnose des GBM respektive Zeitpunkt der Tumoroperation lag der Altersmittelwert der weiblichen Patienten bei 65,4 \pm 12,1 Jahren (Medianwert 69 Jahre) mit einer Altersspanne von 30 bis 84 Jahren und der männlichen Patienten bei 64,6 \pm 11,5 Jahren (Medianwert 69,5 Jahre) mit einer Altersspanne von 39 bis 81 Jahren (Abb. 7).

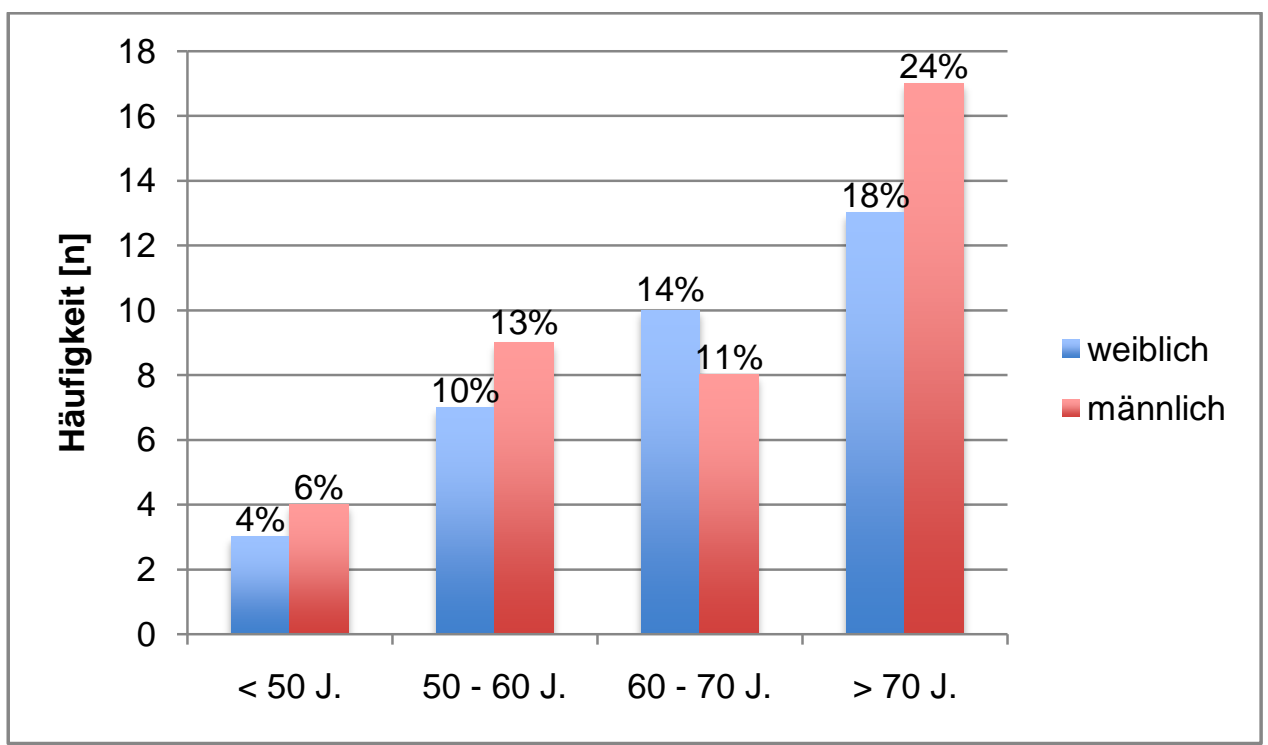

Abb. 7: Geschlechtsabhängige Altersverteilung im GBM-Kollektiv.

\section{$\underline{\text { Antidepressiva-Therapie }}$}

In der experimentellen Gruppe des GBM-Kollektivs wurden 26 Patienten (36,6\%) zusätzlich mit einem Antidepressivum therapiert, die restlichen 45 Patienten $(63,4 \%)$ bildeten die Kontrollgruppe. Von diesen 26 Patienten nahmen 13 Patienten $(50 \%)$ das trizyklische Antidepressivum Amitriptylin, 6 Patienten (23\%) den selektiven Serotonin-Wiederaufnahmehemmer (SSRI) Citalopram sowie 3 Patient (11,5\%) Sertralin und 4 Patienten (15,5\%) das tetrazyklische Antidepressivum Mirtazapin ein (Abb. 8). 


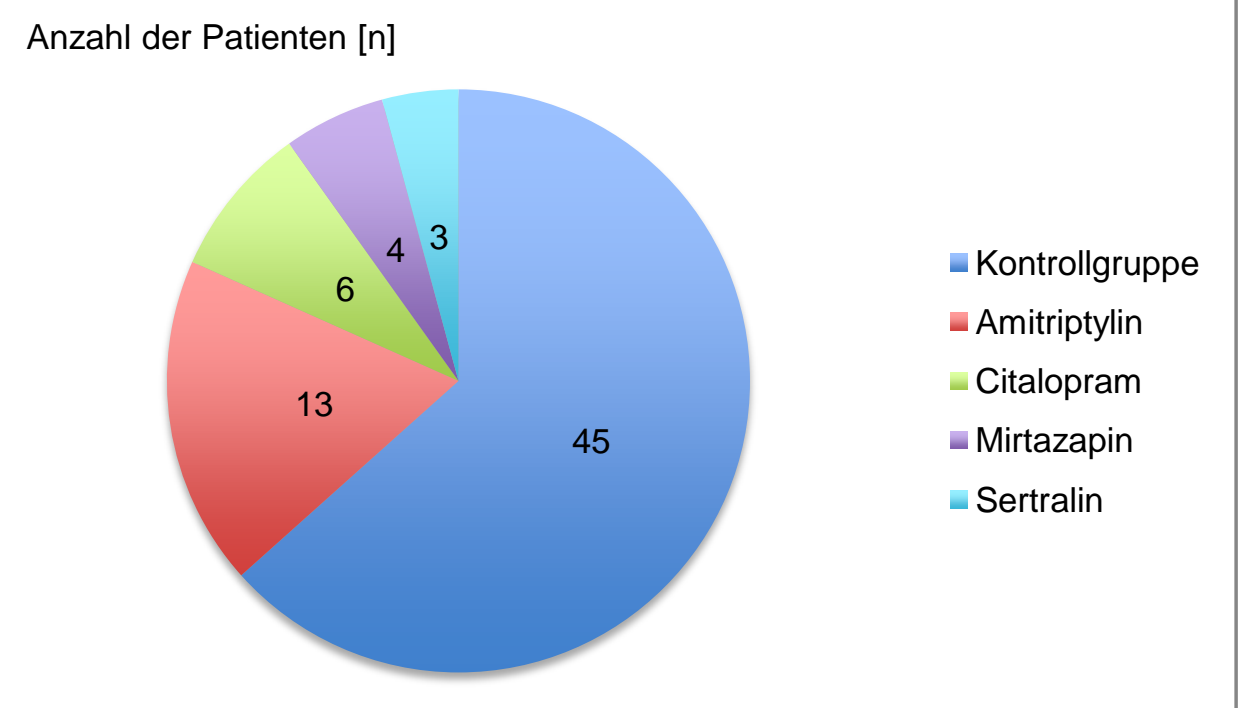

Abb. 8: Verteilung der Antidepressiva im GBM-Kollektiv.

\section{$\underline{\text { Lokalisation der GBM }}$}

Die untersuchten Tumorbiopsien ließen sich durch MRT Aufnahmen des Neurokraniums (insbesondere T1 gewichtete Sequenzen nach Gadolinium-Gabe) den unterschiedlichen Hirnarealen zuordnen (Abb. 9).

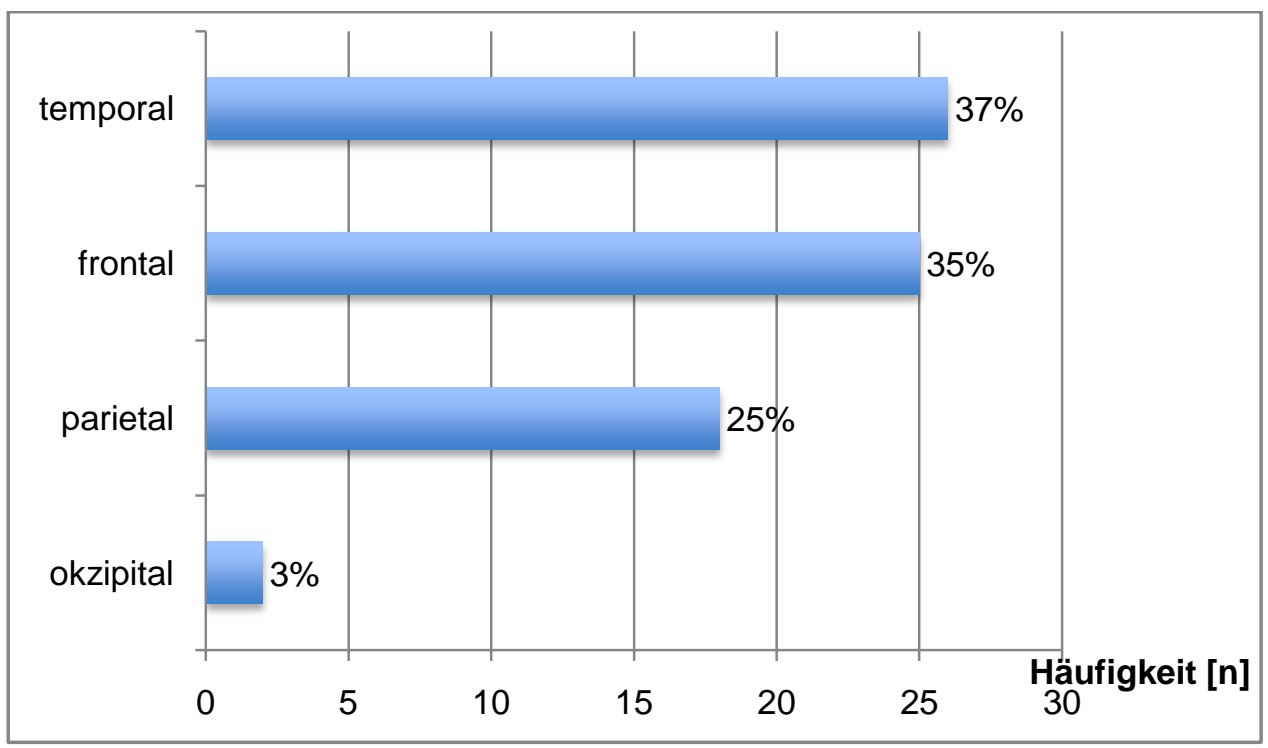

Abb. 9: Verteilung der Tumorlokalisation im GBM-Kollektiv. 


\section{$\underline{\text { Überlebenszeit }}$}

Für die Patienten im GBM-Kollektiv $(n=71)$ ergab sich eine mediane Überlebenszeit von 11 Monaten (95\%-KI 7,8 - 15) (Abb. 10).

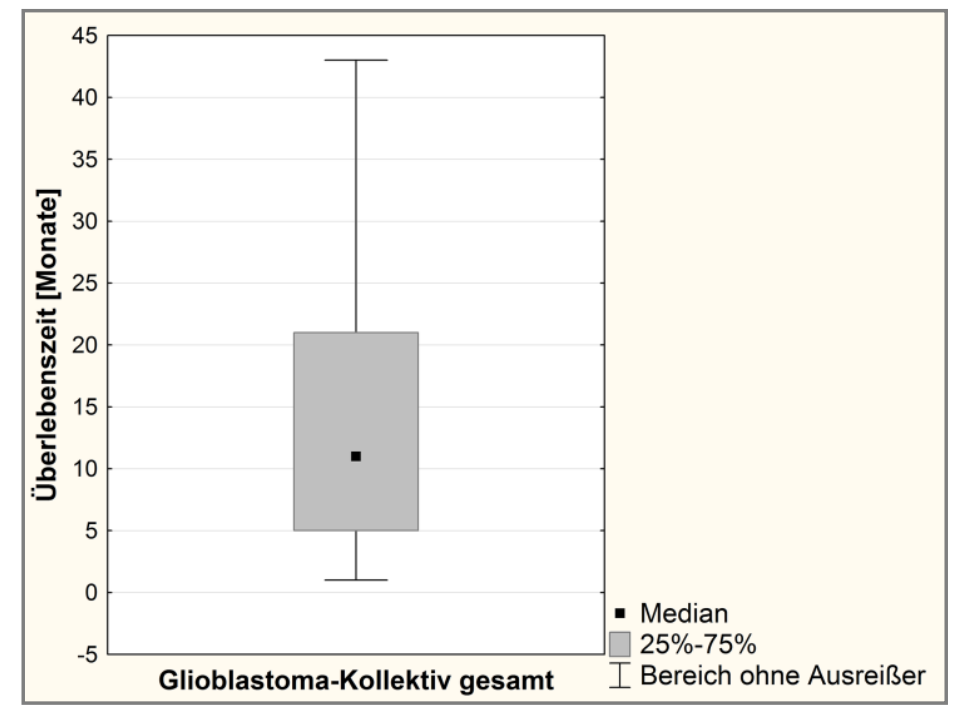

Abb. 10: Boxplot der medianen Gesamtüberlebenszeit im GBM-Kollektiv. 


\subsection{Eag1-Expression}

\subsubsection{Eag1-Expression in Hirnmetastasen-Biopsien}

Die Untersuchung der Eag1-Expression im Hirnmetastasen-Kollektiv ergab in 85,3\% ( $n=64)$ der Fälle eine positive Eag1-Expression (Score-Grad 1+, 2+, 3+) und in 14,7\% ( $n=11)$ der Fälle eine negative Eag1-Expression (Score-Grad 0). Die negativen Fälle verteilten sich zu $63,6 \%(n=7)$ auf Hirnmetastasen eines Bronchialkarzinoms, zu 18,2\% ( $n=2)$ eines Mammakarzinoms und zu je 9,1\% ( $n=1)$ eines Nierenzellkarzinoms und Melanoms. Es wurden 48\% $(\mathrm{n}=36)$ der Fälle mit Eag1 low (Score-Grad 0 und 1+) und 52\% $(\mathrm{n}=39)$ der Fälle mit Eag1 high (Score-Grad 2+ und 3+) bewertet.

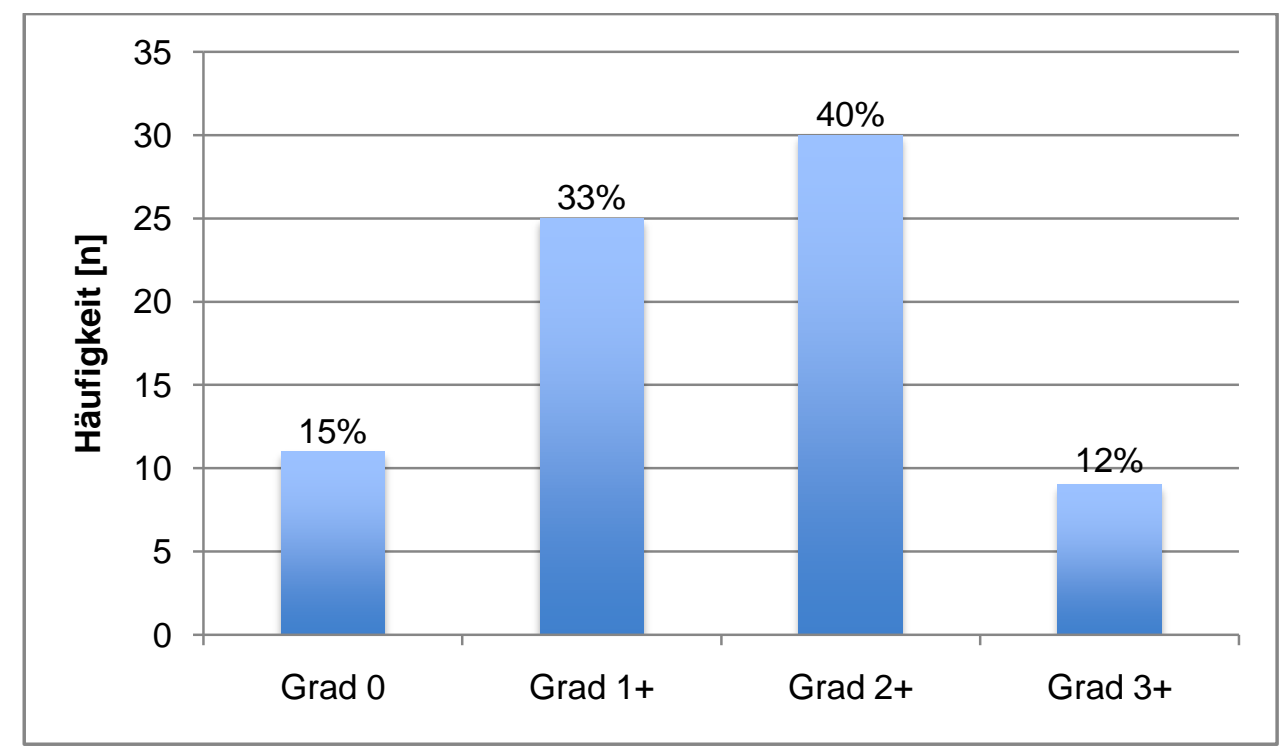

Abb. 11: Verteilung der Eag1-Expressions-Grade im Hirnmetastasen-Kollektiv. 


\section{Positiv-Probe}
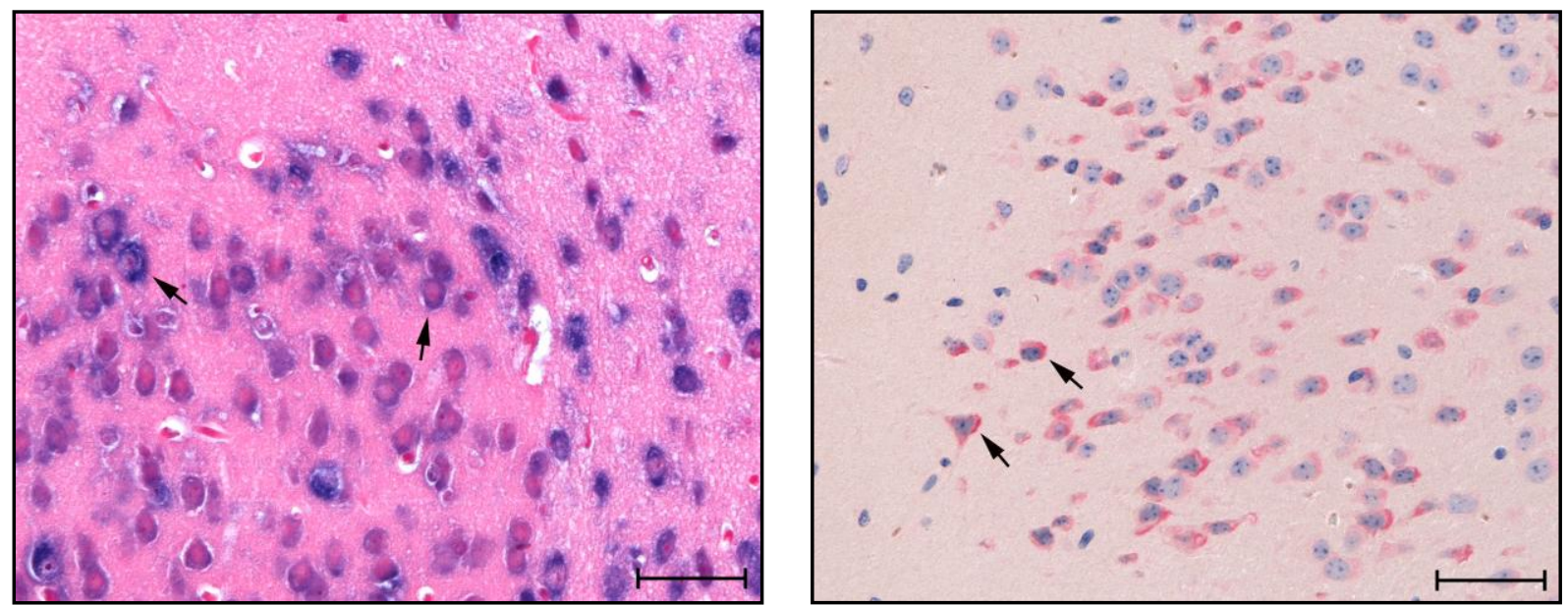

Abb. 12: Positiv-Probe eines Maus-Kortex (adulte C57BI6N Maus) mit dem Chromogen BCIP/NBT (links) und Neufuchsin (rechts) (400fache Vergrößerung, Maßstabskala $50 \mu \mathrm{m}$ ).

\section{Score-Grad 1+}
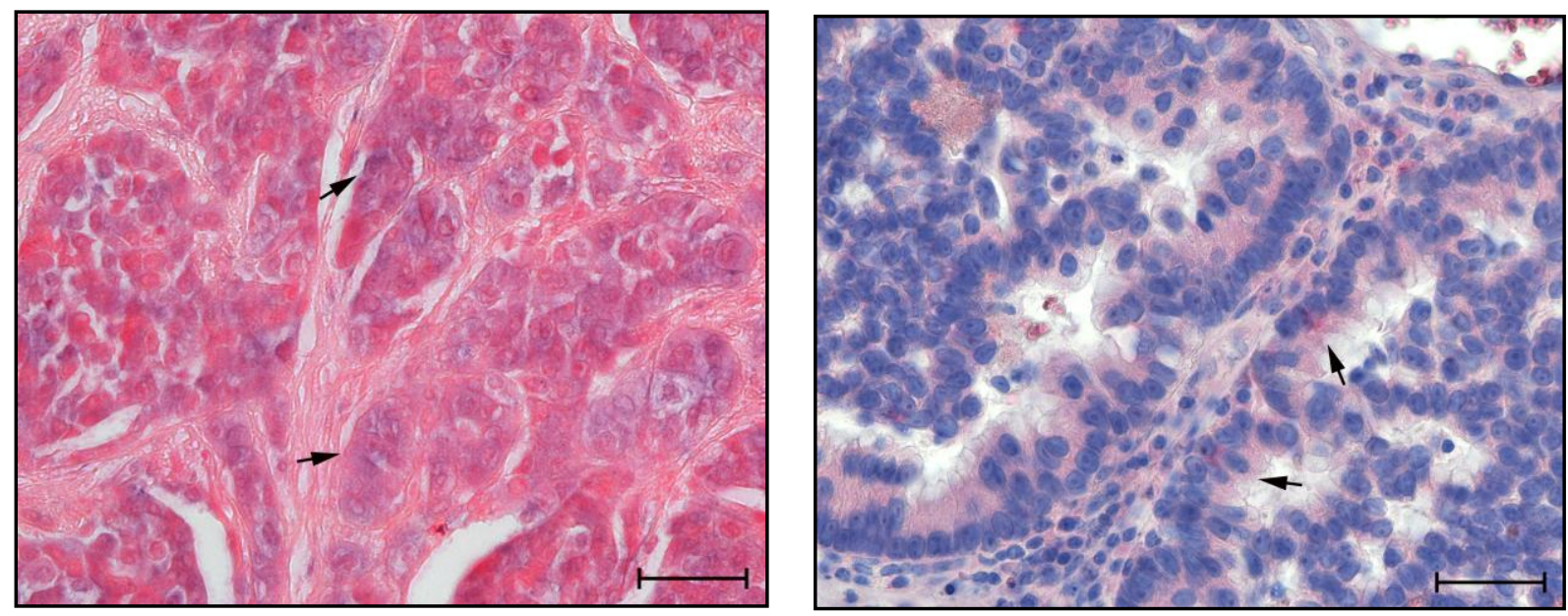

Abb. 13: Eag1-Färbung mit Grad 1+ in Hirnmetastasen eines Bronchialkarzinoms mit dem Chromogen BCIP/NBT (links) und Neufuchsin (rechts) (400fache Vergrößerung, Maßstabskala $50 \mu \mathrm{m}$ ). 

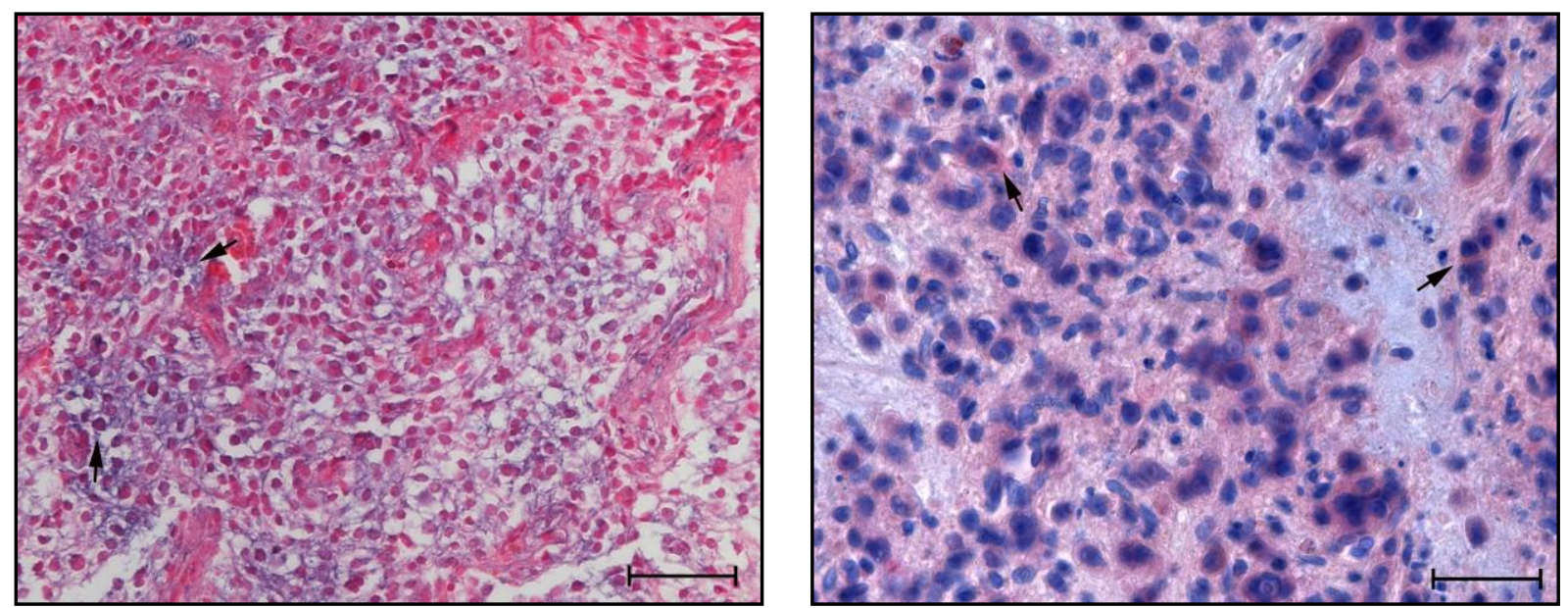

Abb. 14: Eag1-Färbung mit Grad 1+ in Hirnmetastasen eines Mammakarzinoms mit dem Chromogen BCIP/NBT (links) und Neufuchsin (rechts) (400fache Vergrößerung, Maßstabskala $50 \mu \mathrm{m}$ ).

\section{$\underline{\text { Score-Grad 2+ }}$}
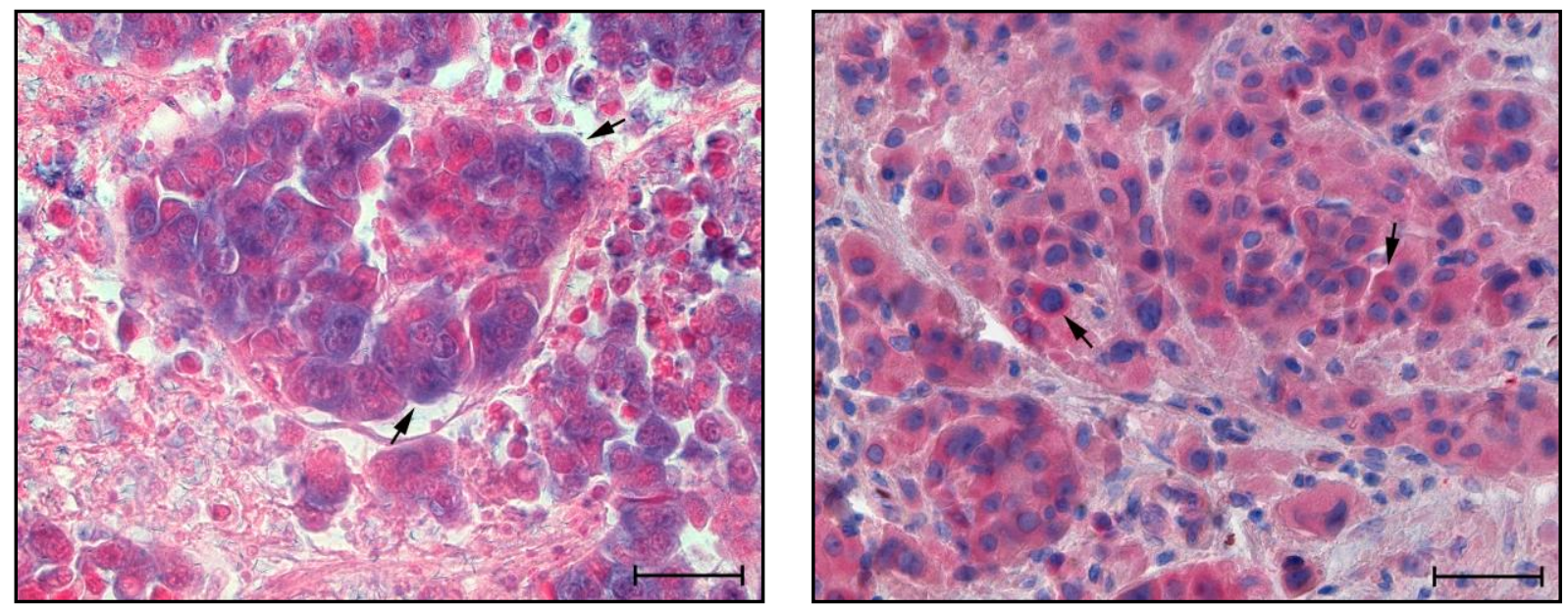

Abb. 15: Eag1-Färbung mit Grad 2+ in Hirnmetastasen eines Bronchialkarzinoms mit dem Chromogen BCIP/NBT (links) und Neufuchsin (rechts) (400fache Vergrößerung, Maßstabskala $50 \mu \mathrm{m}$ ). 

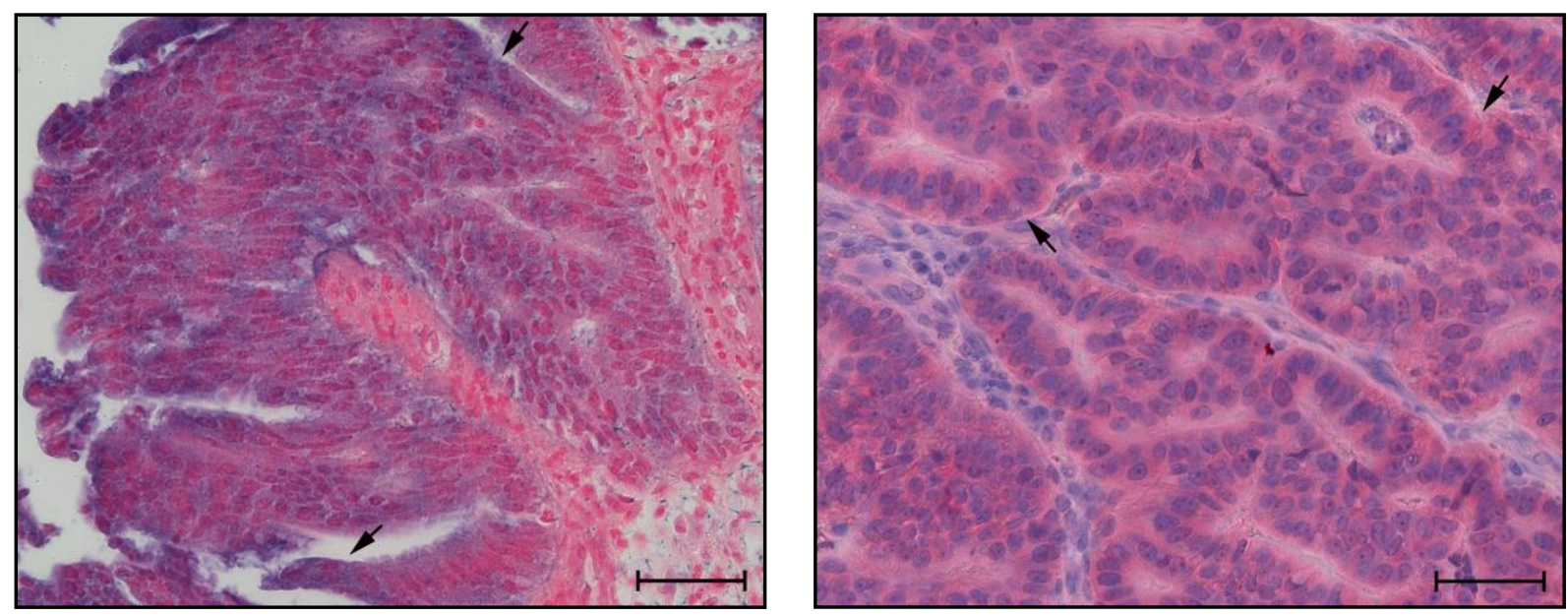

Abb. 16: Eag1-Färbung mit Grad 2+ in Hirnmetastasen eines Magenkarzinoms mit dem Chromogen BCIP/NBT (links) und Neufuchsin (rechts) (400fache Vergrößerung, Maßstabskala $50 \mu \mathrm{m}$ ).

\section{Score-Grad 3+}
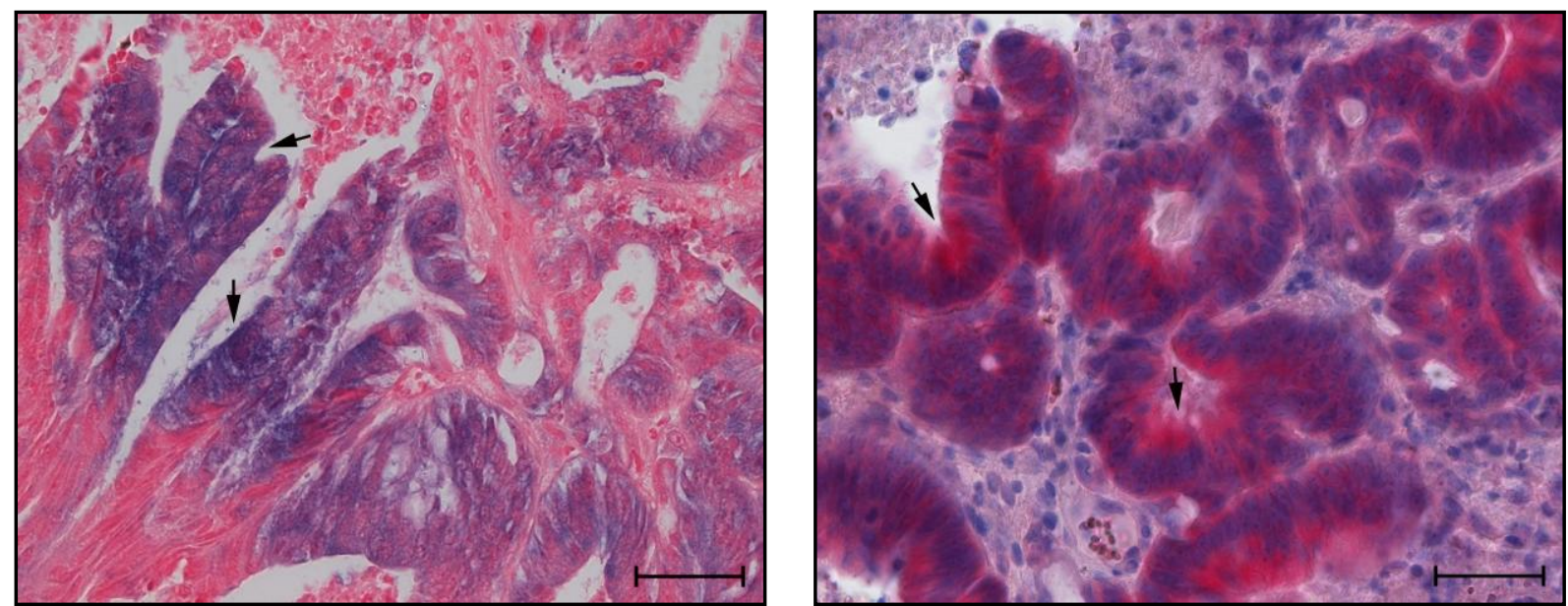

Abb. 17: Eag1-Färbung mit Grad 3+ in Hirnmetastasen eines kolorektalen Karzinoms mit dem Chromogen BCIP/NBT (links) und Neufuchsin (rechts) (400fache Vergrößerung, Maßstabskala 50 $\mu \mathrm{m})$. 


\subsubsection{Eag1-Expression in GBM-Biopsien}

Im GBM-Kollektiv resultierte in 77,5\% $(n=55)$ der Fälle eine positive Eag1-Expression (Score-Grad 1+, 2+, 3+) und in 22,5\% $(n=16)$ der Fälle eine negative Eag1-Expression (Score-Grad 0). Im Vergleich zum Hirnmetastasen-Kollektiv waren mit 60,5\% (n=43) zu $39,5 \%(\mathrm{n}=28)$ mehr Fälle im Bereich Eag1 low (Score-Grad 0 und 1+) als im Bereich Eag1 high (Score-Grad 2+ und 3+).

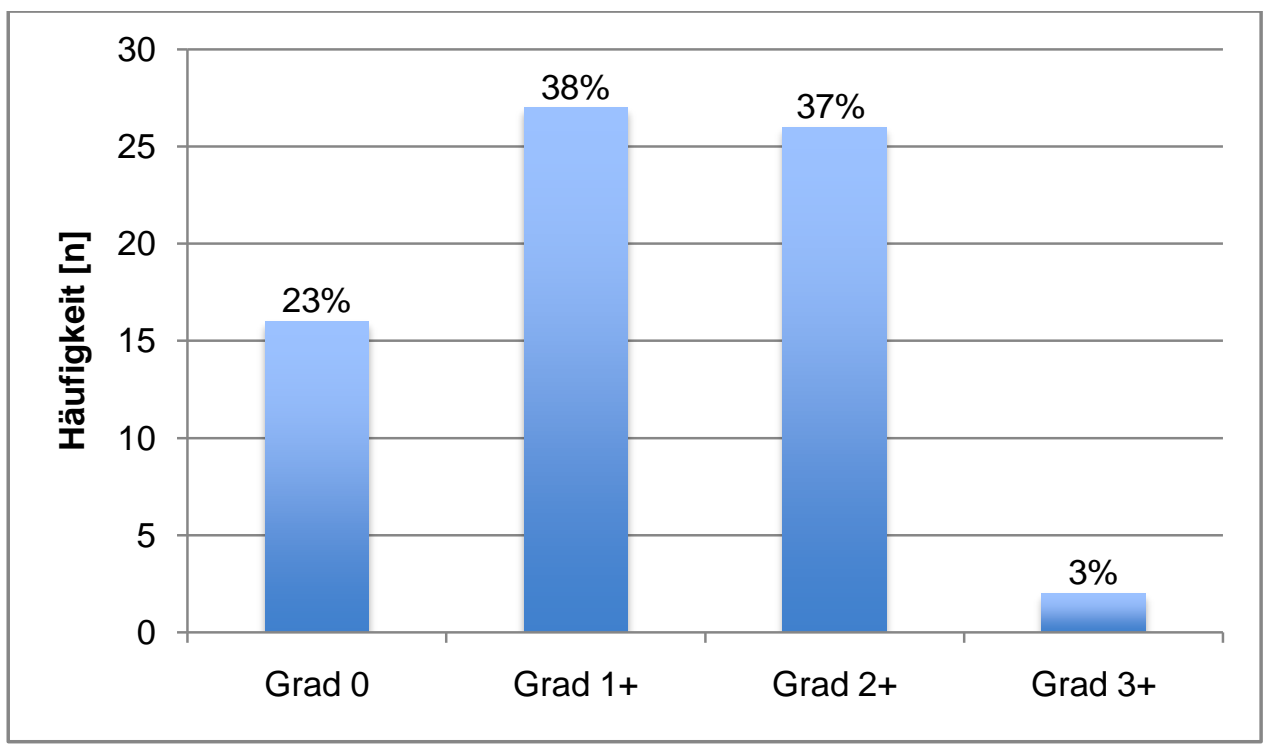

Abb. 18: Verteilung der Eag1-Expressions-Grade im GBM-Kollektiv.

\section{Score-Grad 1+}
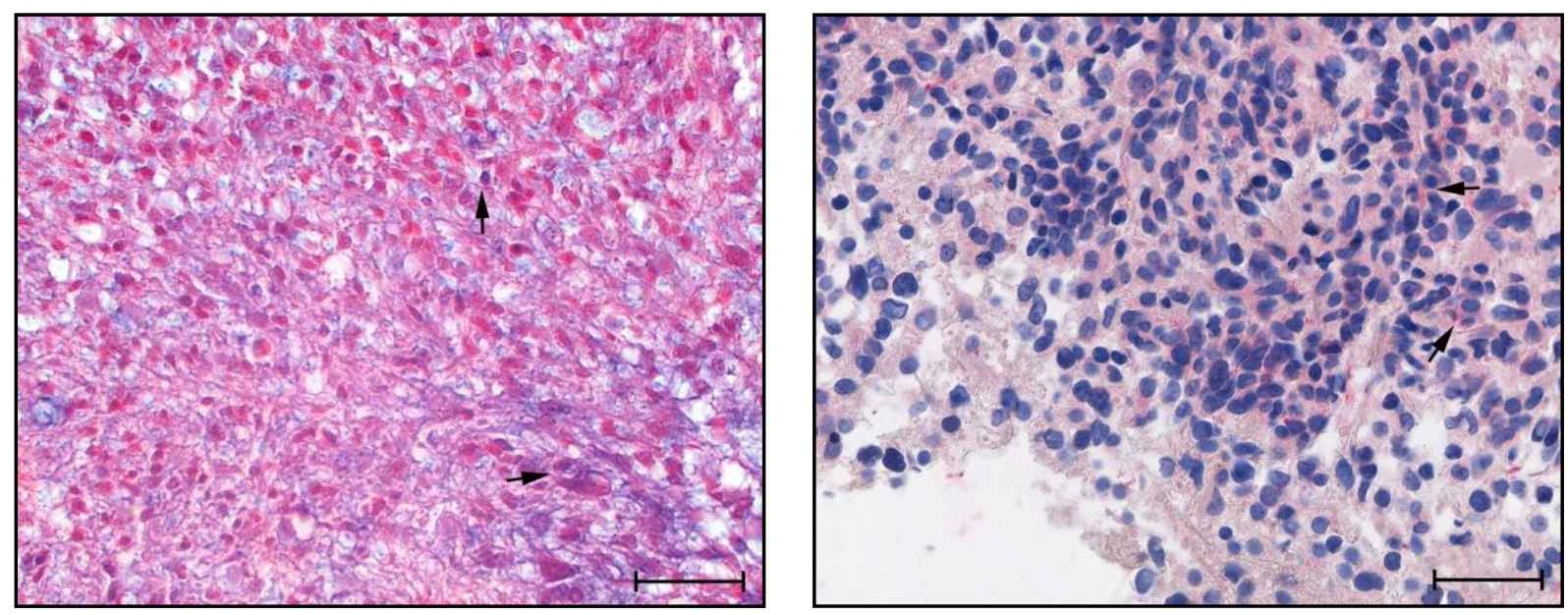

Abb. 19: Eag1-Färbung mit Grad 1+ in GBM mit dem Chromogen BCIP/NBT (links) und Neufuchsin (rechts) (400fache Vergrößerung, Maßstabskala $50 \mu \mathrm{m}$ ). 


\section{$\underline{\text { Score-Grad 2+ }}$}
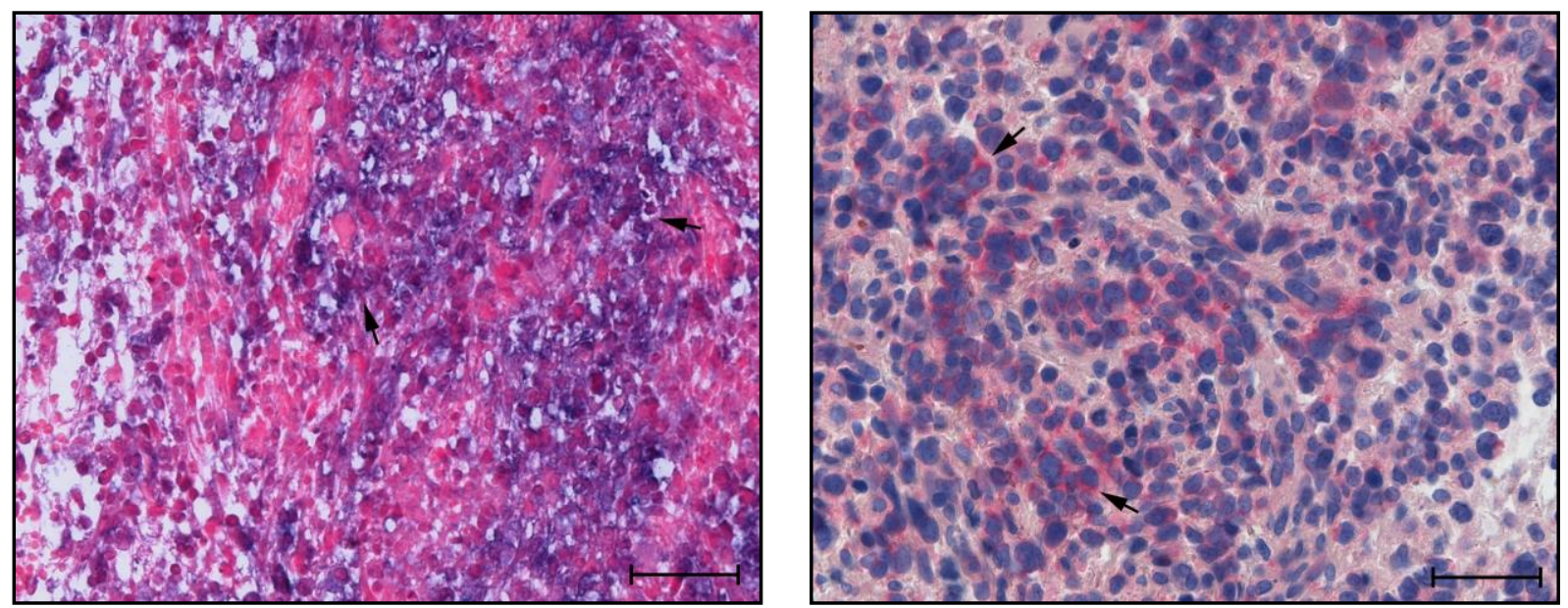

Abb. 20: Eag1-Färbung mit Grad 2+ in GBM mit dem Chromogen BCIP/NBT (links) und Neufuchsin (rechts) (400fache Vergrößerung, Maßstabskala $50 \mu \mathrm{m}$ ).

\section{$\underline{\text { Score-Grad 3+ }}$}
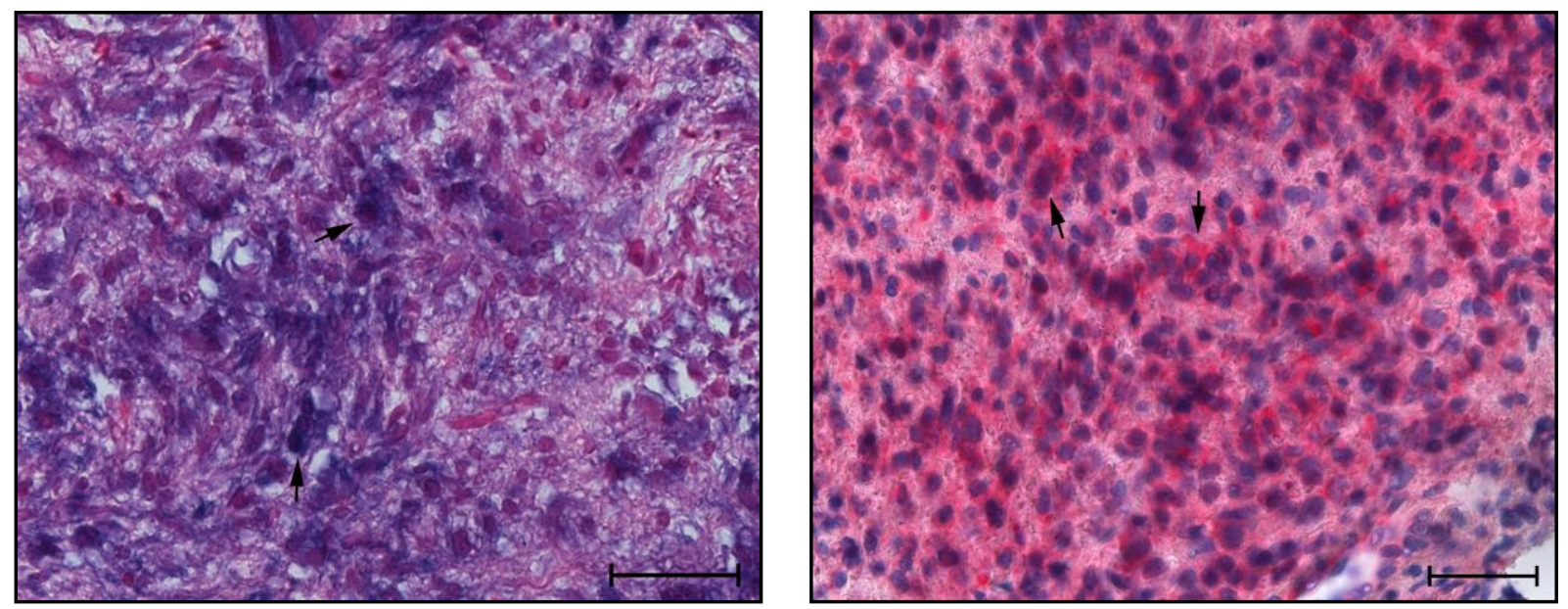

Abb. 21: Eag1-Färbung mit Grad 3+ in GBM mit dem Chromogen BCIP/NBT (links) und Neufuchsin (rechts) (400fache Vergrößerung, Maßstabskala $50 \mu \mathrm{m}$ ). 


\subsection{Einfluss der Eag1-Expression auf die Überlebenszeit}

\subsubsection{Hirnmetastasen-Kollektiv}

Der Einfluss der Eag1-Expression auf die Überlebenszeit wurde mit einem t-Test untersucht, indem die Überlebenszeiten von Patienten verglichen wurden, bei denen im Tumorgewebe Eag1 low respektive Eag1 high festgestellt wurde.

Patienten, bei denen die Untersuchung des Tumorgewebes den Expressions-Grad Eag1 low ergab $(n=36)$, hatten eine mediane Überlebenszeit von 11 Monaten (95\%-KI 7 - 13,7), Patienten mit Expressions-Grad Eag1 high $(\mathrm{n}=39)$ eine mediane Überlebenszeit von 6 Monaten (95\%-KI $3-8,1)(p=0,0119)$.

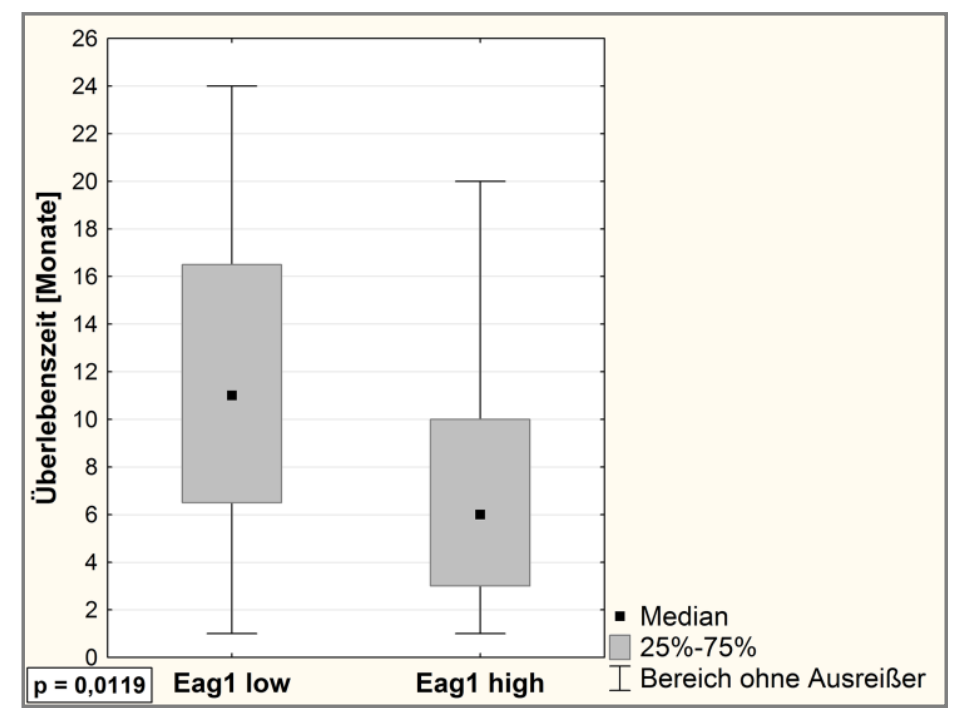

Abb. 22: Boxplot der medianen Überlebenszeit von Patienten im Hirnmetastasen-Kollektiv in Abhängigkeit von der Eag1-Expression. 


\subsubsection{GBM-Kollektiv}

Im GBM-Kollektiv hatten Patienten mit dem im Tumorgewebe festgestellten ExpressionsGrad Eag1 low ( $\mathrm{n}=43$ ) eine mediane Überlebenszeit von 13 Monaten (95\%-KI 9 - 17), Patienten mit Expressions-Grad Eag1 high ( $\mathrm{n}=28)$ eine mediane Überlebenszeit 8 Monaten $(95 \%-K I 5-15,6)(p=0,15)$.

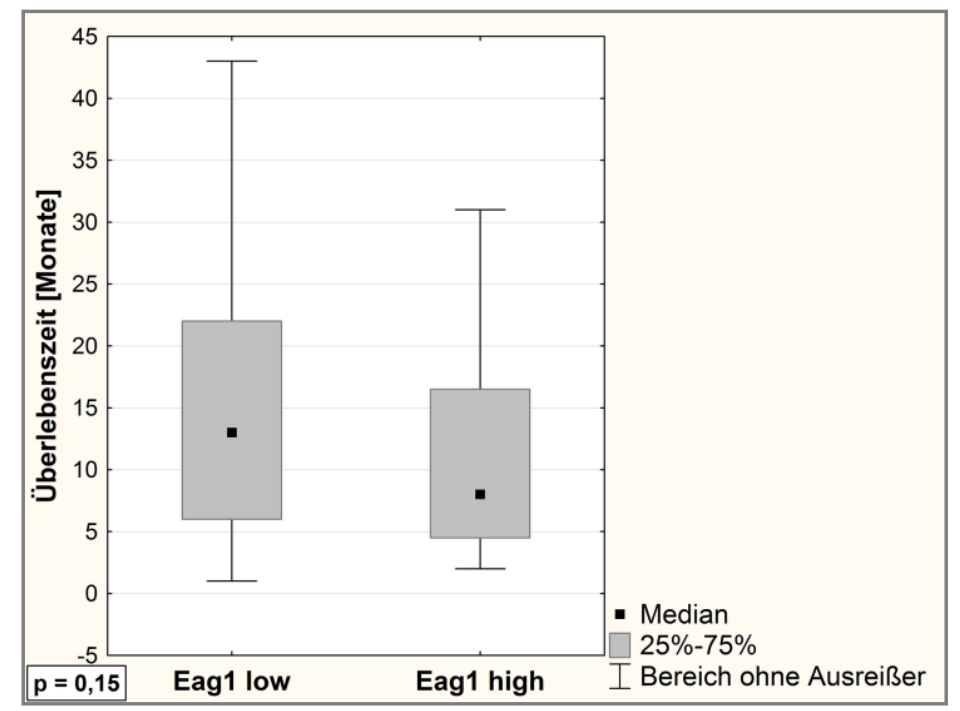

Abb. 23: Boxplot der medianen Überlebenszeit von Patienten im GBM-Kollektiv in Abhängigkeit von der Eag1-Expression. 


\subsection{Einfluss der Antidepressiva-Therapie auf die Überlebenszeit in Abhängigkeit von der Eag1-Expression}

\subsubsection{Hirnmetastasen-Kollektiv}

Die Auswertung der Daten zeigte nur einen Einfluss von Amitriptylin und Citalopram auf Eag1 und nicht von Mirtazapin. Diese Beobachtung geht einher mit der Literatur, in der Amitriptylin (Teschemacher et al. 1999) sowie Citalopram (Witchel et al. 2002) als HERGKanal-Blocker (human Ether-à-go-go related gene) beschrieben sind. HERG-Kanal-Blocker haben auch eine Affinität zu Eag1 (García-Ferreiro et al. 2004). Mirtazapin zählt nicht zu den HERG-Kanal-Blockern, was auch in der Auswertung unserer Daten, die keinen Einfluss von Mirtazapin auf die Überlebenszeit von den Patienten zeigte, überprüft und bestätigt wurde. Durch den gleichen Effekt von Amitriptylin und Citalopram wurden die Daten der Patienten, die Amitriptylin und Citalopram eingenommen hatten, zusammengefügt analysiert.

Mit einer zweifaktoriellen Varianzanalyse wurde untersucht, ob sich die Überlebenszeit von Patienten mit einer Antidepressiva-Therapie von der Überlebenszeit von Patienten in der Kontrollgruppe in Bezug auf die Eag1-Expression unterscheidet. Patienten, die mit Antidepressiva therapiert wurden und bei denen die Untersuchung des Tumorgewebes den Expressions-Grad Eag1 low ergab $(\mathrm{n}=10)$, hatten eine mediane Überlebenszeit von 13 Monaten (95\%-KI 6,1 - 22,8), Patienten der Kontrollgruppe mit Expressions-Grad Eag1 low $(n=25)$ eine mediane Überlebenszeit von 10 Monaten (95\%-KI $7-14,7)(p=0,03)$. Patienten, die mit Antidepressiva therapiert wurden und bei denen die Untersuchung des Tumorgewebes den Expressions-Grad Eag1 high ergab $(n=8)$, hatten eine mediane Überlebenszeit von 6 Monaten (95\%-KI 3 - 9,9), Patienten der Kontrollgruppe mit Expressions-Grad Eag1 high $(n=27)$ eine mediane Überlebenszeit von 6 Monaten $(95 \%-K I 3-9)(p=0,1)$. 

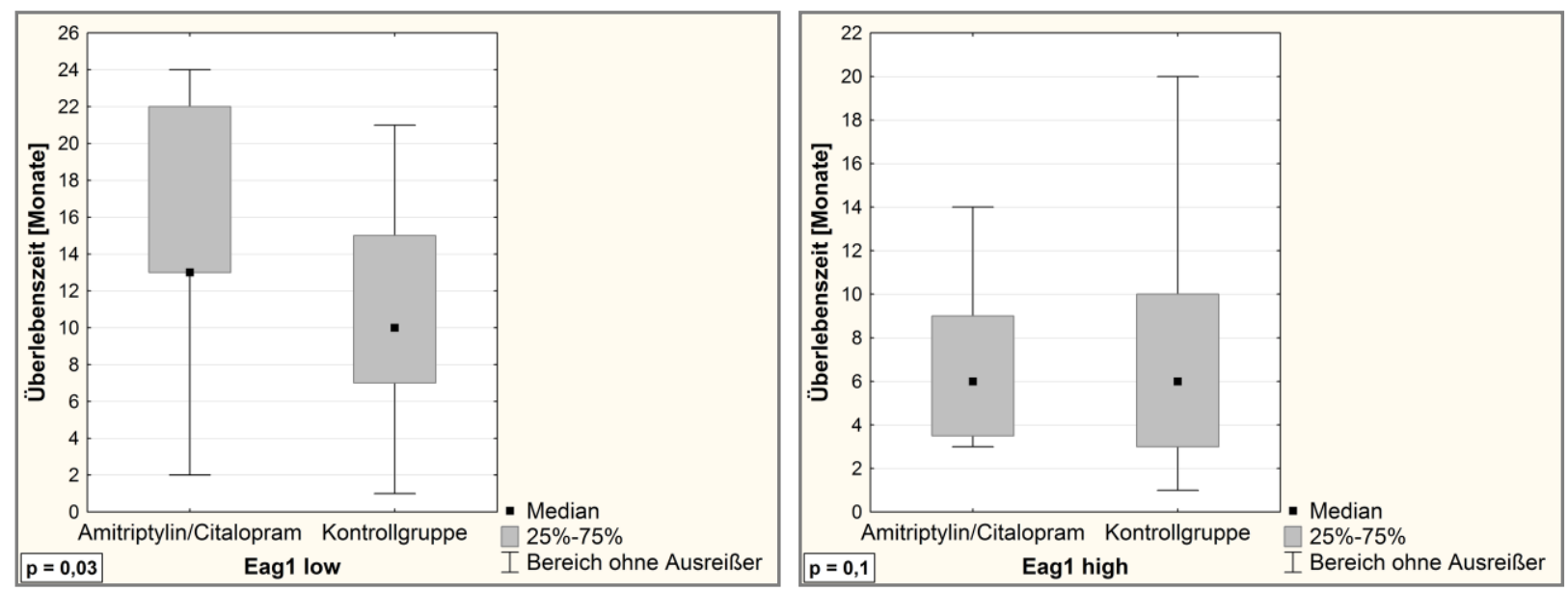

Abb. 24: Boxplot der medianen Überlebenszeit von Patienten im Hirnmetastasen-Kollektiv mit Antidepressiva-Therapie im Vergleich zur Kontrollgruppe, differenziert betrachtet je nach Eag1Expression.

Eine Kaplan-Meier-Kurve der Ergebnisse (Abb. 25) zeigte eine signifikant verlängerte Überlebenszeit von Patienten im gesamten Hirnmetastasen-Kollektiv, bei denen die Eag1Expression im Tumorgewebe mit Eag1 low bewertet wurde (Log-Rank-Test, p=0,04). Zusätzlich zum prognostisch positiven Effekt durch Eag1 low zeigte sich eine verlängerte Überlebenszeit von Patienten, die mit Antidepressiva therapiert wurden und bei denen im Tumorgewebe Eag1 low festgestellt wurde (Log-Rank-Test, $\mathrm{p=0,03).}$

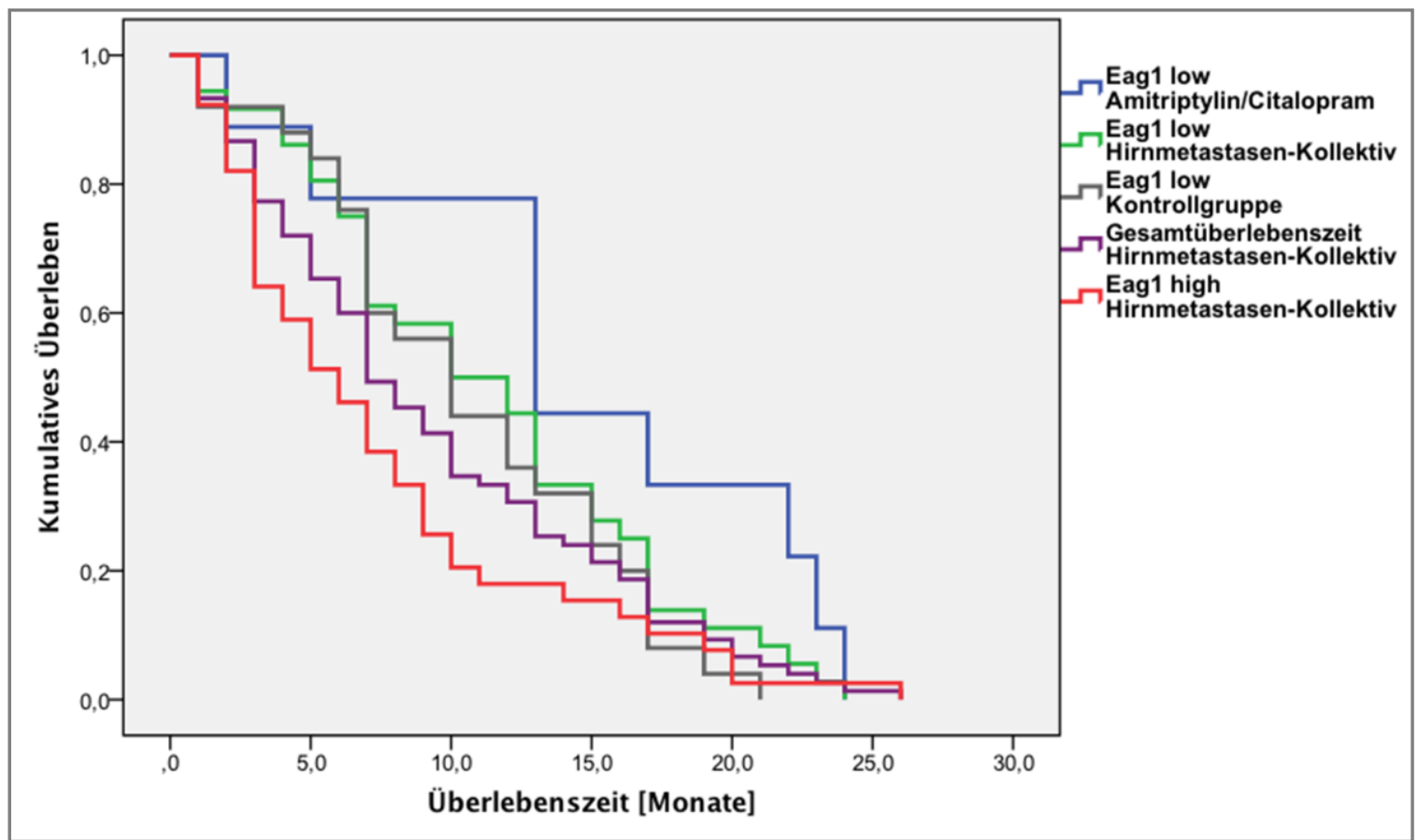

Abb. 25: Kaplan-Meier-Kurve, die den Einfluss der Antidepressiva-Therapie auf die mediane Überlebenszeit von Patienten im Hirnmetastasen-Kollektiv in Abhängigkeit von der Eag1-Expression darstellt. 


\subsubsection{GBM-Kollektiv}

Im GBM-Kollektiv wurden die Daten in gleicher Weise wie im Hirnmetastasen-Kollektiv analysiert, nachdem überprüft und bestätigt werden konnte, dass Mirtazapin auch bei Patienten im GBM-Kollektiv keinen Einfluss auf die Überlebenszeit zeigt. Jedoch nahmen unterschiedlich zum Hirnmetastasen-Kollektiv 3 Patienten das Antidepressivum Sertralin ein, das ebenfalls ein HERG-Kanal-Blocker ist (Lee et al. 2012). Die Analyse der Ergebnisse wurde doppelt durchgeführt, einmal mit den Patienten, die Sertralin eingenommen hatten, und einmal ohne diese. Das Signifikanzniveau änderte sich hierbei nicht.

Patienten, die mit Antidepressiva therapiert wurden und bei denen im Tumorgewebe Eag1 low festgestellt wurde $(\mathrm{n}=15)$, hatten eine mediane Überlebenszeit von 9 Monaten $(95 \%-\mathrm{KI}$ $4,8$ - 15), Patienten der Kontrollgruppe mit Expressions-Grad Eag1 low ( $\mathrm{n}=26)$ eine mediane Überlebenszeit von 15,5 Monaten (95\%-KI 9,1 - 23) ( $p=0,1)$. Patienten, die mit Antidepressiva therapiert wurden und bei denen im Tumorgewebe Eag1 high festgestell wurde $(n=7)$, hatten eine mediane Überlebenszeit von 6 Monaten (95\%-KI 2,6 - 16,6), Patienten der Kontrollgruppe mit Expressions-Grad Eag1 high $(n=19)$ eine mediane Überlebenszeit von 6 Monaten $(95 \%-K I 3,8-16)(p=0,5)$.
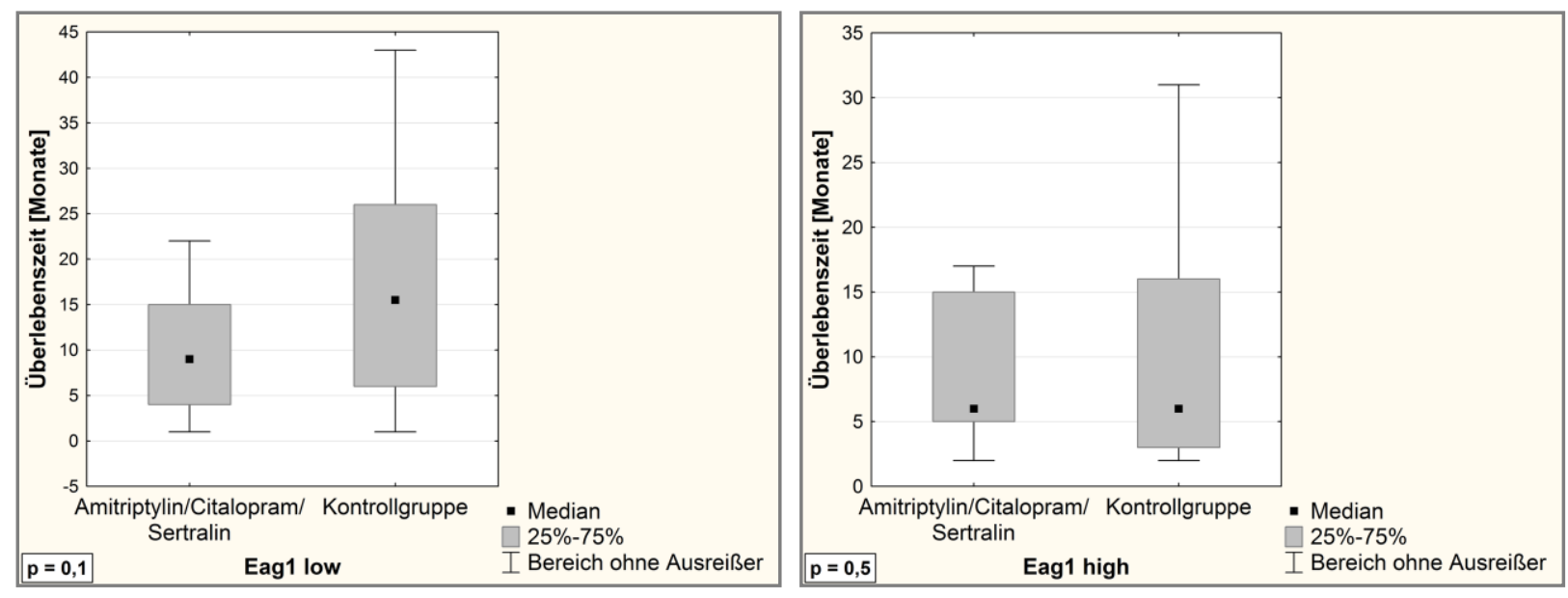

Abb. 26: Boxplot der medianen Überlebenszeit von Patienten im GBM-Kollektiv mit AntidepressivaTherapie im Vergleich zur Kontrollgruppe, differenziert betrachtet je nach Eag1-Expression. 
Eine Kaplan-Meier-Kurve der Ergebnisse (Abb. 27) zeigte eine nur tendenziell verlängerte Überlebenszeit von Patienten im gesamten GBM-Kollektiv, die einen Expressions-Grad von Eag1 low im Tumorgewebe aufwiesen (Log-Rank-Test, $\mathrm{p}=0,1$ ). Patienten, die mit Antidepressiva therapiert wurden und bei denen im Tumorgewebe Eag1 low festgestellt wurde, zeigten konträrer Weise eine verringerte Überlebenszeit im Vergleich zu Patienten der Kontrollgruppe mit Expressions-Grad Eag1 low (Log-Rank-Test, p=0,075).

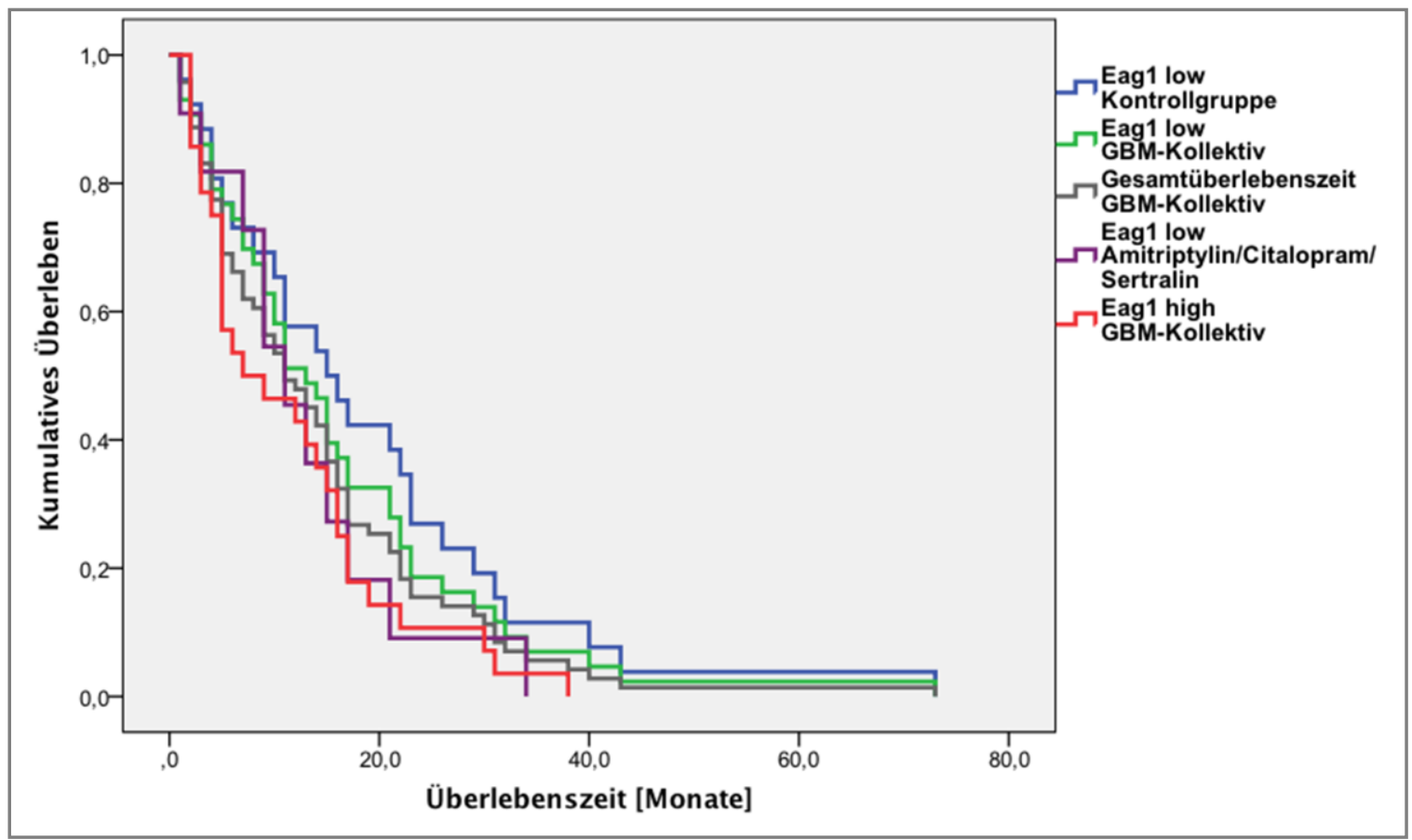

Abb. 27: Kaplan-Meier-Kurve, die den Einfluss der Antidepressiva-Therapie auf die mediane Überlebenszeit von Patienten im GBM-Kollektiv in Abhängigkeit von der Eag1-Expression darstellt. 


\subsection{Betrachtung der Eag1-Expression in unterschiedlichen Hirnarealen in Bezug auf die Überlebenszeit}

\subsubsection{Hirnmetastasen-Kollektiv}

Eine Betrachtung der durch die Tumoren betroffenen Hirnareale zeigte, dass mit $32 \%(n=24)$ zerebelläre und mit 30,6\% ( $n=23)$ frontale Hirnmetastasen im Kollektiv am häufigsten waren, gefolgt von parietalen mit $16 \%(n=12)$, temporalen mit 13,4\% $(n=10)$ und okzipitalen mit $8 \%$ $(n=6)$. In Abbildung 28 sind die einzelnen Expressions-Grade, die in den untersuchten Tumorproben festgestellt wurden, in Bezug auf die Lokalisation des Tumors im Gehirn dargestellt. Es zeigte sich eine verhältnismäßig niedrigere Eag1-Expression im Tumorgewebe mit zerebellärer und frontaler Lage sowie erhöhte Eag1-Expression im Tumorgewebe mit parietaler, temporaler und okzipitaler Lage.

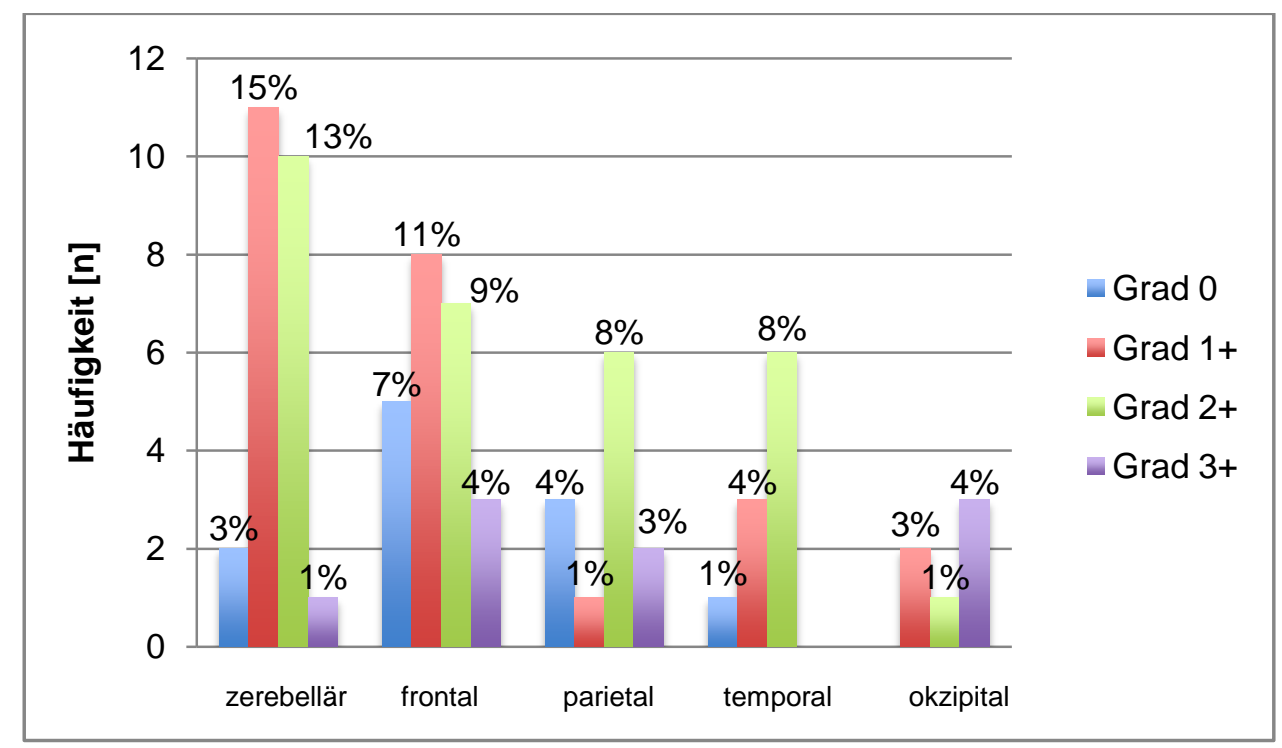

Abb. 28: Verteilung der Eag1-Expressions-Grade auf die Lokalisationen der Hirnmetastasen.

In Bezug auf die Überlebenszeit wurde mit einer zweifaktoriellen Varianzanalyse der Einfluss der topografischen Regionen fronto-parietal, temporo-okzipital, zerebellär und der jeweiligen Eag1-Expression untersucht.

Patienten mit fronto-parietaler Tumorlokalisation und einem im Tumorgewebe festgestellten Expressions-Grad Eag1 low $(\mathrm{n}=17)$ hatten eine mediane Überlebenszeit von 10 Monaten (95\%-KI 7 - 16,9), Patienten mit Expressions-Grad Eag1 high $(\mathrm{n}=18)$ eine mediane Überlebenszeit von 6,5 Monaten (95\%-KI 3 - 10) ( $\mathrm{p}=0,15)$.

Patienten mit temporo-okzipitaler Tumorlokalisation und Expressions-Grad Eag1 low $(\mathrm{n}=6)$ hatten eine mediane Überlebenszeit von 8,5 Monaten (95\%-KI 5,2 - 16,2), Patienten mit 
Expressions-Grad Eag1 high $(\mathrm{n}=10)$ eine mediane Überlebenszeit von 6,5 Monaten $(95 \%-\mathrm{KI}$ $3-14,1)(p=0,6)$.

Patienten mit zerebellärer Tumorlokalisation und Expressions-Grad Eag1 low ( $n=13)$ hatten eine mediane Überlebenszeit von 13 Monaten (95\%-KI 5,6 - 16,4), Patienten mit Expressions-Grad Eag1 high $(\mathrm{n}=11)$ eine mediane Überlebenszeit von 5 Monaten $(95 \%-\mathrm{KI}$ $2,8-8,2)(p=0,03)$.
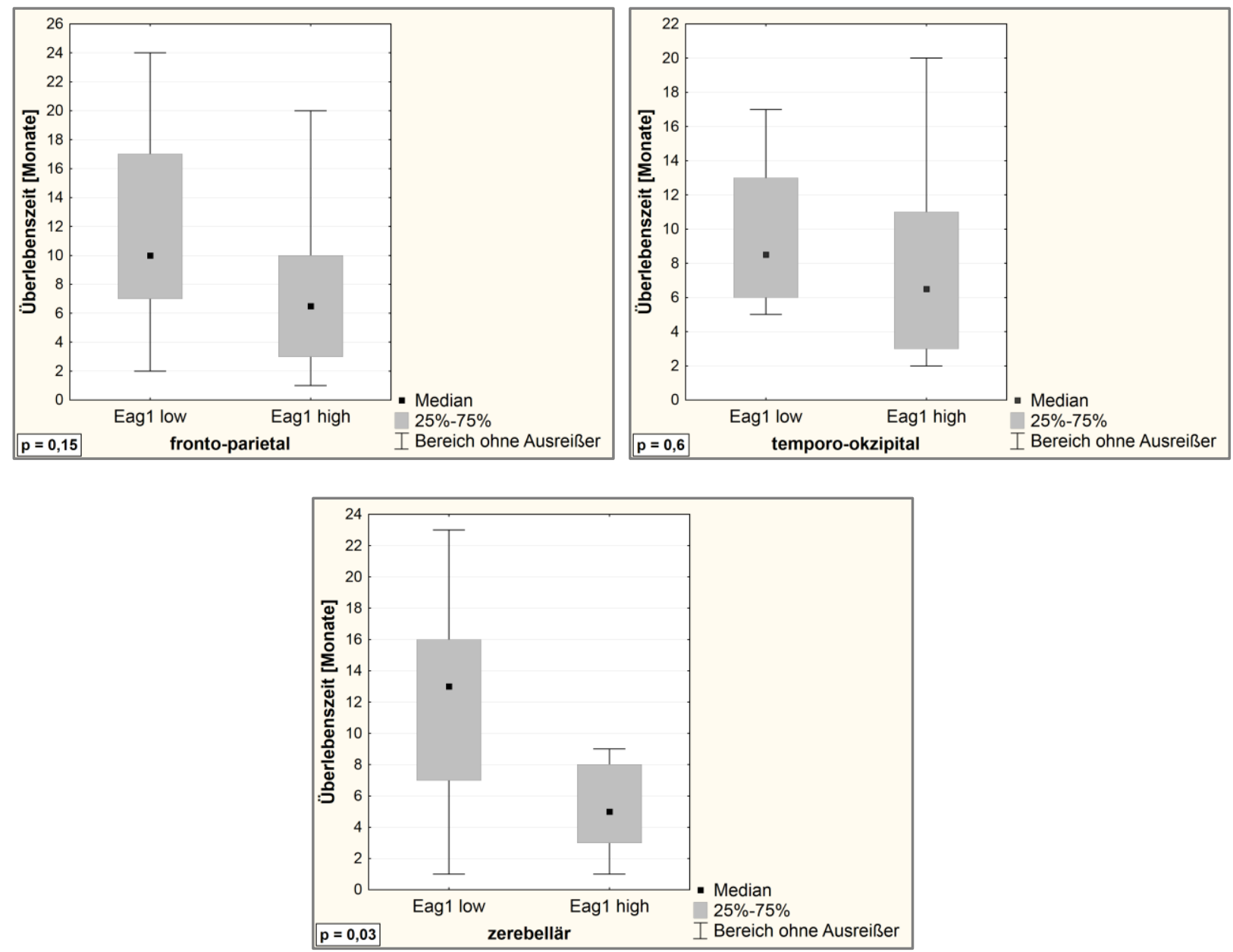

Abb. 29: Boxplot der medianen Überlebenszeit von Patienten im Hirnmetastasen-Kollektiv in Abhängigkeit von der Eag1-Expression, differenziert betrachtet je nach Tumorlokalisation.

\subsubsection{GBM-Kollektiv}

Im GBM-Kollektiv zeigte die Betrachtung der durch die Tumoren betroffenen Hirnareale, dass mit 36,6\% $(n=26)$ temporale und mit 35,2\% $(n=25)$ frontale Glioblastome im Kollektiv am häufigsten waren, gefolgt von parietalen mit 25,4\% $(n=18)$ und okzipitalen mit 2,8\% $(\mathrm{n}=2)$. In Abbildung 30 sind die einzelnen Expressions-Grade, die in den untersuchten Tumorproben festgestellt wurden, in Bezug auf die Lokalisation des Tumors im Gehirn dargestellt. 
Es zeigte sich eine verhältnismäßig niedrigere Eag1-Expression im Tumorgewebe mit frontaler und parietaler Lage sowie eine erhöhte Eag1-Expression im Tumorgewebe mit temporaler Lage.

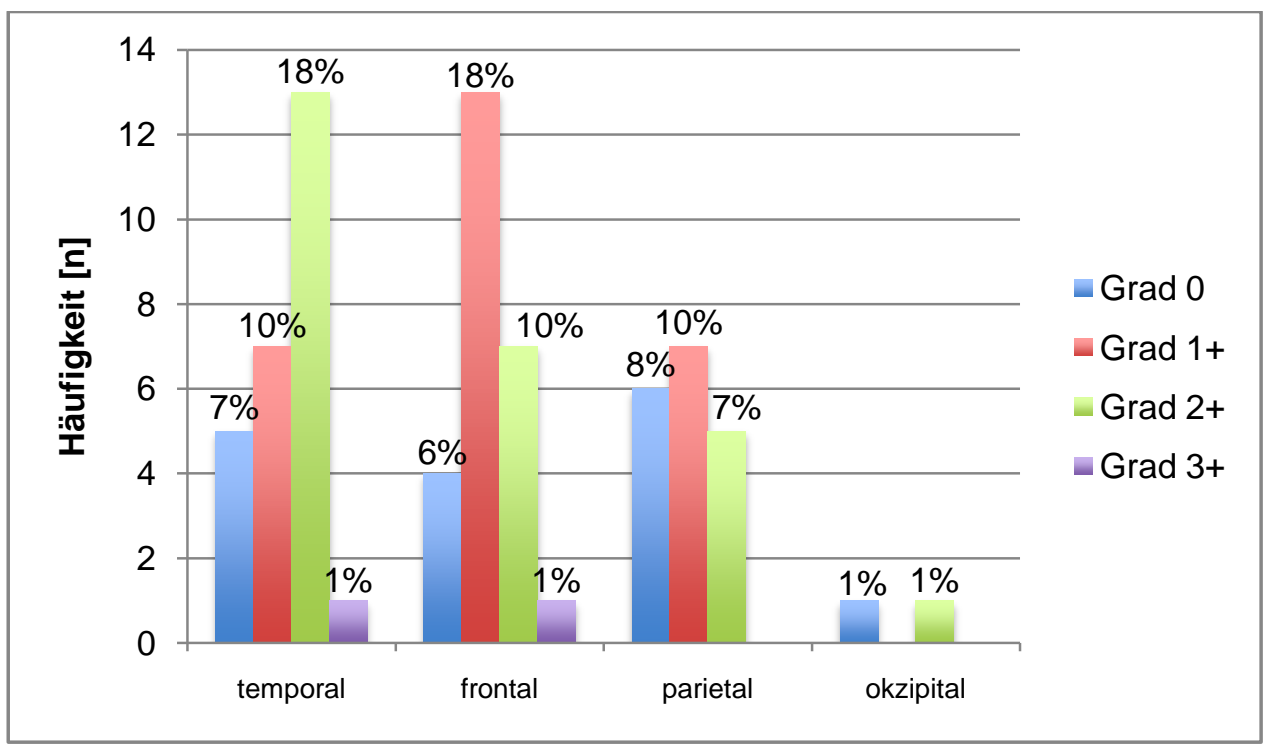

Abb. 30: Verteilung der Eag1-Expressions-Grad auf die Lokalisationen der GBM.

Patienten mit fronto-parietaler Tumorlokalisation und einem im Tumorgewebe festgestellten Expressions-Grad Eag1 low ( $\mathrm{n}=30$ ) hatten eine mediane Überlebenszeit von 12 Monaten (95\%-KI 7,2 - 16,8), Patienten mit Expressions-Grad Eag1 high $(\mathrm{n}=13)$ eine mediane Überlebenszeit von 9 Monaten (95\%-KI 3 - 16,4) ( $p=0,26)$. Patienten mit temporo-okzipitaler Tumorlokalisation und Expressions-Grad Eag1 low $(n=13)$ hatten eine mediane Überlebenszeit von 14 Monaten (95\%-KI 6,6 - 21,4), Patienten mit Expressions-Grad Eag1 high $(\mathrm{n}=15)$ eine mediane Überlebenszeit von 7 Monaten (95\%-KI 5 - 16,7) $(p=0,36)$.
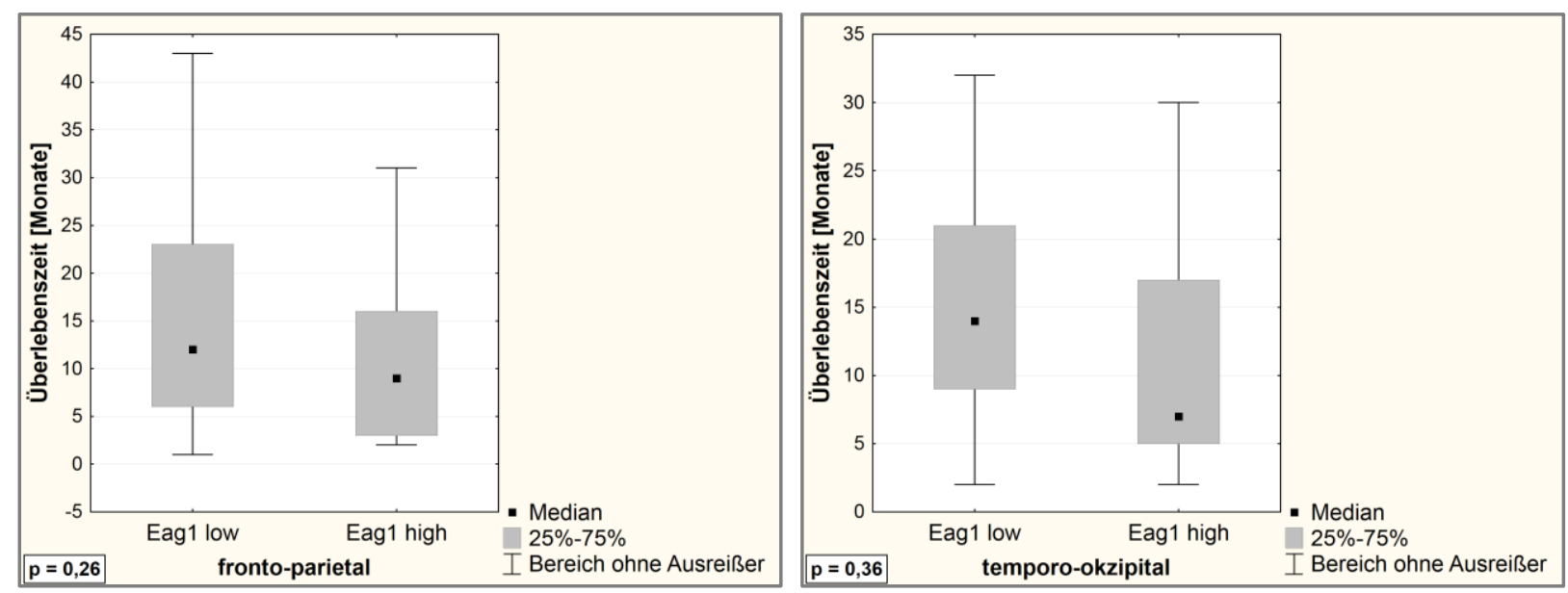

Abb. 31: Boxplot der medianen Überlebenszeit von Patienten im GBM-Kollektiv in Abhängigkeit von der Eag1-Expression, differenziert betrachtet je nach Tumorlokalisation. 


\subsection{Geschlechtsspezifische Analyse der Überlebenszeit in Abhängigkeit von der Eag1-Expression}

\subsubsection{Hirnmetastasen-Kollektiv}

Zur genaueren Betrachtung, welchen Einfluss das Geschlecht der Patienten hat, wurde mit einer zweifaktoriellen Varianzanalyse untersucht, ob sich die Überlebenszeit von weiblichen und männlichen Patienten in Bezug auf die Eag1-Expression unterscheidet.

Weibliche Patienten, bei denen im Tumorgewebe ein Expressions-Grad Eag1 low festgestellt wurde $(n=23)$, hatten eine mediane Überlebenszeit von 13 Monaten (95\%-KI 7 - 15,6), weibliche Patienten mit Expressions-Grad Eag1 high $(n=13)$ eine mediane Überlebenszeit von 9 Monaten $(95 \%-K I 5-13,8)(p=0,5)$.

Männliche Patienten mit im Tumorgewebe festgestellten Expressions-Grad Eag1 low $(\mathrm{n}=13)$ hatten eine mediane Überlebenszeit von 8 Monaten (95\%-KI 6 - 15,8), männliche Patienten mit Expressions-Grad Eag1 high $(n=26)$ eine mediane Überlebenszeit von 3,5 Monaten $(95 \%-K I 3-7)(p=0,039)$.
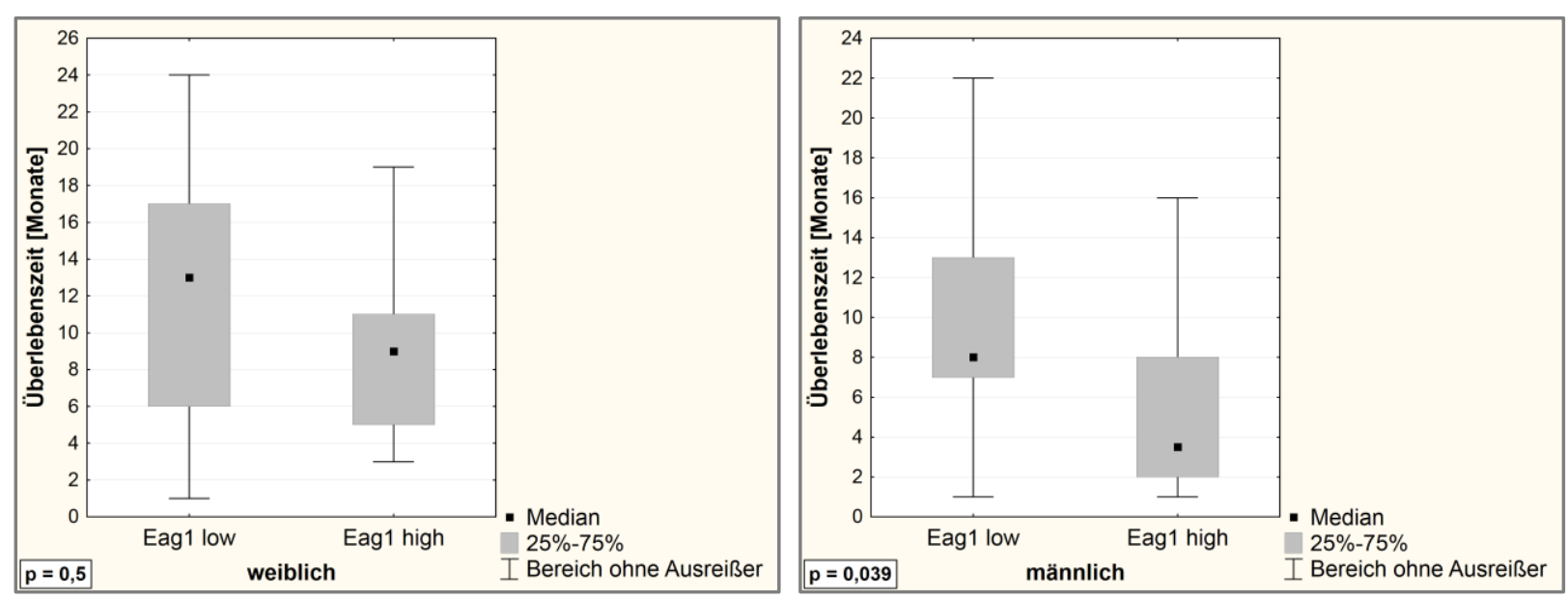

Abb. 32: Boxplot der medianen Überlebenszeit von weiblichen und männlichen Patienten im Hirnmetastasen-Kollektiv in Abhängigkeit von der Eag1-Expression. 


\subsubsection{GBM-Kollektiv}

Im GBM-Kollektiv wurde der Einfluss des Geschlechts ebenfalls untersucht. Weibliche Patienten, bei denen im Tumorgewebe ein Expressions-Grad Eag1 low festgestellt wurde $(n=17)$, hatten eine mediane Überlebenszeit von 11 Monaten (95\%-KI 7 -21,9), weibliche Patienten mit Expressions-Grad Eag1 high $(\mathrm{n}=16)$ eine mediane Überlebenszeit von 5 Monaten (95\%-KI 3,6 - 16) ( $p=0,49)$.

Männliche Patienten mit im Tumorgewebe festgestellten Expressions-Grad Eag1 low ( $\mathrm{n}=26)$ hatten eine mediane Überlebenszeit von 14,5 Monaten (95\%-KI 9,5 - 21), männliche Patienten mit Expressions-Grad Eag1 high $(\mathrm{n}=12)$ eine mediane Überlebenszeit von 13,5 Monaten $(95 \%-K I 5,2-17)(p=0,31)$.
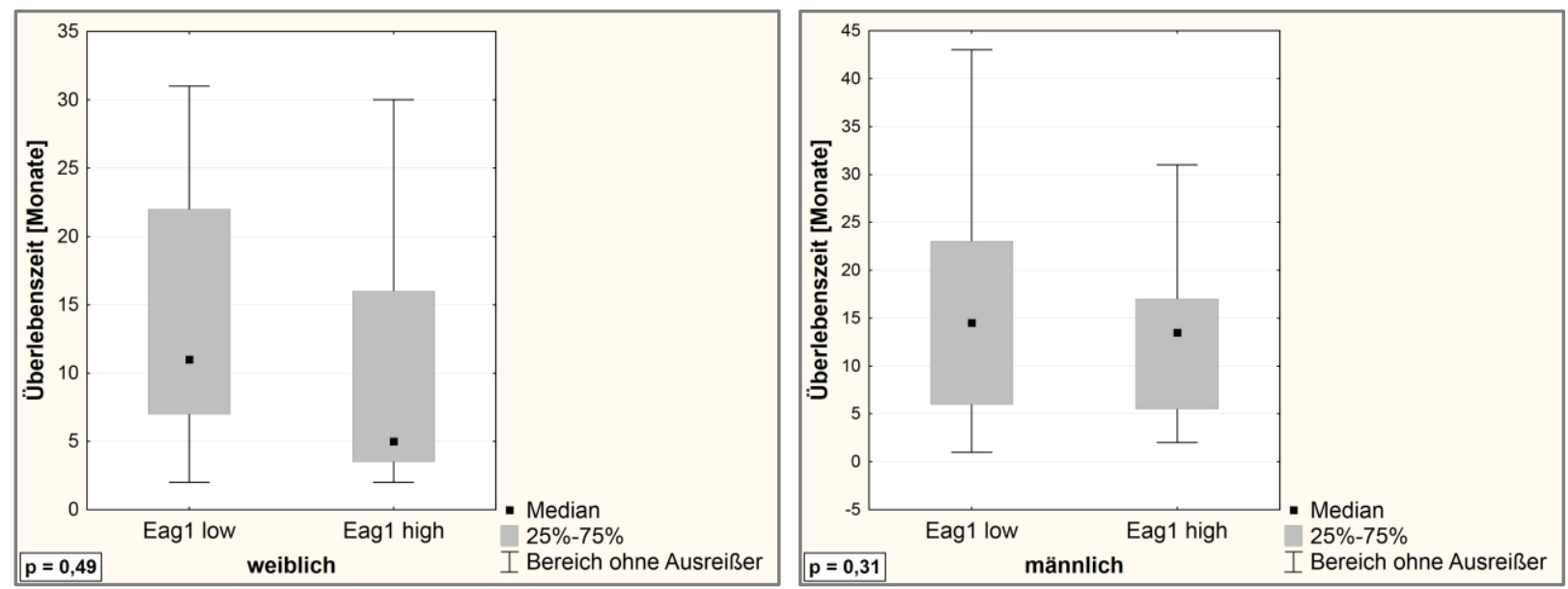

Abb. 33: Boxplot der medianen Überlebenszeit von weiblichen und männlichen Patienten im GBMKollektiv in Abhängigkeit von der Eag1-Expression. 


\section{IV) Diskussion}

\subsection{Das Kollektiv}

Die Schwierigkeit bei der Zusammenstellung der Kollektive bestand darin, dass die Anzahl der Tumor-Patienten, die wegen einer endogenen Depression zusätzlich mit Antidepressiva therapiert wurden, sehr limitiert war. Es konnten somit keine einschränkenden Einschlusskriterien gestellt werden, die es erlaubt hätten, im Hirnmetastasen-Kollektiv Patienten mit dem gleichen Primärtumor zu untersuchen. Bezüglich der Dauermedikation der jeweiligen Patienten wurde jedoch darauf geachtet, dass neben der Antidepressiva-Therapie keine weitere Dauermedikation mit neurologischer Wirkung (zum Beispiel Antiepileptika oder Kortikosteroide) vorhanden war.

\subsubsection{Hirnmetastasen-Kollektiv}

Die Geschlechtsverteilung im Hirnmetastasen-Kollektiv von 36 (48\%) weiblichen Patienten und 39 (52\%) männlichen Patienten war nahezu ausgeglichen. Epidemiologische Daten zu Patienten mit Hirnmetastasen sind nicht einheitlich in der Literatur, eine retrospektive Analyse von über 15.000 schwedischen Patienten über einen Zeitraum von 19 Jahren gibt jedoch eine Vergleichsmöglichkeit (Smedby et al. 2009): In dieser Studie war die Geschlechtsverteilung mit 53,1\% weiblichen und 46,9\% männlichen Patienten auch nahezu ausgeglichen, so dass von einem repräsentativen Kollektiv der vorliegenden Studie auszugehen ist.

In der vorliegenden Studie lag der Medianwert des Erkrankungsalters der weiblichen Patienten bei 59 Jahren und der männlichen Patienten bei 61 Jahren. Diese Werte kommen den Vergleichswerten in der Literatur von 64 Jahren bei weiblichen Patienten und 67 Jahren bei männlichen Patienten nahe (Smedby et al. 2009).

Die Häufigkeitsverteilung der primären Tumoren im Kollektiv mit der größten Fallanzahl beim Bronchialkarzinom, gefolgt von Mammakarzinom, Melanom und dem kolorektalen Karzinom, wird unterstützt durch die Datenlage in der Literatur (Smedby et al. 2009).

\subsubsection{GBM-Kollektiv}

Die Zusammensetzung des GBM-Kollektivs der vorliegenden Studie aus 33 weiblichen und 38 männlichen Patienten (Verhältnis 1:1,15) geht mit epidemiologischen Daten aus der Literatur einher, die aufzeigen, dass Männer im Verhältnis von 1:1,34 etwas häufiger von dieser Tumorart betroffen sind als Frauen (Ohgaki und Kleihues 2005). 
Auch das mittlere Erkrankungsalter der weiblichen Patienten im Kollektiv von 65,4 \pm 12,1 Monaten und der männlichen Patienten von 64,6 \pm 11,5 Monaten deckt sich näherungsweise mit dem mittleren Erkrankungsalter von Glioblastoma-Patienten (62,2 \pm 13,4 Monaten) aus einer großangelegten Studie (Ohgaki und Kleihues 2005).

\subsection{Eag1 als Tumor-Marker}

Die Expression von Eag1 in gesundem Gewebe ist sehr limitiert und nur im Gehirn und sporadisch in extrazerebralem Gewebe nachweisbar (Pardo et al. 1999; Hemmerlein et al. 2006; Martin et al. 2008). Im Gehirn ist das natürliche Vorkommen von Eag1 wiederum reduziert auf spezifische Bereiche wie den Kortex, Hippocampus, Hypothalamus und das Zerebellum (Martin et al. 2008). Zu erwähnen ist, dass in immunhistochemisch untersuchtem Tumorgewebe häufig ein zytoplasmatisches Färbemuster von Eag1 zu beobachten ist. Elektrophysiologische Experimente beweisen jedoch eindeutig eine membranständige Lage von Eag1 (Pardo et al. 1999). Die Schwierigkeit Eag1 immunhistochemisch alleinig membranbezogen darzustellen ist in der Literatur bekannt (Hemmerlein et al. 2006; Mello de Queiroz et al. 2006). Zudem ist eine intrazelluläre Antigen-Reaktion, welche die membranbezogene maskiert, kein unbekannter Effekt bei der immunhistochemischen Untersuchung von Kaliumkanälen (Saganich et al. 2001). Auch im Speziellen für GBM ist diese Beobachtung beschrieben worden (Masi et al. 2005). Um diesem Effekt entgegenzuwirken, wurde zur Verbesserung der Eag1-Färbung eine zweite Methodik mit dem Chromogen Neufuchsin durchgeführt. Das Chromogen BCIP/NBT bewirkt durch seine intensive Blaufärbung eine verstärkte Hintergrundfärbung und somit auch eine Verstärkung des zytoplasmatischen Signals. Für beide Chromogene resultierte bei der Auswertung der Gewebeschnitte der gleiche Score, so dass für die Gesamtaussage beide Färbungen verwendet werden konnten.

\subsubsection{Hirnmetastasen-Kollektiv}

Eine Überexpression von Eag1 in Tumorgewebe von Hirnmetastasen wurde bisher noch nicht untersucht. In extrazerebralen Tumoren konnte Eag1 jedoch schon als Tumor-Marker beschrieben werden (siehe Abschnitt 1.1.2). Die untersuchten Tumor-Biopsien zeigten in 85,3\% ( $n=64)$ der Fälle eine positive Eag1-Expression und 52\% ( $n=39)$ davon lagen im Bereich Eag1 high. Folglich ist davon auszugehen, dass Eag1 auch in Tumorgewebe von Hirnmetastasen als Tumor-Marker anzusehen ist. Dieses Ergebnis wird gestützt durch Studien gleicher Methodik, in denen eine positive Eag1-Expression in Tumorgewebe von Magenkarzinomen in 70,5\% $(n=67)$ der Fälle (Ding et al. 2007 a), in Tumorgewebe von 
kolorektalen Karzinomen in 76,3\% ( $n=58)$ der Fälle (Ding et al. 2007 b), in Tumorgewebe von Oesophaguskarzinomen in 75\% $(n=51)$ der Fälle (Ding et al. 2008) und in Sarkomen der Weichgewebe in 71\% ( $n=150)$ der Fälle (Mello de Queiroz et al. 2006) gefunden wurde.

\subsubsection{GBM-Kollektiv}

Die Eag1-Expression in Tumor-Biopsien von Gliomen wurde das erste Mal auf der Ebene der mRNA untersucht mit dem Ergebnis, dass eine Überexpression von Eag1 nur in niedriggradigen Astrozytomen und nicht in hochgradigen (GBM) nachzuweisen war (Patt et al. 2004). Eine darauf folgende Studie untersuchte die Eag1-Expression durch die Bestimmung der mRNA per PCR sowie des Proteins per Immunhistochemie: Auf beiden Ebenen wurde eine Überexpression von Eag1 in GBM festgestellt (Masi et al. 2005). Dieses Ergebnis konnte in aktuellen Studien durch die Beobachtung einer Überexpression von Eag1 in GBM bestätigt werden (Bai et al. 2013; Cunha et al. 2013).

In der vorliegenden Studie wurde in 77,5\% $(n=55)$ der Fälle eine positive Eag1-Expression gefunden mit 39,5\% ( $n=28)$ der Fälle im Bereich Eag1 high und 60,5\% ( $n=43)$ im Bereich Eag1 low. Somit zeigt sich im Vergleich zu den Ergebnissen im Hirnmetastasen-Kollektiv eine prozentual kleinere Anzahl an Fällen mit positiver Eag1-Expression und weniger Fälle im Bereich Eag1 high. Der Anteil von 77,5\% der Fälle mit positiver Eag1-Expression ist jedoch vergleichbar mit den Werten, die bei immunhistochemischen Analysen von extrazerebralen Karzinomen resultierten (siehe Abschnitt 4.2.1). Dahingehend kann Eag1 auch bei GBM als Tumor-Marker bewertet werden. Die geringe Anzahl an Fällen mit Eag1 high im GBM-Kollektiv zeigt, dass unsere Ergebnisse näher bei den Ergebnissen von Patt et al. (2004) liegen als von Masi et al. (2005) und Bai et al. (2013). Die Ergebnisse von Cunha et al. (2013) sind für den direkten Vergleich eher ungeeignet, da mit kultivierten Tumorzelllinien gearbeitet wurde und nicht mit Tumorgewebe, das bei Tumorresektionen entnommen wurde. Eine mögliche Erklärung für den Unterschied zwischen den gefundenen Ergebnissen und den Ergebnissen von Masi et al. (2005) und Bai et al. (2013) könnte in der Entnahme des Tumorgewebes zu finden sein. Die Entnahme von Tumorgewebe für die neuropathologische Diagnostik wird in der Klinik für Neurochirurgie Göttingen immer im volumetrischen Zentrum des Tumors vorgenommen. Somit ist die Wahrscheinlichkeit von normalem Hirngewebe in den entnommenen Proben sehr gering. Dies ist für die Studie von großer Bedeutung, da Eag1 in normalem Hirngewebe vorkommt (Pardo et al. 1999; Hemmerlein et al. 2006) und entsprechend das Ergebnis der Eag1-Expression in den Gewebeproben verfälscht würde respektive eine erhöhte Eag1-Expression resultieren würde. Zumindest in der Studie von Bai et al. (2013) scheint die Entnahme nicht im volumetrischen Zentrum des Tumors vorgenommen worden zu sein, da sich im „Material und Methoden“-Teil der Publikation die 
Anmerkung finden lässt, dass tumorzellfreie Bereiche der Gewebeproben zur Abgrenzung des Tumorgewebes neuropathologisch erkannt wurden. In der Studie von Masi et al. (2005) gibt es keine genaueren Angaben zur Entnahme des Tumorgewebes.

\subsection{Eag1 als Prognose-Marker}

Eag1 ist in seiner Funktion als Prognose-Marker bei Krebserkrankungen schon vereinzelt beschrieben worden. Studien zeigten, dass eine niedrige Eag1-Expression im Tumorgewebe von Oesophaguskarzinomen (Ding et al. 2008), Ovarialkarzinomen (Asher et al. 2010) und auch bei einer akuten myeloischen Leukämie (Agarwal et al. 2010) mit einer signifikant verlängerten Überlebenszeit von den Patienten korreliert.

Für Hirnmetastasen und Glioblastoma multiforme gibt es hierfür noch keine Daten. Demnach wurde das Kollektiv auf einen Effekt der Eag1-Expression auf die Überlebenszeit untersucht.

\subsubsection{Hirnmetastasen-Kollektiv}

Patienten, bei denen die Untersuchung des Tumorgewebes Eag1 low ergab (mediane Überlebenszeit 11 Monate), zeigten eine signifikant verlängerte Überlebenszeit gegenüber Patienten mit Eag1 high (mediane Überlebenszeit 6 Monate) ( $\mathrm{p}=0,0119)$. Dieses Ergebnis zeigt, dass die Expression von Eag1 als Prognose-Marker bei Patienten mit Hirnmetastasen bewertet werden kann. Die gleichen Beobachtungen bei extrazerebralen Karzinomen von Ding et al. (2008) und Asher et al. (2010) unterstützen das Ergebnis. Des Weiteren die Studie von Agarwal et al. (2010) mit gleichen Ergebnissen auf Ebene der mRNA. Es zeigt sich, dass durch verschiedene Methoden eine Korrelation von Expression und Überlebenszeit mit gleichem Ergebnis resultiert. Zu erwähnen ist, dass im Kollektiv nur die neurochirurgische Therapie und adjuvante Therapie der Hirnmetastasen einheitlich war, die Therapie der primären Tumoren jedoch nicht. Weitere Daten aus experimentellen Tiermodellen mit einheitlichen Faktoren sind daher anzustreben. Die Resultate der vorliegenden Studie bestätigen die Hypothese, dass Eag1 auch bei Hirnmetastasen als Prognose-Marker verwendet werden kann. Die Bestimmung der Eag1-Expression in der Tumorbiopsie eines Patienten könnte in der klinischen Therapie von Nutzen sein, da dadurch individuelle Erkenntnisse über die Prognose des Patienten gewonnen werden, die es ermöglichen eine personalisierte Therapie einzuleiten. 


\subsubsection{GBM-Kollektiv}

Die Ergebnisse der durchgeführten Studie zeigten bei Patienten, die im Tumorgewebe Eag1 low aufwiesen, zwar eine deutlich verlängerte Überlebenszeit (mediane Überlebenszeit 13 Monate) im Vergleich zu Patienten, bei denen die Untersuchung des Tumorgewebes Eag1 high ergab (mediane Überlebenszeit 8 Monate), eine statistische Signifikanz konnte für dieses Ergebnis jedoch nicht gefunden werden $(p=0,15)$. Somit kann die Eag1-Expression im GBM-Kollektiv als alleiniger Prognose-Marker noch nicht als aussagekräftiger Marker herangezogen werden. Studien mit größeren Patientenzahlen sind notwendig, um eine prognostische Funktion von Eag1 bei Patienten mit GBM zu bestätigen. Eine mögliche Erklärung, weshalb die Eag1-Expression in GBM keinen signifikanten Einfluss auf die Prognose zeigt, könnte darin liegen, dass die Inaktivierung des Tumorsuppressors-p53 mit einer Überexpression von Eag1 assoziiert ist (Lin et al. 2011). Eine Mutation von TP53 und folglich eine Inaktivierung des Tumorsuppressors-p53 ist jedoch nur in ca. 15\% aller GBM zu finden (Riemenschneider et al. 2010). Primäre, de novo entstandene GBM weisen eine EGFR-Amplifikation ohne TP53-Mutation auf (von Deimling et al. 1995; Kleihues und Ohgaki 1999). Da es sich bei allen Fällen, die in das GBM-Kollektiv eingeschlossen wurden, nach klinischer Anamnese um primäre GBM handelt, ist von einer geringeren Inzidenz von TP53Mutationen auszugehen. Folglich besteht die Möglichkeit, dass auch eine Überexpression von Eag1 seltener auftritt und dadurch ein Effekt auf die Prognose nicht entstehen kann.

\subsection{Eag1 als mögliches medikamentöses Oncotarget}

Ergebnisse, die eine Verringerung der Proliferationsrate von Tumorzellen durch die Blockade von Eag1 mittels Antidepressiva zeigen, liegen bisher für das trizyklische Antidepressivum Imipramin vor (Gavrilova-Ruch et al. 2002; García-Ferreiro et al. 2004). Es handelt sich um In-Vitro-Studien. Anhand klinischer Patientendaten liegen bisher noch keine Daten vor, die eine Korrelation zwischen verringerter Proliferationsrate und verlängerter Überlebenszeit von Patienten aufzeigen. Demzufolge wurde in der vorliegenden Studie die Wirkung von Antidepressiva auf die Überlebenszeit von Patienten untersucht. Das von den meisten Patienten im Kollektiv eingenommene Antidepressivum Amitriptylin gehört zu den trizyklischen Antidepressiva wie Imipramin. Beide Wirkstoffe sind HERG-Kanal-Blocker (Teschemacher et al. 1999). Elektrophysiologische Experimente konnten zeigen, dass HERG-Kanal-Blocker auch eine große Affinität zu Eag1 haben (García-Ferreiro et al. 2004). Zudem besteht eine große Ähnlichkeit im molekularen Aufbau der lonenkanäle Eag1 und HERG. Eine nähere Betrachtung diesbezüglich durch Gómez-Varela et al. (2006) hat zwar gezeigt, dass es durchaus Unterschiede im Aufbau der Kanäle geben muss, dies hat jedoch nur zur Folge, 
dass blockierende Wirkstoffe an unterschiedlichen Bereichen der Kanäle binden. Aufgrund dieser Erkenntnisse wurde dem am zweithäufigsten eingenommenen Antidepressivum Citalopram eine Wirkung auf Eag1 zugesprochen, da es auch zu den HERG-Kanal-Blockern zählt (Witchel et al. 2002). Die Auswertung der Daten bestätigte die Annahme, dadurch dass sich nur ein Einfluss von Amitriptylin und Citalopram auf Eag1 zeigte, nicht jedoch von Mirtazapin. Dies geht einher mit der Literatur, da Mirtazapin nicht zu den HERG-KanalBlockern zählt.

\subsubsection{Hirnmetastasen-Kollektiv}

Im Hirnmetastasen-Kollektiv zeigten Patienten mit Eag1-Expression low, die Amitriptylin oder Citalopram eingenommen hatten, eine signifikant erhöhte Überlebenszeit (mediane Überlebenszeit 13 Monate) gegenüber der Kontrollgruppe (mediane Überlebenszeit 10 Monate) $(p=0,03)$. Bei Patienten mit Eag1-Expression high, die Amitriptylin oder Citalopram eingenommen hatten (mediane Überlebenszeit 6 Monate), zeigte sich jedoch kein signifikanter Unterschied in der medianen Überlebenszeit im Vergleich zur Kontrollgruppe (mediane Überlebenszeit 6 Monate) ( $p=0,1)$. Die Kaplan-Meier-Analyse (siehe Abschnitt 3.4.1) zeigte eine verlängerte Überlebenszeit von Patienten des gesamten Hirnmetastasen-Kollektivs, bei denen die Eag1-Expression im Tumorgewebe low war, mit einer zusätzlich verlängerten Überlebenszeit von Patienten, die im Tumorgewebe Eag1 low aufwiesen und mit Antidepressiva therapiert wurden. Somit kann die in der Fragestellung aufgestellte Hypothese bestätigt werden, dass eine niedrige Eag1-Expression einen prognostisch günstigen Effekt auf die Überlebenszeit hat. Zudem kann eine Blockade von Eag1 durch Antidepressiva bei Patienten mit Expressionsgrad Eag1 low im Tumorgewebe eine weitere Verlängerung der Überlebenszeit bewirken. Die Frage stellt sich, weshalb kein Effekt bei Patienten mit Expressionsgrad Eag1 high im Tumorgewebe zu erkennen war, da bei mehr Kaliumkanälen in der Membran der Tumorzellen davon auszugehen ist, dass die Blockade durch Antidepressiva einen größeren Effekt auf die Proliferationsrate haben müsste. Erkenntnisse darüber wurden in der Studie von Downie et al. (2008) gewonnen: Die Tumorprogression kann durch eine Blockade von Eag1 mittels Imipramin zwar stark eingeschränkt werden, eine Mutation von Eag1, welche die Permeabilität des Kanales eliminiert, kann jedoch nicht zu einer alleinigen Verhinderung der Tumorprogression führen. Als möglicher Einfluss von Eag1, unabhängig von der normalen Funktion als lonenkanal, konnte in selbiger Studie aufgezeigt werden, dass die Überexpression von Eag1 mit einer Erhöhung der HIF-1Aktivität mit einhergehender VEGF-Sekretion und Tumor-Vaskularisierung assoziiert ist. Tumorzellen mit Eag1 high und entsprechender Überexpression von VEGF scheinen durch die suffiziente Neoangiogenese des Tumors nicht auf die Überexpression von Eag1 zum 
Überleben angewiesen zu sein. Folglich zeigt die Blockade von Eag1 durch Antidepressiva bei diesen Tumoren keine einschränkende Wirkung auf das Tumorwachstum respektive eine Verbesserung der Überlebenszeit. Hierzu lässt sich eine Beobachtung aus dem GBMKollektiv heranziehen: VEGF ist in Tumorzellen von GBM stark überexprimiert (Jain et al. 2007). Durch die verbesserte Vaskularisierung des Tumors ergibt sich ein Vorteil auf die Überlebensrate der Tumorzellen, weshalb diese scheinbar weniger auf die Überexpression von Eag1 angewiesen sind. Dies zeigt sich daran, dass im GBM-Kollektiv nur 39,5\% der Tumoren eine Eag1-Expression im Bereich Eag1 high aufwiesen, im HirnmetastasenKollektiv dagegen $52 \%$.

Der vielversprechende Effekt von trizyklischen Antidepressiva die Proliferationsrate von Tumorzellen einzuschränken, konnte durch die erst kürzlich publizierten Ergebnisse der Arbeitsgruppe um Jahchan et al. (2013) bestätigt werden: In Zelllinien und in einem Mausmodell zeigte sich, dass der Einfluss von trizyklischen Antidepressiva wie Imipramin und auch Amitriptylin auf humane Tumorzellen von neuroendokrinen Tumoren wie dem kleinzelligen Bronchialkarzinom zur Apoptose selbiger führt. Hierbei werden autokrine Überlebenssignale der Tumorzellen, vermittelt durch Neurotransmitter und ihrer G-Proteingekoppelter Rezeptoren (GPCR) durch Antidepressiva unterbrochen. Ein Nutzen für die klinische Therapie könnte durch die gewonnenen Erkenntnisse der vorliegenden Studie darin liegen, dass durch die Bestimmung der Eag1-Expression in Tumorbiopsien eine Aussage über die Prognose möglich ist. Im weiteren Schritt kann versucht werden die Überlebenszeit von Patienten mit Hirnmetastasen und niedriger Eag1-Expression durch eine Beeinflussung von Eag1 mit einer Antidepressiva-Therapie zu verlängern. Jedoch ist zu erwähnen, dass es im Rahmen der retrospektiven Analyse der Patientenakten nicht möglich gewesen ist exakte Daten darüber zu ermitteln, über welchen Zeitraum die Patienten das Antidepressivum eingenommen haben, um eine Dosiswirkung des Medikaments auf Eag1 zu erfassen. Die Studie von Jahchan et al. (2013) konnte aber bereits in einem Bronchialkarzinom-Mausmodell zeigen, dass eine Eag1-Blockade durch eine Antidepressiva-Dosis, die der therapeutischen Dosis in der Therapie einer endogenen Depression entspricht, bewirkt werden kann. Mit der vorliegenden Studie konnten erste Ergebnisse bezüglich einer Blockade von Eag1 durch Antidepressiva bei Patienten mit Hirnmetastasen gezeigt werden. Im Anschluss an diese Studie sind jedoch Daten aus einer In-Vivo-Studie (HirnmetastasenTiermodell) anzustreben, um den direkten und Dosis-kontrollierten Einfluss von Antidepressiva auf die Tumorbildung weiter zu untersuchen. 


\subsubsection{GBM-Kollektiv}

Im Gegensatz zum Hirnmetastasen-Kollektiv zeigte sich im GBM-Kollektiv ein konträres Ergebnis mit einer verlängerten Überlebenszeit von Patienten der Kontrollgruppe mit Eag1Expression low (mediane Überlebenszeit 15,5 Monate) im Vergleich zu Patienten der experimentellen Gruppe mit Eag1-Expression low (mediane Überlebenszeit 9 Monate) $(p=0,1)$. Bei Patienten mit Eag1-Expression high und Antidepressiva-Therapie (mediane Überlebenszeit 6 Monate) ergab sich kein Unterschied in der Überlebenszeit im Vergleich zur Kontrollgruppe (mediane Überlebenszeit 6 Monate) $(p=0,5)$. Ein Einfluss auf die Überlebenszeit durch die Blockade von Eag1 mit Antidepressiva konnte im GBM-Kollektiv somit nicht gezeigt werden. Eine mögliche Erklärung ist die Expression von VEGF in GBM: Eine erhöhte Eag1-Expression steht in Verbindung mit einer Überexpression von VEGF und scheint diese zu verstärken (Downie et al. 2008). In GBM ist VEGF jedoch stark überexprimiert (Jain et al. 2007). Die Blockade von Eag1 durch Antidepressiva kann in Tumorzellen von Hirnmetastasen mit Eag1 low die VEGF-Sekretion beeinflussen und einen einschränkenden Einfluss auf die Neoangiogenese und das Wachstum des Tumors haben. Dies spiegelt sich in der verlängerten Überlebenszeit von den Patienten wider. $\mathrm{Da}$ in Tumorzellen von GBM mit Eag1 low die VEGF-Expression - unabhängig von Eag1 - stark erhöht ist, lässt dies darauf schließen, dass die Blockade von Eag1 durch Antidepressiva keinen gewichtigen Einfluss auf das Tumorwachstum nehmen kann und sich dadurch eine Verlängerung der Überlebenszeit nicht abzeichnet.

Auffallend anhand der Überlebenszeitanalyse im GBM-Kollektiv, dargestellt durch die Kaplan-Meier-Kurve in Abschnitt 3.4.2, ist die verlängerte Überlebenszeit von Patienten ohne endogene Depression der Kontrollgruppe gegenüber den verglichenen Gruppen. Dies führt zu der Frage, welchen Einfluss die Depression der Patienten auf die Überlebenszeit hat. Metaanalysen von Satin et al. (2009) sowie Pinquart und Duberstein (2010) haben durch signifikant verringerte Überlebenszeiten eine schlechtere Prognose von Patienten aufgezeigt, die zusätzlich zu ihrer Krebserkrankung an einer Depression litten. Eine Studie von Pirl et al. (2012) hat basierend auf diesen Erkenntnissen Patienten mit metastasierendem nicht-kleinzelligen Bronchialkarzinom und Depression mit Patienten einer Kontrollgruppe verglichen und die signifikant schlechtere Prognose von depressiven Patienten bestätigt. Folglich könnte ein Effekt durch Depression bestehen, der sich im Hirnmetastasen-Kollektiv nicht zeigt, da die Wirkung der Blockade von Eag1 prognostisch schwerer wiegt, im GBMKollektiv jedoch zu erkennen ist. 


\subsection{Einfluss klinischer Parameter auf die Eag1-Expression}

In Bezug auf die Eag1-Expression wurden klinische Parameter in mehreren Studien zu extrazerebralen Karzinomen wie dem Magenkarzinom (Ding et al. 2007 a), dem kolorektalen Karzinom (Ding et al. 2007 b), Oesophaguskarzinom (Ding et al. 2008) und in Sarkomen der Weichgewebe (Mello de Queiroz et al. 2006) untersucht. Eine signifikante Korrelation mit der Eag1-Expression konnte für Lymphknoten-Metastasierung und Tumor-Stage (Ding et al. 2007 a), Tumorgröße und Metastasierung (Ding et al. 2007 b), Tiefe der Tumorinfiltration (Ding et al. 2008) und histologischer Typisierung (Mello de Queiroz et al. 2006) gezeigt werde. Parameter wie Alter, Geschlecht oder Tumorlokalisation sind in den beschriebenen Studien jedoch nicht als signifikante Faktoren gefunden worden.

\subsubsection{Hirnmetastasen-Kollektiv}

Eine geschlechtsabhängige Untersuchung der Eag1-Expression mit Bezug auf die Überlebenszeit ergab im Hirnmetastasen-Kollektiv einen signifikanten Einfluss: Männliche Patienten, bei denen die Untersuchung des Tumorgewebes Eag1 low ergab (mediane Überlebenszeit 8 Monate), hatten eine signifikant längere Überlebenszeit als männliche Patienten mit Expressionsgrad Eag1 high (mediane Überlebenszeit 3,5 Monate) (zweifaktorielle Varianzanalyse, $\mathrm{p}=0,039$ ). $\mathrm{Da}$ in anderen, schon angesprochenen Studien betreffend Eag1 (siehe Abschnitt 4.5) kein Einfluss des Geschlechts respektive des männlichen Geschlechts gesehen wurde, kann das Ergebnis nicht als eindeutig gewertet werden. Weitere Analysen mit größeren Kollektiven sind notwendig, um zu klären, ob bei männlichen Patienten die schlechtere Prognose bei erhöhter Eag1-Expression deutlicher ausfällt. Eine genauere Betrachtung der Eag1-Expression in den betroffenen Lokalisationen mit Bezug auf die Überlebenszeit zeigte im Hirnmetastasen-Kollektiv bei zerebellärer Lage der Metastase eine signifikant verlängerte Überlebenszeit von Patienten mit Expressionsgrad Eag1 low im Tumorgewebe (mediane Überlebenszeit 13 Monaten) gegenüber Patienten mit Expressionsgrad Eag1 high (mediane Überlebenszeit 5 Monate) (Zweifaktorielle Varianzanalyse, $p=0,03$ ). In der Studie von Lagerwaard et al. (1999) zu prognostisch relevanten Faktoren bei Patienten mit Hirnmetastasen konnte kein Einfluss durch die Lokalisation der Metastase festgestellt werden. Es ist daher nicht eindeutig zu werten wie aussagekräftig der Einfluss der Tumorlokalisation ist. Ein Einfluss ist nicht zu erwarten, da die Eag1-Expression vom Profil der Tumorzelle abhängig ist und nicht von der Lokalisation des Gewebes. 


\subsubsection{GBM-Kollektiv}

Im GBM-Kollektiv konnten keine signifikanten Ergebnisse bezüglich des Geschlechts oder der Tumorlokalisation gefunden werden. Eine Studie hohen Evidenzgrades zur Untersuchung prognostischer Faktoren bei Patienten mit GBM konnte aufzeigen, dass das Geschlecht und die Tumorlokalisation keinen Einfluss hat (Gorlia et al. 2008). Demzufolge werden die Ergebnisse der vorliegenden Studie durch die Datenlage in der Literatur unterstützt. 


\section{V) Zusammenfassung und Ausblick}

Das Glioblastoma multiforme ist eine maligne Neoplasie astrozytären bzw. oligoastrozytären Ursprungs und stellt den häufigsten primären Hirntumor im Erwachsenenalter dar. Hirnmetastasen zählen zu den sekundären Hirntumoren und treten am häufigsten als abgesiedelte maligne Tochtergeschwulste von Bronchial- und Mammakarzinomen sowie Melanomen auf. Trotz multimodaler Therapiemöglichkeiten in der klinischen Routine weisen Patienten mit diesen malignen Hirntumoren derzeit immer noch eine sehr eingeschränkte Prognose mit einer medianen Überlebenszeit von circa einem Jahr auf. Ziel aktueller Forschung ist es, durch neue molekulare Marker Tumorzellen gezielt anzugreifen, um einen prognostischen Vorteil zu erwirken.

Der spannungsgesteuerte Kaliumkanal Eag1 ist ein Membranprotein, das physiologisch nur im Gehirn exprimiert ist und durch ionische Aktivitäten die Zellteilung beeinflusst. Es ist beobachtet worden, dass Eag1 ein molekularer Marker ist, da Eag1 in den allermeisten extrazerebralen Karzinomen überexprimiert ist, was mit einer Erhöhung der Tumorzellproliferationsrate, Überexpression von VEGF sowie Inaktivierung des Tumorsuppressors-p53 assoziiert ist. Daraus resultiert ein begünstigtes Tumorwachstum, das mit einer schlechteren Prognose der Patienten einhergeht. Vielversprechende Ergebnisse konnten aufzeigen, dass durch die Hemmung von Eag1 durch unter anderem monoklonale Antikörper, siRNA und Medikamente wie Astemizol und trizyklische Antidepressiva das Tumorwachstum eingeschränkt werden kann.

In der vorliegenden Arbeit wurde die Eag1-Expression in Tumorbiopsien von Hirnmetastasen und GBM zur Vervollständigung der Datenlage untersucht. Die durchgeführte immunhistochemische Untersuchung konnte eine ähnlich hohe Expression zeigen, wie sie in extrazerebralen Karzinomen gefunden wurde. In Hirnmetastasen ergab sich im Vergleich zu GBM eine höhere Positivitätsrate der Eag1-Expression. Die Ergebnisse bestätigen die Hypothese, dass Eag1 in Hirnmetastasen und GBM als Tumor-Marker anzusehen ist und tragen dazu bei, dass die Bestimmung der Eag1-Expression Bestandteil der Routinediagnostik werden könnte.

Einflüsse auf die Prognose der Patienten wurden mit Überlebenszeitanalysen untersucht. Bei Patienten mit Hirnmetastasen zeigte sich, dass eine erhöhte Eag1-Expression mit einer signifikant verringerten Überlebenszeit korreliert. Diese Beobachtung deutet darauf hin, dass die Bestimmung der Eag1-Expression bei Patienten mit Hirnmetastasen als PrognoseMarker herangezogen werden könnte. Eine komparative Analyse der Überlebenszeit zeigte, dass eine zusätzliche Antidepressiva-Therapie - bei niedriger Eag1-Expression - mit einer signifikant verlängerten medianen Überlebenszeit korreliert. Der gezielte medikamentöse Angriff der Tumorzellen über Eag1 scheint somit eine Möglichkeit darzustellen, die Prognose 
von Patienten mit Hirnmetastasen zu verbessern. Bei Patienten mit GBM konnten keine signifikanten Korrelationen zwischen der Patientengruppe, die Antidepressiva eingenommen hatte, und der Kontrollgruppe festgestellt werden. Diese Beobachtungen gehen einher mit der Erkenntnis, dass die Tumorpathogenese in GBM und Hirnmetastasen verschiedenen Mechanismen unterliegt. Daher liegt der Schluss nahe, dass Eag1 in der Tumorpathogenese von GBM und Hirnmetastasen auch unterschiedliche Einflüsse auf die Proliferationsrate von Tumorzellen haben könnte. Der Einfluss einer Blockade von Eag1 auf die Überlebensfähigkeit der Tumorzellen könnte demnach variieren und abhängig von der Tumorentität sein.

Weiterhin wurden klinische Parameter wie Geschlecht und Tumorlokalisation untersucht.

Hierbei ergaben sich keine Korrelationen bezüglich der Überlebenszeit und der Eag1Expression.

Die Ergebnisse der vorliegenden Dissertation zeigen auf, dass Eag1 einen Stellenwert als molekularer Marker bei Hirnmetastasen und GBM besitzt. Weitere Analysen zur molekularen Charakterisierung von GBM werden dazu beitragen aufzuklären, welche Beteiligung Eag1 an unterschiedlichen onkologischen pathways hat und welche Beeinflussungen bezüglich p53, EGFR, p16, p14, IDH1, IDH2 und Angiogenese-regulierender Gene wie VEGF zu erwarten sind. Die Ergebnisse aus dem Hirnmetastasen-Kollektiv tragen zu einer möglichen individualisierten Therapie der Patienten bei. Je nach Eag1-Expression könnten die Patienten in Zukunft zusätzlich durch eine Blockade von Eag1 mit Medikamenten (z.B. Antidepressiva) oder monoklonalen Antikörpern gezielt therapiert werden. 


\section{VI) Verzeichnis der verwendeten Abkürzungen}

\begin{tabular}{|c|c|}
\hline ALA & 5-Aminolävulinsäure \\
\hline ANOVA & analysis of variance \\
\hline AP & alkalische Phosphatase \\
\hline BCIP & 5-Brom-4-Chlor-3-Indoxylphosphat \\
\hline BRAF & $\mathrm{B}$ rapidly accelerated fibrosarcoma \\
\hline BSA & bovine serum albumin \\
\hline $\mathrm{Ca}$ & Karzinom \\
\hline CBTRUS & Central Brain Tumor Registry of the United States \\
\hline $\mathrm{CHO}$ (Zellen) & chinese hamster ovary \\
\hline cox2 & Clyclooxygenase-2 \\
\hline CpG & Cytosin-Phospatidyl-Guanin \\
\hline CUP & cancer of unknown primary \\
\hline DEPC & Diethylpyrocarbonat \\
\hline DGN & Deutsche Gesellschaft für Neurologie \\
\hline DNA & deoxyribonucleic acid \\
\hline Eag1 & Ether-à-go-go-1 \\
\hline EDTA & Ethylendiamintetraacetat \\
\hline EGF & epidermal growth factor \\
\hline EGFR & epidermal growth factor receptor \\
\hline EMT & epithelial-mesenchymal transition \\
\hline GBM & Glioblastoma multiforme \\
\hline
\end{tabular}




\begin{tabular}{|c|c|}
\hline GPA & graded prognostic assessment \\
\hline GPCR & G protein-coupled receptor \\
\hline HER2/neu & human epidermal growth factor receptor 2 \\
\hline HERG & human Ether-à-go-go related gene \\
\hline HGF & hepatocyte growth factor \\
\hline HGFR/c-Met & hepatocyte growth factor receptor \\
\hline HIF-1 & Hypoxie-induzierter Faktor 1 \\
\hline ICD & International Statistical Classification of Diseases \\
\hline $\mathrm{IDH}-1 / 2$ & Isocitratdehydrogenase-1/2 \\
\hline IGF & insulin-like growth factor \\
\hline $\mathrm{KI}$ & Konfidenzintervall \\
\hline MAP & mitogen activated protein \\
\hline MET & mesenchymal-epithelial transition \\
\hline MGMT & $\mathrm{O}^{6}$-Methylguanin-DNA-Methyltransferase \\
\hline mRNA & messenger RNA \\
\hline MRT & Magnetresonanztomographie \\
\hline mTOR & mammalian target of Rapamycin \\
\hline $\mathrm{NADPH}$ & Nicotinamidadenindinukleotidphosphat \\
\hline NBT & Nitroblau-Tetrazoliumchlorid \\
\hline NGF & nerve growth factor \\
\hline PCR & polymerase chain reaction \\
\hline PI3K & Phosphoinositid-3-Kinase \\
\hline
\end{tabular}


PLK-1 polo like kinase 1

PTEN phosphatase and tensin homolog

RNA ribonucleic acid

RPA recursive partitioning analysis

RTOG Radiation Therapy Oncology Group

SCID severe combined immunodeficiency

SCLC small cell lung cancer

shRNA small hairpin RNA

siRNA small interfering RNA

SSRI selective serotonin reuptake inhibitor

TBS tris-buffered saline

TGF- $\beta \quad$ transforming growth factor $\beta$

TGFBR transforming growth factor $\beta$ receptor

TMS1 target of methylation-induced silencing-1

TP53 tumor protein p53

TRAIL tumor necrosis factor related apoptosis inducing ligand

VCAM-1 vascular cell adhesion molecule 1

VEGF vascular endothelial growth factor

WBRT whole brain radiation therapy

WHO World Health Organization 


\section{VII) Literaturverzeichnis}

Agarwal JR, Griesinger F, Stühmer W, Pardo LA (2010): The potassium channel Ether à gogo is a novel prognostic factor with functional relevance in acute myeloid leukemia. Mol Cancer $\underline{9}, 18-34$

Al-Shamy G, Sawaya R (2009): Management of brain metastases: the indispensable role of surgery. J Neurooncol $\underline{92,}$ 275-282

Ashcroft FM: Ion Channels and Disease. Academic Press, New York 2000

Ashcroft FM (2006): From molecule to malady. Nature 440, 440-447

Asher V, Khan R, Warren A, Shaw R, Schalkwyk GV, Bali A, Sowter HM (2010): The Eag potassium channel as a new prognostic marker in ovarian cancer. Diagn Pathol $\underline{5}, 78-86$

Aupérin A, Arriagada R, Pignon JP, Le Péchoux C, Gregor A, Stephens RJ, Kristjansen PE, Johnson BE, Ueoka H, Wagner H (1999): Prophylactic Cranial Irradiation for Patients with Small-Cell Lung Cancer in Complete Remission. N Engl J Med 341, 476-484

Bai Y, Liao H, Liu T, Zeng X, Xiao F, Luo L, Guo H, Guo L (2013): MiR-296-3p regulates cell growth and multi-drug resistance of human glioblastoma by targeting ether-à-go-go (EAG1). Eur J Cancer $\underline{49}, 710-724$

Becher MW, Abel TW, Thompson RC, Weaver KD, Davis LE (2006): Immunhistochemical Analysis of Metastatic Neoplasms of the Central Nervous System. J Neuropathol Exp Neurol $\underline{65}, 935-944$

Bos PD, Zhang XH, Nadal C, Shu W, Gomis RR, Nguyen DX, Minn AJ, van de Vijver MJ, Gerald WL, Foekens JA (2009): Genes that mediate breast cancer metastasis to the brain. Nature $\underline{459}, 1005-1009$

Carmona FJ, Villanueva A, Vidal A, Munoz C, Puertas S, Penin RM, Gomà M, Lujambio A, Piulats JM, Mesía R (2012): Epigenetic disruption of cadherin-11 in human cancer metastasis. J Pathol $\underline{228}, 230-240$

Chambers AF, Groom AC, MacDonald IC (2002): Dissemination and growth of cancer cells in metastatic sites. Nat Rev Cancer 2 , 563-572 
Chen G, Davies MA (2012): Emerging insights into the molecular biology of brain metastases. Biochem Pharmacol $\underline{83}$, 305-314

Chuang HN, van Rossum D, Sieger D, Siam L, Klemm F, Bleckmann A, Bayerlová M, Farhat K, Scheffel J, Schulz M (2013): Carcinoma Cells Misuse the Host Tissue Damage Response to Invade the Brain. Glia $\underline{61}, 1331-1346$

Cunha LC, Del Bel E, Pardo LA, Stühmer W, Titze-de-Almeida R (2013): RNA interference with EAG1 enhances interferon gamma injury to glioma cells in vitro. Anticancer Res $\underline{33}$, $865-870$

Davis FG, Dolecek TA, McCarthy BJ, Villano JL (2012): Toward determining the lifetime occurrence of metastatic brain tumors estimated from 2007 United States cancer incidence data. Neuro Oncol 14, 1171-1177

Delattre JY, Krol G, Thaler HAT, Posner JB (1988): Distribution of brain metastases. Arch Neurol $\underline{45}, 741-744$

Diener HC, Weimar C: Leitlinien für Diagnostik und Therapie in der Neurologie. 5. Auflage; Thieme Verlag, Stuttgart 2012

Ding XW, Luo HS, Jin X, Yan JJ, Ai YW (2007 a): Aberrant expression of Eag1 potassium channels in gastric cancer patients and cell lines. Med Oncol $\underline{24}, 345-350$

Ding XW, Yan JJ, An P, Lü P, Luo HS (2007 b): Aberrant expression of ether à go-go potassium channel in colorectal cancer patients and cell lines. World J Gastroenterol $\underline{13}$, 1257-1261

Ding XW, Wang XG, Luo HS, Tan SY, Gao S, Luo B, Jiang H (2008): Expression and Prognostic Roles of Eag1 in Resected Esophageal Squamous Cell Carcinomas. Dig Dis Sci $\underline{53}, 2039-2044$

Downie BR, Sánchez A, Knötgen H, Contreras-Jurado C, Gymnopoulos M, Weber C, Stühmer W, Pardo LA (2008): Eag1 Expression Interferes with Hypoxia Homeostasis and induces Angiogenesis in Tumors. J Biol Chem 283, 36234-36240

Engel J, Eckel R, Kerr J, Schmidt M, Fürstenberger G, Richter R, Sauer H, Senn HJ, Hölzel D (2003): The process of metastasisation for breast cancer. Eur J Cancer $\underline{39}, 1794-1806$ 
Esteller M, Garcia-Foncillas J, Andion E, Goodman SN, Hidalgo OF, Vanaclocha V, Baylin SB, Herman JG (2000): Inactivation of the DNA-repair gene MGMT and the clinical response of gliomas to alkylating agents. N Engl J Med $\underline{343}, 1350-1354$

Farías LMB, Ocana DB, Díaz L, Larrea F, Ávila-Chávez E, Cadena A, Hinojosa LM, Lara G, Villanueva LA, Vargas C (2004): Ether à go-go Potassium Channels as Human Cervical Cancer Markers. Cancer Res $\underline{64}$, 6996-7001

Felsberg J, Reifenberger G (2000): Neuropathologie und molekulare Grundlagen von Metastasen im zentralen Nervensystem. Onkologe $\underline{6}, 919-929$

Fernandez AF, Assenov Y, Martin-Subero Jl, Balint B, Siebert R, Taniguchi H, Yamamoto H, Hidalgo M, Tan AC, Galm O (2012): A DNA methylation fingerprint of 1628 human samples. Genome Res 22, 407-419

Fidler IJ (1970): Metastasis: guantitative analysis of distribution and fate of tumor embolilabeled with 125 I-5-iodo-2'-deoxyuridine. J Natl Cancer Inst $\underline{45}$, 773-782

Fidler IJ (2003): The pathogenesis of cancer metastasis: the 'seed and soil' hypothesis revisited. Nat Rev Cancer $\underline{3}$, 453-458

García-Ferreiro RE, Kerschensteiner D, Major F, Monje F, Stühmer W, Pardo LA (2004): Mechanism of Block of hEag1 $\mathrm{K}^{+}$Channels by Imipramine and Astemizole. J Gen Physiol $\underline{124}, 301-317$

Gaspar LE, Scott C, Rotman M, Asbell S, Phillips T, Wasserman T, McKenna WG, Byhardt R (1997): Recursive Partitioning Analysis (RPA) of Prognostic Factors in three Radiation Therapy Oncology Group (RTOG) Brain Metastases Trials. Int J Radiat Oncol Biol Phys $\underline{37}$, 745-751

Gavrilova-Ruch O, Schönherr K, Gessner G, Schönherr R, Klapperstück T, Wohlrab W, Heinemann SH (2002): Effects of Imipramine on Ion Channels and Prolifertation of IGR1 Melanoma Cells. J Membr Biol $\underline{188}, 137-149$

Gavrilovic IT, Posner JB (2005): Brain metastases: epidemiology and pathophysiology. J Neurooncol $\underline{75}, 5-14$

Gómez-Varela D, Contreras-Jurado C, Furini S, García-Ferreiro R, Stühmer W, Pardo LA (2006): Different relevance of inactivation and F468 residue in the mechanisms of hEag1 channel blockage by astemizole, imipramine and dofetilide. FEBS Lett $\underline{580}, 5059-5066$ 
Gómez-Varela D, Zwick-Wallasch E, Knötgen H, Sánchez A, Hettmann T, Ossipov D, Weseloh R, Contreras-Jurado C, Rothe M, Stühmer W (2007): Monoclonal Antibody Blockade of the Human Eag1 Potassium Channel Function Exerts Antitumor Activity. Cancer Res $\underline{67}, 7343-7349$

Gorlia T, van den Bent MJ, Hegi ME, Mirimanoff RO, Weller M, Cairncross JG, Eisenhauer E, Belanger K, Brandes AA, Allgeier A (2008): Nomograms for predicting survival of patients with newly diagnosed glioblastoma: prognostic factor analysis of EORTC and NCIC trial 26981-22981/CE.3. Lancet Oncol $\underline{9}$, 29-38

Hanahan D, Weinberg RA (2011): Hallmarks of cancer: the next generation. Cell 144, 646674

Hart IR, Fidler IJ (1980): Role of organ selectivity in the determination of metastatic patterns of B16 melanoma. Cancer Res $\underline{40}, 2281-2287$

Hartung F, Stühmer W, Pardo LA (2011): Tumor cell-selective apoptosis induction through targeting of $\mathrm{K}_{\mathrm{v}} 10.1$ via bifunctional TRAIL antibody. Mol Cancer $\underline{10}$, 109-124

Hegi ME, Diserens AC, Gorlia T, Hamou MF, de Tribolet N, Weller M, Kros JM, Hainfellner JA, Mason W, Mariani L (2005): MGMT Gene Silencing and Benefit from Temozolomide in Glioblastoma. N Engl J Med $\underline{352}, 997-1003$

Hemmerlein B, Weseloh RM, Mello de Queiroz F, Knötgen H, Sánchez A, Rubio ME, Martin S, Schliephacke T, Jenke M, Radzun HJ (2006): Overexpression of Eag I potassium channels in clinical tumors. Mol Cancer $\underline{5}, 41-54$

Herman JG, Baylin SB (2003): Gene Silencing in Cancer in Association with Promoter Hypermethylation. N Engl J Med $\underline{349}$, 2042-2054

Holash J, Maisonpierre PC, Compton D, Alexander CR, Zagzag D, Yancopoulos GD, Wiegand SJ (1999): Vessel Cooption, Regression and Growth in Tumors Mediated by Angiopoietins and VEGF. Science 284, 1994-1998

Iliou MS, da Silva-Diz V, Carmona FJ, Ramalho-Carvalho J, Heyn H, Villanueva A, Munoz P, Esteller M (2013): Impaired DICER1 function promotes stemness and metastasis in colon cancer. Oncogene doi:10.1038/onc.2013.398 
Jahchan NS, Dudley JT, Mazur PK, Flores N, Yang D, Palmerton A, Zmoos AF, Vaka D, Tran KQ, Zhou M (2013): A Drug Repositioning Approach Identifies Tricyclic Antidepressants as Inhibitors of Small Cell Lung Cancer and Other Neuroendocrine Tumors. Cancer Discov $\underline{3}, 1364-1377$

Jain RK, di Tomaso E, Duda DG, Loeffler JS, Sorensen AG, Batchelor TT (2007): Angiogenesis in brain tumours. Nat Rev Neurosci $\underline{8}, 610-622$

Kalkanis SN, Kondziolka D, Gaspar LE, Burri SH, Asher AL, Cobbs CS, Ammirati M, Robinson PD, Andrews DW, Loeffler JS (2010): The role of surgical resection in the management of newly diagnosed brain metastases: a systematic review and evidence-based clinical practice guideline. J Neurooncol $\underline{96}, 33-43$

Kienast Y, von Baumgarten L, Fuhrmann M, Klinkert WE, Goldbrunner R, Herms J, Winkler F (2010): Real-time imaging reveals the single steps of brain metastasis formation. Nat Med $\underline{16}, 116-122$

Kleihues P, Ohgaki H (1999): Primary and secondary glioblastomas: From concept to clinical diagnosis. Neuro Oncol $\underline{1}, 44-51$

Kocher M, Soffietti R, Abacioglu U, Villà S, Fauchon F, Baumert BG, Fariselli L, Tzuk-Shina T, Kortmann RD, Carrie C (2011): Adjuvant Whole-Brain Radiotherapy Versus Observation After Radiosurgery or Surgical Resection of One to Three Cerebral Metastases: Results of the EORTC 22952-26001 Study. J Clin Oncol 29, 134-141

Kunzelmann K (2005): Ion Channels and Cancer. J Membr Biol 205, 159-173

Laferriere J, Houle F, Huot J (2002): Regulation of the Metastatic Process by E-Selectin and Stress-Activated Protein Kinase-2/p38. Ann N Y Acad Sci $\underline{973}$, 562-572

Lagerwaard FJ, Levendag PC, Nowak PJ, Eijkenboom WM, Hanssens PE, Schmitz PI (1999): Identification of prognostic factors in patients with brain metastases: a review of 1292 patients. Int J Radiat Oncol Biol Phys $\underline{43}, 795-803$

Langley RR, Fidler IJ (2013): The Biology of Brain Metastasis. Clin Chem 59, 180-189

Langley RR, Carlisle R, Ma L, Specian RD, Gerritsen ME, Granger DN (2001): Endothelial expression of vascular cell adhesion molecule-1 correlates with metastatic pattern in spontaneous melanoma. Microcirculation $\underline{8}, 335-345$ 
Laperriere N, Zuraw L, Cairncross G (2002): Radiotherapy for newly diagnosed malignant glioma in adults: a systematic review. Radiother Oncol 64, 259-273

Lassman AB, DeAngelis LM (2003): Brain metastases. Neurol Clin 21, 1-23

Lee HA, Kim KS, Hyun SA, Park SG, Kim SJ (2012): Wide spectrum of inhibitory effects of sertraline on cardiac ion channel. Korean J Physiol Pharmacol 16, 327-332

Lin H, Li Z, Chen C, Luo X, Xiao J, Dong D, Lu Y, Yang B, Wang Z (2011): Transcriptional and post-transcriptional mechanisms for oncogenic overexpression of ether à go-go $\mathrm{K}_{+}$ channel. PloS One $\underline{6}, 1-10$

Louis DN, Ohgaki H, Wiestler OD, Cavenee WK, Burger PC, Jouvet A, Scheithauer BW, Kleihues P (2007): The 2007 WHO Classification of Tumours of the Central Nervous System. Acta Neuropathol 114, 97-109

Lowery FJ, Yu D (2012): Growth factor signaling in metastasis: current understanding and future opportunities. Cancer Metastasis Rev $\underline{31}$, 479-491

Lujambio A, Calin GA, Villanueva A, Ropero S, Sánchez-Céspedes M, Blanco D, Montuenga LM, Rossi S, Nicoloso MS, Faller WJ (2008): A microRNA DNA methylation signature for human cancer metastasis. Proc Natl Acad Sci USA $\underline{105}, 13556-13561$

Luzzi KJ, MacDonald IC, Schmidt EE, Kerkvliet N, Morris VL, Chambers AF, Groom AC (1998): Multistep nature of metastatic inefficiency: dormancy of solitary cells after successful extravasation and limited survival of early micrometastases. Am J Pathol 153, 865-873

Macaluso M, Paggi MG, Giordano A (2003): Genetic and epigenetic alterations as hallmarks of the intricate road to cancer. Oncogene $\underline{22}, 6472-6478$

Marchetti D, Li J, Shen R (2000): Astrocytes Contribute to the Brain-metastatic Specificity of Melanoma Cells by Producing Heparanase. Cancer Res $\underline{60}$, 4767-4770

Martin S, Lino de Oliveira C, Mello de Queiroz F, Pardo LA, Stühmer W, Del Bel E (2008): Eag1 potassium channel immunhistochemistry in the CNS of adult rat and selected regions of human brain. Neuroscience $\underline{155}, 833-844$

Martinez R, Schackert G, Esteller M (2007): Hypermethylation of the proapoptotic gene TMS1/ASC: Prognostic importance in glioblastoma multiforme. J Neurooncol $\underline{82}, 133-139$ 
Masi A, Becchetti A, Restano-Cassulini R, Polvani S, Hofmann G, Buccoliero AM, Paglierani M, Pollo B, Taddei GL, Gallina P (2005): hERG1 channels are overexpressed in glioblastoma multiforme and modulate VEGF secretion in glioblastoma cell lines. $\mathrm{Br} \mathrm{J}$ Cancer $\underline{93}, 781-792$

Mehta MP, Paleologos NA, Mikkelsen T, Robinson PD, Ammirati M, Andrews DW, Asher AL, Burri SH, Cobbs CS, Gaspar LE (2010): The role of chemotherapy in the management of newly diagnosed brain metastases: a systemic review and evidence-based clinical practice guideline. J Neurooncol $\underline{96}, 71-83$

Mello de Queiroz F, Suarez-Kurtz G, Stühmer W, Pardo LA (2006): Ether à go-go potassium channel expression in soft tissue sarcoma patients. Mol Cancer $\underline{5}, 42-52$

Menéndez ST, Viallaronga MA, Rodrigo JP, Álvarez-Teijeiro S, García-Carracedo D, Urdinguio RG, Fraga MF, Pardo LA, Viloria CG, Suárez C (2012): Frequent aberrant expression of the human ether à go-go (hEAG1) potassium channel in head and neck cancer: pathobiological mechanisms and clinical implications. J Mol Med $\underline{90}, 1173-1184$

Michaelson JS, Silverstein M, Sgroi D, Cheongsiatmoy JA, Taghian A, Powell S, Hughes K, Comegno A, Tanabe KK, Smith B (2003): The effect of tumor size and lymph node status on breast carcinoma lethality. Cancer $\underline{98}, 2133-2143$

Muller PA, Vousden KH (2013): p53 mutations in cancer. Nat Cell Biol 15, 2-8

Nieswandt B, Hafner M, Echtenacher B, Männel DN (1999): Lysis of Tumor Cells by Natural Killer Cells in Mice Is Impeded by Platelets. Cancer Res $\underline{59}, 1295-1300$

Ohgaki H, Kleihues P (2005): Population-based studies on incidence, survival rates, and genetic alterations in astrocytic and oligodendroglial gliomas. J Neuropathol Exp Neurol $\underline{64}$, 479-489

Ohgaki H, Kleihues P (2007): Genetic Pathways to Primary and Secondary Glioblastoma. Am J Pathol $\underline{170}, 1446-1453$

Omuro AMP, Faivre S, Raymond E (2007): Lessons learned in the development of targeted therapy for malignant gliomas. Mol Cancer Ther $\underline{6}, 1909-1919$

Onishi M, Kurozumi K, Ichikawa T, Date I (2013): Mechanisms of Tumor Development and Anti-angiogenic Therapy in Glioblastoma Multiforme. Neurol Med Chir $\underline{53}$, 755-763 
Ortiz CS, Montante-Montes D, Saqui-Salces M, Hinojosa LM, Gamboa-Domínguez A, Hernández-Gallegos E, Martínez-Benítez B, Del Rosario Solís-Pancoatl M, García-Villa E, Ramírez A (2011): Eag1 potassium channels as markers of cervical dysplasia. Oncol Rep 26, $1377-1383$

Ostrom QT, Gittleman H, Farah P, Ondracek A, Chen Y, Wolinsky Y, Stroup NE, Kruchko C, Barnholtz-Sloan JS (2013): CBTRUS Statistical Report: Primary Brain and Central Nervous System Tumors Diagnosed in the United States 2006-2010. Neuro Oncol 15, 1-56

Ouadid-Ahidouch H, Le Bourhis X, Roudbaraki M, Toillon RA, Delcourt P, Prevarskaya N (2001): Changes in the $\mathrm{K}^{+}$current-density of MCF-7 cells during progression through the cell cycle: possible involvement of a h-ether a-go-go $\mathrm{K}^{+}$channel. Receptors Channels $\underline{7}$, 345-356

Ousingsawat J, Spitzner M, Puntheeranurak S, Terraciano L, Tornillo L, Bubendorf L, Kunzelmann K, Schreiber R (2007): Expression of Voltage-Gated Potassium Channels in Human and Mouse Colonic Carcinoma. Clin Cancer Res 13, 824-831

Paget S (1889): The distribution of secondary growths in cancer of the breast. Lancet 1,571 573

Pardo LA (2004): Voltage-Gated Potassium Channels in Cell Proliferation. Physiology $\underline{19}$, 285-292

Pardo LA, Brüggemann A, Camacho J, Stühmer W (1998): Cell Cycle-related Changes in the Conducting Properties of r-eag K+ Channels. J Cell Biol 143, 767-775

Pardo LA, del Camino D, Sánchez A, Alves F, Brüggemann A, Beckh S, Stühmer W (1999): Oncogenic Potential of EAG K ${ }^{+}$channels. EMBO J $\underline{18}, 5540-5547$

Pardo LA, Contreras-Jurado C, Zientkowska M, Alves F, Stühmer W (2005): Role of Voltagegated Potassium Channels in Cancer. J Membr Biol 205, 115-124

Parsons DW, Jones S, Zhang X, Lin JCH, Leary RJ, Angenendt P, Mankoo P, Carter H, Siu IM, Gallia GL (2008): An Integrated Genomic Analysis of Human Glioblastoma Multiforme. Science $\underline{321}, 1807-1812$

Patchell RA, Tibbs PA, Regine WF, Dempsey RJ, Mohiuddin M, Kryscio RJ, Markesbery WR, Foon KA, Young B (1998): Postoperative Radiotherapy in the Treatment of Single Metastases to the Brain: A Randomized Trial. JAMA 280, 1485-1489 
Patt S, Preußat K, Beetz C, Kraft R, Schrey M, Kalff R, Schönherr K, Heinemann SH (2004): Expression of ether à go-go potassium channels in human gliomas. Neurosci Lett $\underline{368}, 249$ 253

Pinquart M, Duberstein PR (2010): Depression and cancer mortality: a meta-analysis. Psychol Med 누, 1797-1810

Pirl WF, Greer JA, Traeger L, Jackson V, Lennes IT, Gallagher ER, Perez-Cruz P, Heist RS, Temel JS (2012): Depression and Survival in Metastatic Non-Small-Cell Lung Cancer: Effects of Early Palliative Care. J Clin Oncol $\underline{30}, 1310-1315$

Preusser M, Capper D, Ilhan-Mutlu A, Berghoff AS, Birner P, Bartsch R, Marosi C, Zielinski C, Mehta MP, Winkler F (2012): Brain metastases: pathobiology and emerging targeted therapies. Acta Neuropathol $\underline{123}, 205-222$

Ramakrishna R, Rostomily R (2013): Seed, soil and beyond: The basic biology of brain metastasis. Surg Neurol Int $\underline{4}, 256-264$

Ridley AJ, Schwartz MA, Burridge K, Firtel RA, Ginsberg MH, Borisy G, Parsons JT, Horwitz AR (2003): Cell Migration: Integrating Signals from Front to Back. Science 302, 1704-1709

Riemenschneider MJ, Jeuken JWM, Wesseling P, Reifenberger G (2010): Molecular diagnostics of gliomas: state of the art. Acta Neuropathol $\underline{120}, 567-584$

Saganich MJ, Machado E, Rudy B (2001): Differential expression of genes encoding subthreshold-operating voltage-gated K+ channels in brain. J Neurosci 21, 4609-4624

Sathornsumetee S (2011): Therapeutic strategies to target multiple kinases in glioblastoma. Anticancer Agents Med Chem 11, 700-711

Satin JR, Linden W, Phillips MJ (2009): Depression as a predictor of disease progression and mortality in cancer patients: a meta-analysis. Cancer $\underline{115}, 5349-5361$

Schackert G, Fidler IJ (1988): Development of in vivo models for studies of brain metastasis. Int J Cancer $\underline{41}, 589-594$

Schackert G, Fidler IJ (2000): Die Biologie von Hirnmetastasen. Onkologe $\underline{6}$, 976-985

Schmid UD, Honegger HP, Pescia R (2002): Chirurgie der Hirnmetastasen. Schweiz Med Forum $\underline{50}, 1187-1194$ 
Slotman B, Faivre-Finn C, Kramer G, Rankin E, Snee M, Hatton M, Postmus P, Colette L, Musat E, Senan S (2007): Prophylactic Cranial Irradiation in Extensive Small-Cell Lung Cancer. N Engl J Med 357, 664-672

Smedby KE, Brandt L, Bäcklund ML, Blomqvist P (2009): Brain metastases admissions in Sweden between 1987 and 2006. Br J Cancer 101, 1919-1924

Sperduto PW, Berkey B, Gaspar LE, Mehta M, Curran W (2008): A New Prognostic Index and Comparison to three other Indices for Patients with Brain Metastases: An Analysis of 1,960 Patients in the RTOG Database. Int J Radiat Oncol Biol Phys $\underline{70}, 510-514$

Stummer W, Pichlmeier U, Meinel T, Wiestler OD, Zanella F, Reulen HJ (2006): Fluorescence-guided surgery with 5-aminolevulinic acid for resection of malignant glioma: a randomised controlled multicentre phase III trial. Lancet Oncol $\underline{7}, 392-401$

Stummer W, Reulen HJ, Meinel T, Pichlmeier U, Schumacher W, Tonn JC, Rohde V, Oppel F, Turowski B, Woiciechowsky C (2008): Extent of Resection and Survival in Glioblastoma Multiforme: Identification of and Adjustment for Bias. Neurosurgery $\underline{62}, 564-576$

Stupp R, Mason WP, van den Bent MJ, Weller M, Fisher B, Taphoorn MJB, Belanger K, Brandes AA, Marosi C, Bogdahn U (2005): Radiotherapy plus Concomitant and Adjuvant Temozolomide for Glioblastoma. N Engl J Med $\underline{352}$, 987-996

Stupp R, Hegi ME, Mason WP, van den Bent MJ, Taphoorn MJB, Janzer RC, Ludwin SK, Allgeier A, Fisher B, Berlanger K (2009): Effects of radiotherapy with concomitant and adjuvant temozolomide versus radiotherapy alone on survival in glioblastoma in a randomised phase III study: 5-year analysis of the EORTC-NCIC trial. Lancet Oncol $\underline{10}$, 459466

Teschemacher AG, Seward EP, Hancox JC, Witchel HJ (1999): Inhibition of the current of heterologously expressed HERG potassium channels by imipramine and amitriptyline. $\mathrm{Br} \mathrm{J}$ Pharmacol $\underline{128}$, 479-485

Thiery JP, Acloque H, Huang RYJ, Nieto MA (2009): Epithelial-mesenchymal transitions in development and disease. Cell $\underline{139}, 871-890$

von Deimling A, Louis DN, Wiestler OD (1995): Molecular pathways in the formation of gliomas. Glia $\underline{15}$, 328-338 
Weber C, Mello de Queiroz F, Downie BR, Suckow A, Stühmer W, Pardo LA (2006): Silencing the Activity and Proliferative Properties of the Human Eagl Potassium Channel by RNA Interference. J Biol Chem 281, 13030-13037

Weiss L (1990): Metastatic inefficiency. Adv Cancer Res 느, 159-211

Wick W, Weller M, Weiler M, Batchelor T, Yung AWK, Platten M (2011): Pathway inhibition: emerging molecular targets for treating glioblastoma. Neuro Oncol $\underline{13}, 566-579$

Witchel HJ, Pabbathi VK, Hofmann G, Paul AA, Hancox JC (2002): Inhibitory actions of the selective serotonin re-uptake inhibitor citalopram on HERG and ventricular L-type calcium currents. FEBS Lett $\underline{512}, 59-66$

Wonderlin WF, Strobl JS (1996): Potassium Channels, Proliferation and G1 Progression. J Membr Biol 154, 91-107

Wu J, Wu X, Zhong D, Zhai W, Ding Z, Zhou Y (2012): Short Hairpin (shRNA) Ether à go-go 1 (Eag1) Inhibition of Human Osteosarcoma Angiogenesis via VEGF/PI3K/AKT Signaling. Int J Mol Sci $\underline{13}, 12573-1258$

Yan H, Parsons DW, Jin G, McLendon R, Rasheed BA, Yuan W, Kos I, Batinic-Haberle I, Jones S, Riggins GJ (2009): IDH1 and IDH2 Mutations in Gliomas. N Engl J Med $\underline{360}$, 765773

Yano S, Shinohara H, Herbst RS, Kuniyasu H, Bucana CD, Ellis LM, Davis DW, McConkey DJ, Fidler IJ (2000): Expression of Vascular Endothelial Growth Factor Is Necessary but not Sufficient for Production and Growth of Brain Metastasis. Cancer Res $\underline{60}$, 4959-4967

Yao D, Dai C, Peng S (2011): Mechanism of the Mesenchymal-Epithelial Transition and Its Relationship with Metastatic Tumor Formation. Mol Cancer Res $\underline{9}, 1608-1620$ 


\section{Danksagung}

Mein besonderer Dank gilt Herrn PD Dr. Ramón Martínez-Olivera für die Bereitstellung des interessanten Themas der Dissertation, das entgegengebrachte Vertrauen sowie für seine fachliche Beratung, Unterstützung und auch Geduld während der gesamten Zeit.

Beim Klinikdirektor Herrn Prof. Dr. Veit Rohde bedanke ich mich für die Möglichkeit, meine Dissertation in der Klinik für Neurochirurgie anfertigen zu dürfen.

Meinem Betreuer im Max-Planck-Institut für Experimentelle Medizin, Herrn Prof. Dr. Luis Pardo, möchte ich für die Ermöglichung der praktischen Durchführung meiner Dissertation in den Laboren der Abteilung für Molekulare Biologie neuronaler Signale sehr herzlich danken. Mein besonderer Dank auch dafür, dass er immer vertrauensvoller Ansprechpartner für mich war und vor allem für seine besondere Unterstützung auch in schwierigen Phasen.

Dr. Sabine Martin danke ich vielmals für die Einführung in die Laborarbeit, für alles was ich lernen durfte und dafür, dass sie zu jeder Zeit Ansprechpartnerin für mich war und mir immer mit Rat und Tat zur Seite stand, was mir eine große Hilfe und Unterstützung war.

Für die freundliche Bereitstellung aller nötigen Sachmittel bedanke ich mich recht herzlich beim Abteilungsdirektor und geschäftsführenden Leiter des Max-Planck-Institutes für Experimentelle Medizin, Herrn Prof. Dr. Walter Stühmer.

Bedanken möchte ich mich des Weiteren bei Herrn PD Dr. Walter Schulz-Schaeffer für seine fachliche Expertise bezüglich der Immunhistochemie und der MTA Tatjana Pfander für ihre sehr freundliche Unterstützung bei methodischen Testreihen in der Neuropathologie.

Institutsdirektor Prof. Dr. Wolfgang Brück danke ich für die Bereitstellung der neuropathologischen Gewebeproben. 


\section{Lebenslauf}

Mein Name ist Julian Michael Schell, ich wurde am 14.06.1986 in Filderstadt geboren. Im Juli des Jahres 1993 wurde ich in die Tübinger Freie Waldorfschule eingeschult. Nach 13 Schuljahren erhielt ich dort die Hochschulreife im Juni 2006 (Abschlussnote: 2,2). Es folgte die Ableistung des Zivildienstes, den ich von Juli 2006 bis April 2007 in der Universitätsklinik für Hals-, Nasen- und Ohrenheilkunde Tübingen (Direktor: Prof. Dr. Dr. h.c. mult. H. P. Zenner) absolvierte. Von Mai 2007 bis Juli 2007 arbeitete ich im Rahmen eines Pflegepraktikums an der Universitätsklinik für Hals-, Nasen- und Ohrenheilkunde Tübingen.

Zum Wintersemester 2007/2008 begann ich mein Hochschulstudium an der Eberhard-KarlsUniversität zu Tübingen mit dem Studiengang Biologie. Nach einem Semester erhielt ich für das nachfolgende Sommersemester 2008 einen Studienplatz für das Studium der Zahnmedizin an der Johannes-Gutenberg-Universität zu Mainz. Dort absolvierte ich von April 2008 bis Oktober 2010 die 5 vorklinischen Semester des Zahnmedizinstudiums und schloss diesen Teil des Studiums mit der zahnärztlichen Vorprüfung ab (Gesamtergebnis: gut; 1,75). Während dieser Zeit arbeitete ich von Juli 2009 bis März 2010 als studentischer Hilfswissenschaftler im Zentrum für Klinische Studien am Zentrum für Kinder- und Jugendmedizin der Universitätsklinik Mainz (Direktor: Prof. Dr. F. Zepp). Für den klinischen Teil des Zahnmedizinstudiums wechselte ich an die Georg-August-Universität zu Göttingen und begann dort das erste klinische Semester zum Wintersemester 2010/2011. Zu Beginn des 8. Fachsemesters, im Wintersemester 2011/2012, begann ich die wissenschaftliche Arbeit an meiner Dissertation in der Klinik für Neurochirurgie im Zentrum für Neurologische Medizin der Medizinischen Fakultät der Universität zu Göttingen. Nach dem 10. Fachsemester, im Wintersemester 2012/2013, wurde ich zum zahnärztlichen Staatsexamen zugelassen, welches ich mit der letzten Prüfung am 05.06.2013 beendete und somit die zahnärztliche Prüfung bestand (Gesamtergebnis: sehr gut, 1,15). Für meine Leistungen im 10. Fachsemester wurde mir von der Abteilung für Präventive Zahnmedizin, Parodontologie und Kariologie (Komm. Direktor: Prof. Dr. M. Hülsmann) der Alex-Motsch-Studentenpreis verliehen.

Seit Beginn des Jahres 2014 bin ich als Assistenzzahnarzt für Oralchirurgie in der Klinik für Mund-, Kiefer- und Gesichtschirurgie des Katharinenhospitals, Klinikum Stuttgart (Direktor: Prof. Dr. Dr. D. Weingart) angestellt. 